University of Louisville

ThinkIR: The University of Louisville's Institutional Repository

Electronic Theses and Dissertations

$5-2011$

\title{
The case of the Women's United Soccer Association : explaining the rise and fall of a social movement organization.
}

Meghan O'Connor McDonogh

University of Louisville

Follow this and additional works at: https://ir.library.louisville.edu/etd

\section{Recommended Citation}

McDonogh, Meghan O'Connor, "The case of the Women's United Soccer Association : explaining the rise and fall of a social movement organization." (2011). Electronic Theses and Dissertations. Paper 945. https://doi.org/10.18297/etd/945

This Doctoral Dissertation is brought to you for free and open access by ThinkIR: The University of Louisville's Institutional Repository. It has been accepted for inclusion in Electronic Theses and Dissertations by an authorized administrator of ThinkIR: The University of Louisville's Institutional Repository. This title appears here courtesy of the author, who has retained all other copyrights. For more information, please contact thinkir@louisville.edu. 
THE CASE OF THE WOMEN'S UNITED SOCCER ASSOCIATION: EXPLAINING THE RISE AND FALL OF A SOCIAL MOVEMENT ORGANIZATION

By

Meghan O'Connor McDonogh

B.A., American University 2001

M.Ed., The University of Georgia, 2002

A Dissertation

Submitted to the Faculty of the

Graduate School of the University of Louisville

In Partial Fulfillment of the Requirements

For the Degree of

Doctor of Philosophy

Department of Leadership, Foundations and Human Resource Administration

University of Louisville

Louisville, Kentucky

May 2011 
西

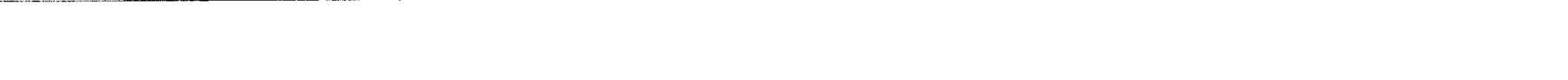
. .
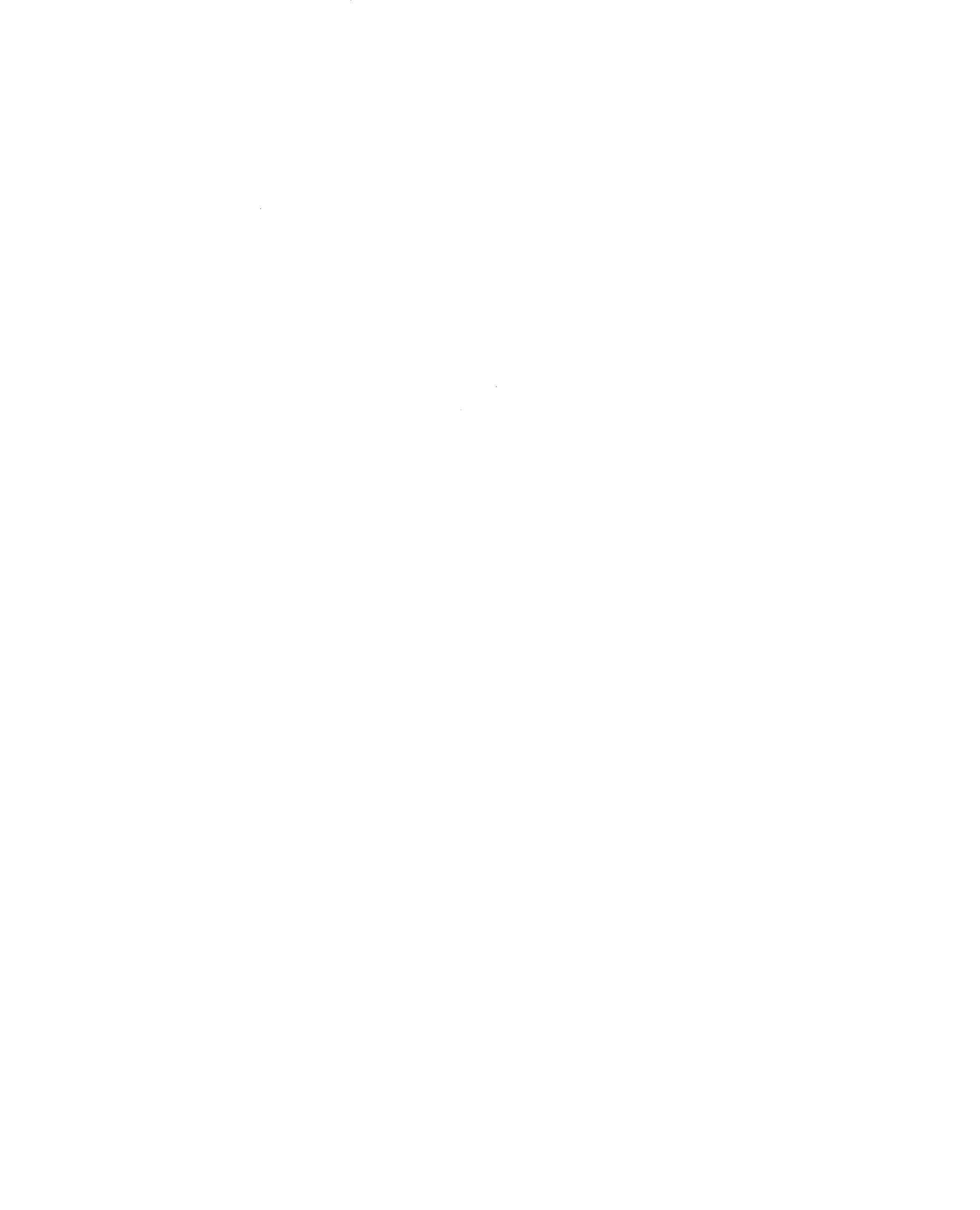
THE CASE OF THE WOMEN'S UNITED SOCCER ASSOCIATION: EXPLAINING THE RISE AND FALL OF A SOCIAL MOVEMENT ORGANIZATION

\section{By}

Meghan O’Connor McDonogh

B.A., American University 2001

M.Ed., The University of Georgia, 2002

A Dissertation Approved on

April 15, 2011

By the following Dissertation Committee:

Dissertation Co-Director (Mary Hums)

Dissertation Co-Director (John Keedy)

Dan Mahony

Laurie Rhodebeck 


\section{DEDICATION}

To my mom, for always expecting more from me

and

To all the women in US Soccer who I grew up in awe of and served as role models to me and to young girls around the world. 


\section{ACKNOWLEDGEMENTS}

I would like to thank first and foremost my co-advisors, Dr. Mary Hums and Dr. John Keedy, Dr. Hums for providing kind guidance and patience as I worked in crazy spurts to complete this and to Dr. Keedy for his attention to detail in the design of this study as well as his patience with my schedule. Additionally, I would like to thank the other members of the committee, Dr. Dan Mahony and Dr. Laurie Rhodebeck, not only for their patience and time, but for their insightful comments throughout this process.

Just as Dr. Hums is my academic mentor, along my professional career I have been fortunate enough to encounter several individuals that have provided great support. "Mama Mar" (Marlene Bjornsrud), Ilisa Kessler, and Mike Allen each, in their own individual way, have provided me with a constant source of support.

This dissertation could never have come to fruition without the generous gift of time for the WUSA leaders whom I interviewed. I will never be able to adequately thank them for all of their help throughout this process.

Finally, I would like to thank my friends and family. My friends were wonderful in supporting me and cheering me along as were my family, especially my mother, father, stepfather, and my Yorkie, Percy Bob. I never could have completed this endeavor without their support, both financially and mentally as there were days I was certainly ready to pack it in. Special thanks to my mom for her additional editing, constant support, and in pushing me to finish; to my dad for providing encouragement and 
financial assistance, even ensuring I had a constant balance on my gold Starbucks card and food in my fridge; and to my stepdad for making sure I was always informed of any soccer happenings. 


\section{ABSTRACT \\ THE CASE OF THE WOMEN'S UNITED SOCCER ASSOCIATION: EXPLAINING THE RISE AND FALL OF A SOCIAL MOVEMENT ORGANIZATION

\author{
Meghan O’Connor McDonogh
} \\ April 15, 2011}

The purpose of this study is to examine the creation and demise of the WUSA, and to establish the league as a social movement organization (SMO) within the context of the rich body of social movement literature. In explaining the rise and fall of the WUSA, three research questions were answered: (a) How was the WUSA founded? (b) Why was the WUSA founded? and (c) Why did the WUSA fail?

The design used to answer these research questions is a case study design from a historical analysis perspective. Eight in-depth interviews were conducted with WUSA leaders. The interviews were then transcribed and coded to establish themes answering each research question while also establishing the WUSA as a SMO.

Three themes emerged to answer the question "How was the WUSA founded?" They were: (a) the 1999 Women's World Cup Championship Team, (b) John Hendricks, and, (c) the "collision" of these two entities. Three themes also emerged in answering the question "Why was the WUSA founded?" and were: (a) players provided great roles models, (b) the desire for a premier women's soccer league, and (c) the passion surrounding the players. Five themes emerged to answer the question "Why did the 
WUSA fail?": (a) inadequate business plan, (b) lack of support for women's sports, (c) lack of trust in leadership, (d) a mixed league identification/branding message, and (e) inevitable sense of failure.

This study adds to social movement literature as well as provides insight for those starting new professional sport leagues. 
TABLE OF CONTENTS

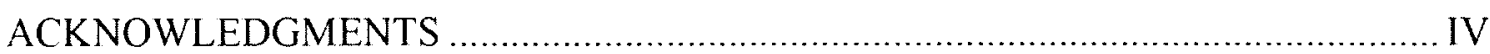

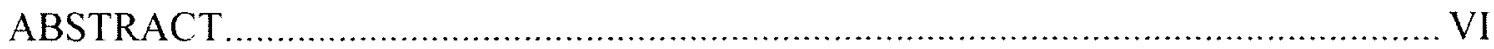

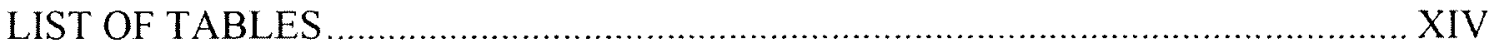

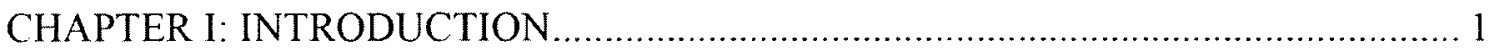

Timeline of Events Related to the Organization of Women's Professional Soccer ........... 3

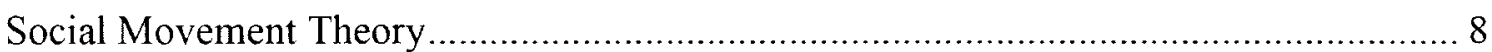

Sport and social movements .......................................................................... 8

Prevailing schools of thought in social movement literature ..................................... 10

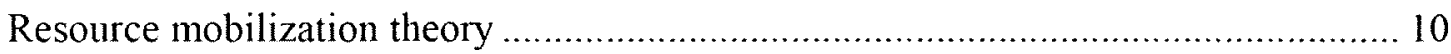

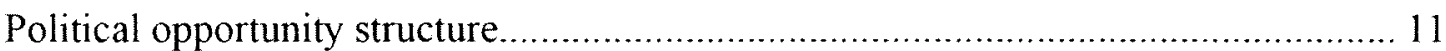

Cultural cognitive/framing/new social movement theory ........................................... 11

Success and failure of social movements and social movement organizations ............ 12

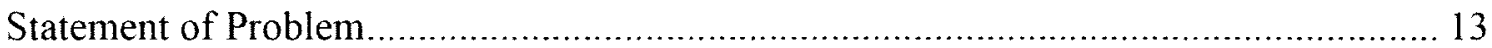

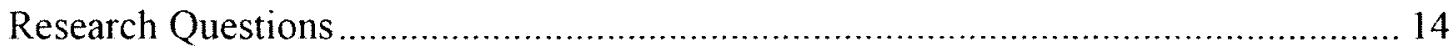

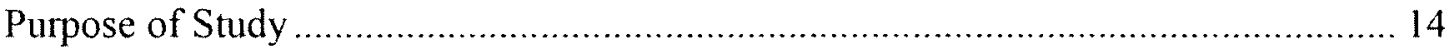

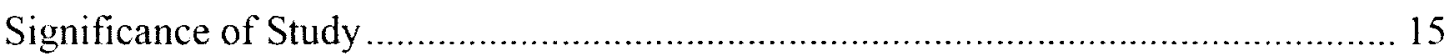

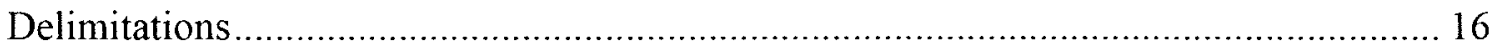

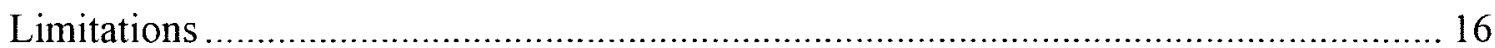

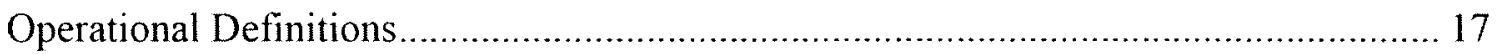

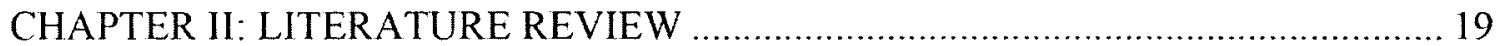




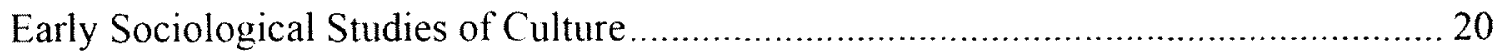

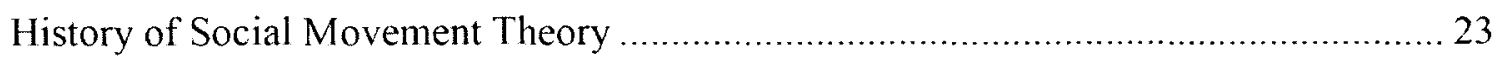

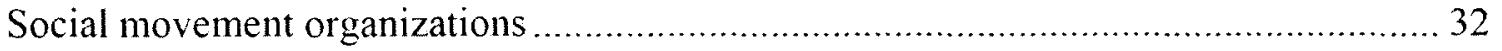

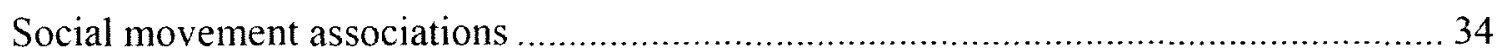

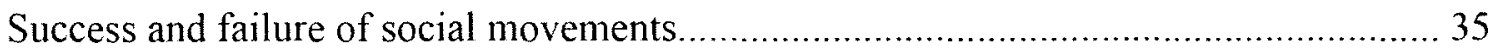

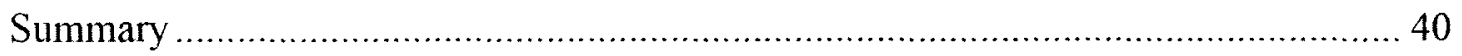

Prevailing Schools of Thought in Social Movement Theory .................................... 41

Cultural cognitive/framing/new social movement theory................................. 41

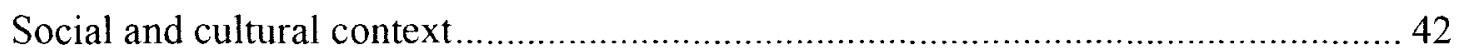

Collective identity/personal values and beliefs................................................ 46

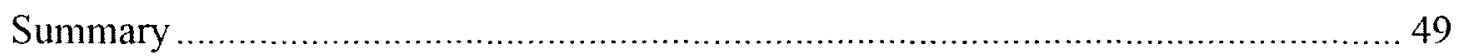

Political Opportunity Structure/Political Processes ............................................... 50

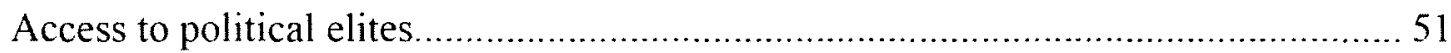

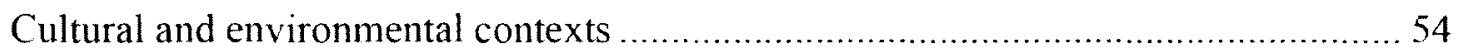

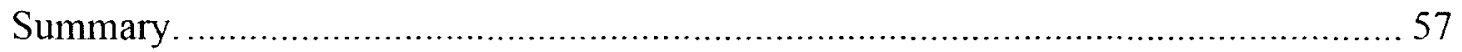

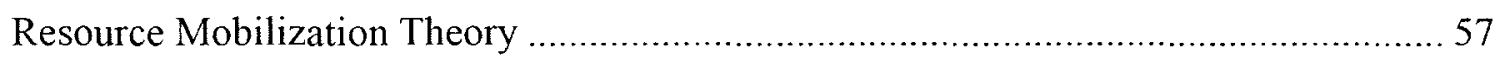

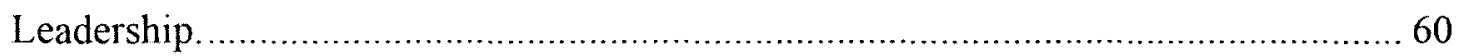

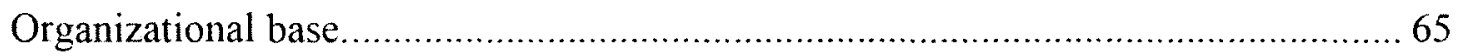

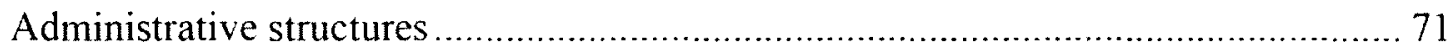

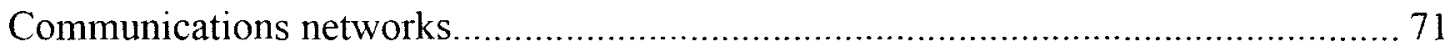

Cooperation with like-minded organizations............................................... 88

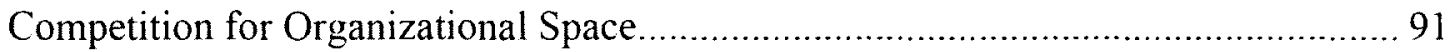

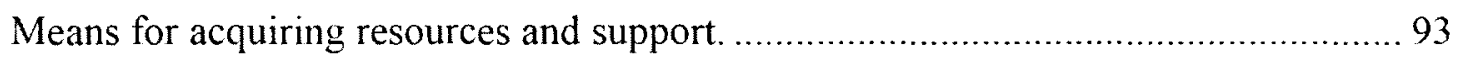




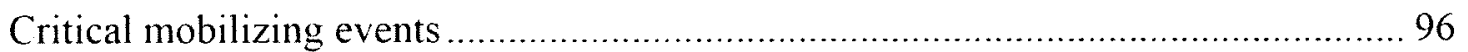

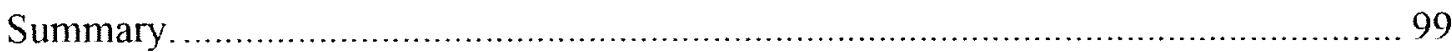

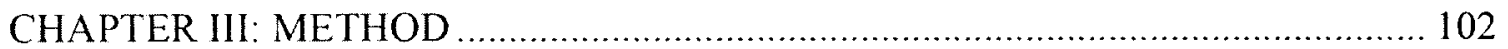

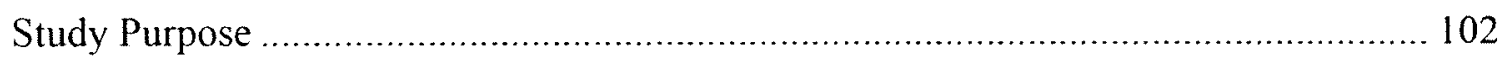

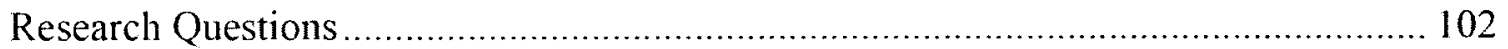

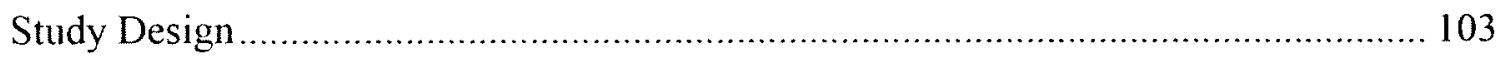

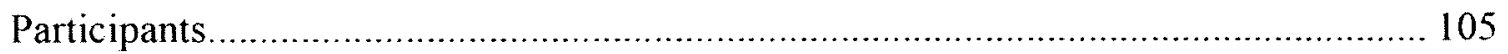

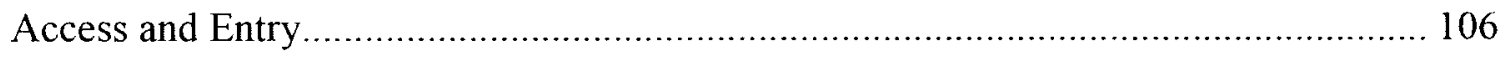

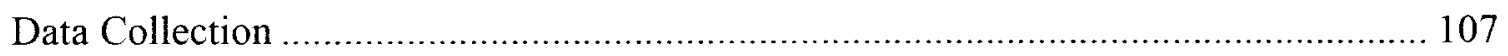

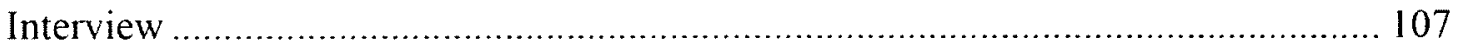

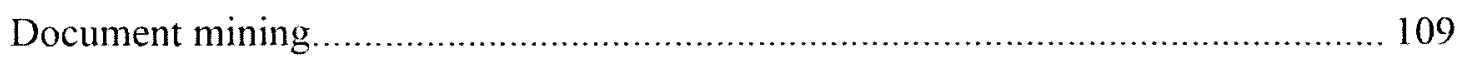

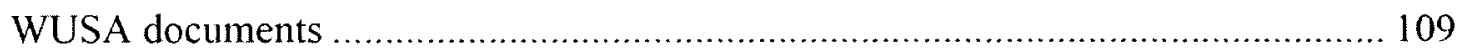

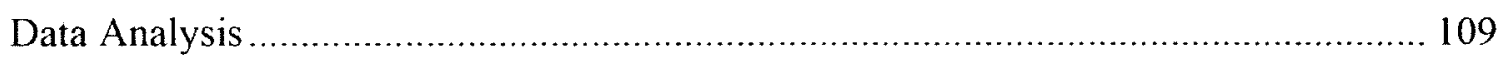

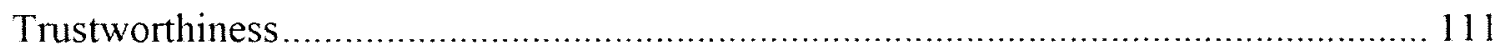

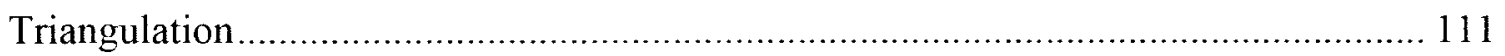

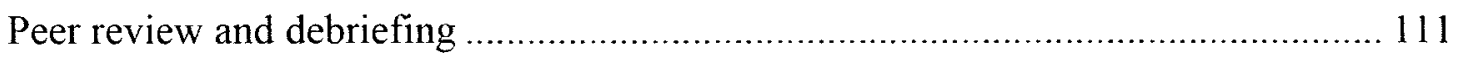

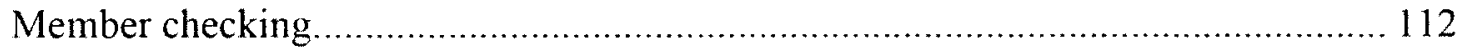

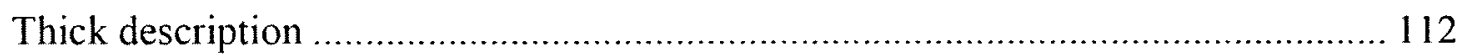

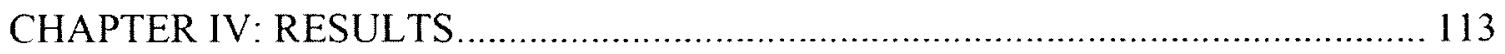

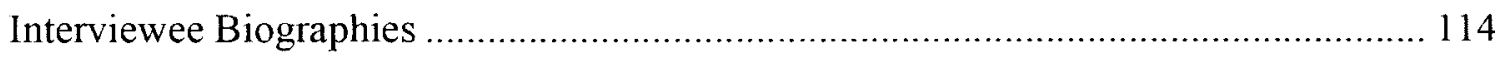

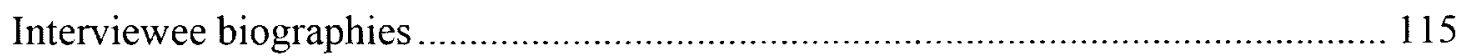

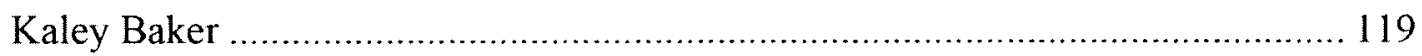

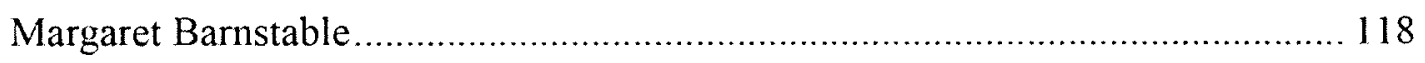




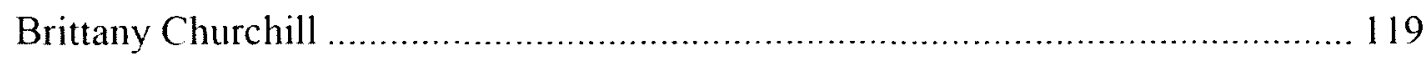

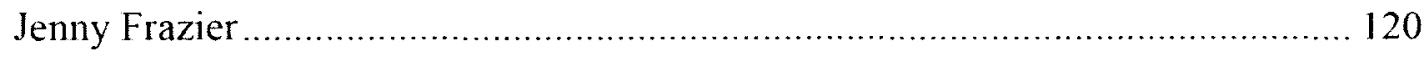

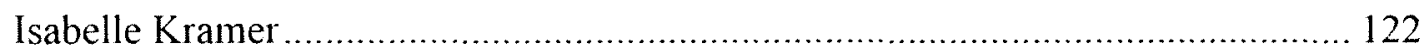

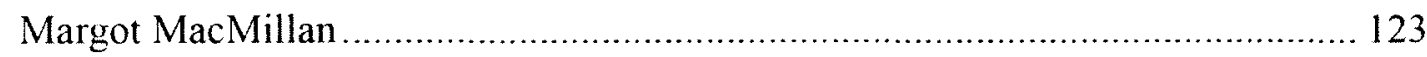

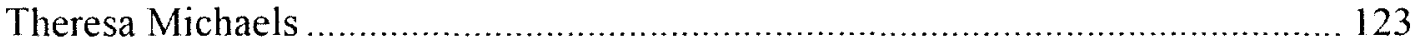

Shanna

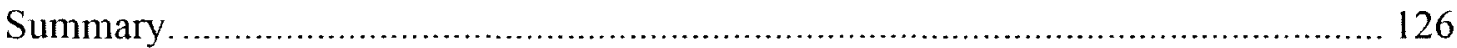

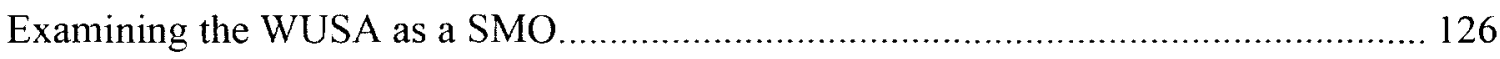

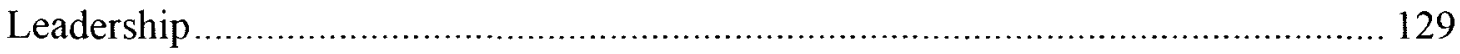

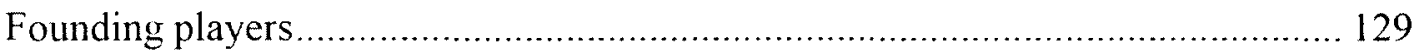

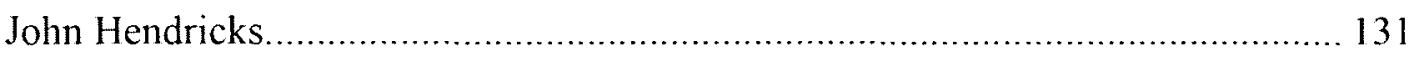

Like-minded organizations and access to political elites..................................... 133

Competition for organizational space and acquiring resources and support. ......... 140

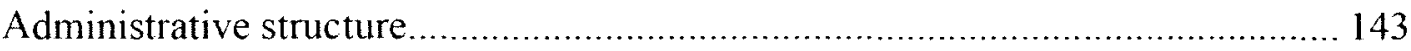

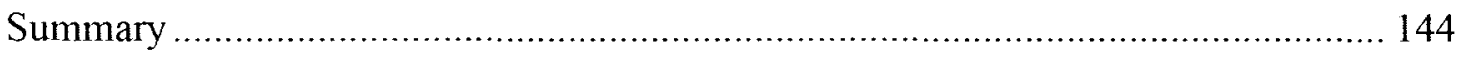

RQ 1: How Was the WUSA Founded?................................................................. 146

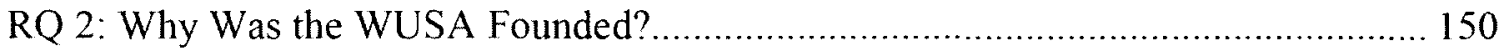

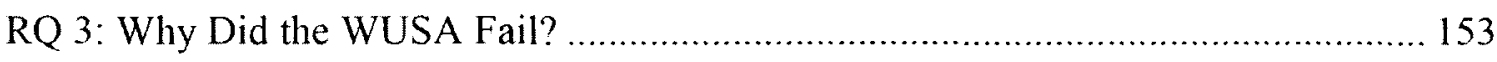

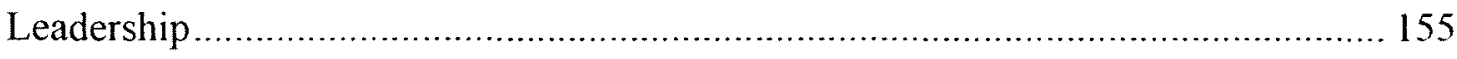

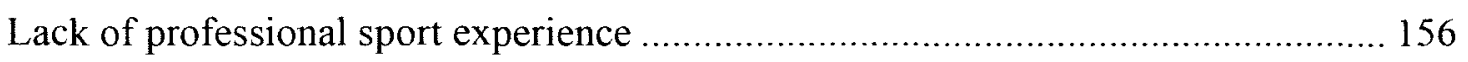

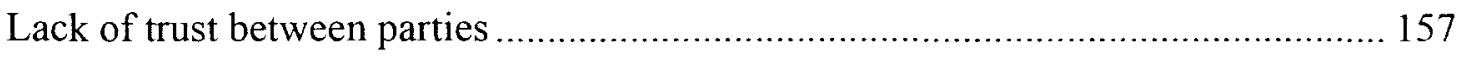

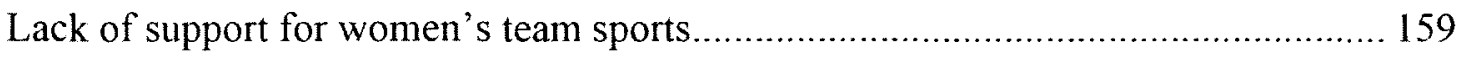

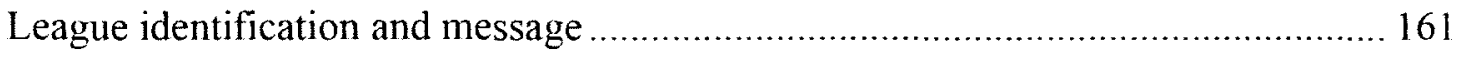


Inevitable failure

Summary

Summary

CHAPTER V: SUMMARY OF FINDINGS, DISCUSSION, AND IMPLICATIONS 169

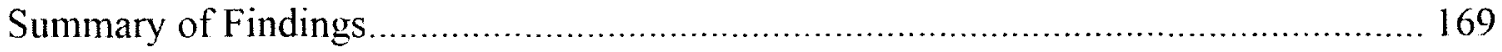

Research Question 1: How Was the WUSA Founded? ....................................... 171

Research Question 2: Why Was the WUSA Founded? ...................................... 171

Research Question 3: Why Did the WUSA Fail? ................................................ 173

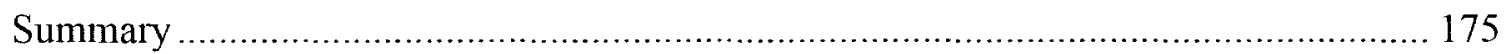

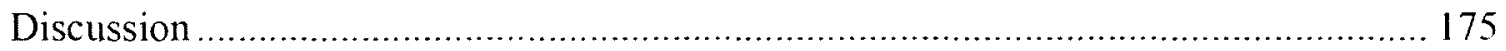

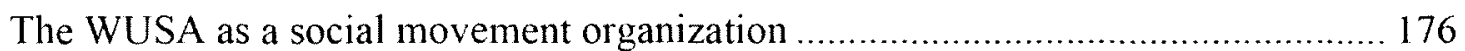

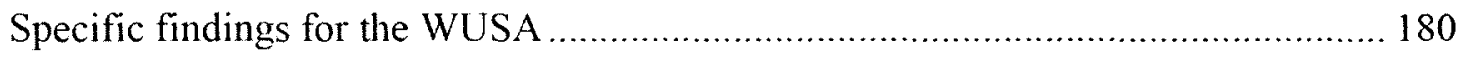

Factors specific to the creation of the WUSA …................................................. 180

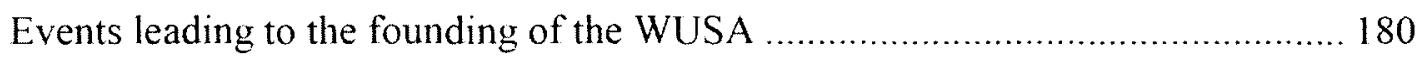

The founding players and John Hendricks................................................ 182

Factors specific to the failure of the WUSA ................................................. 182

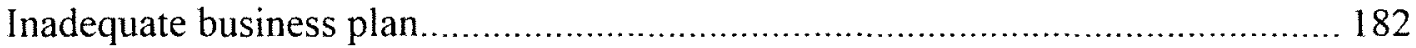

Lack of a clearly defined message/branding identity ..................................... 183

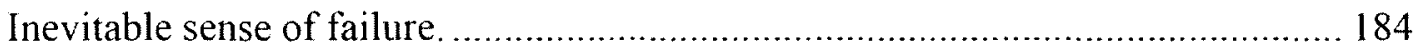

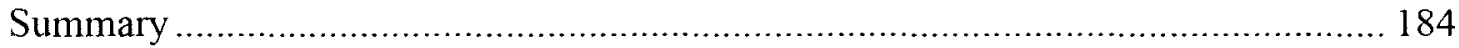

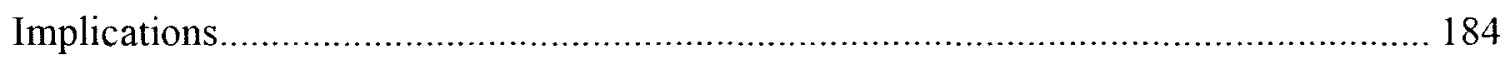

Implications for social movement theorists .................................................. 184

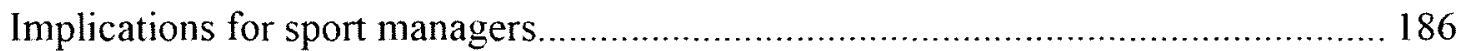


Directions for Future Research

The importance of a solid business plan 189

Comparing the WUSA to other women's professional sport leagues 190

Social and cultural context of women's professional sport 192

Media coverage 193

Use of new social media 193

Conclusion 194

REFERENCES 195

APPENDIX A INTERVIEW PROTOCOL. 209

APPENDIX B: INTERVIEW PROTOCOL 211

APPENDIX C: CODING MAP 214

CURRICULUM VITAE 215 


\section{LIST OF TABLES}

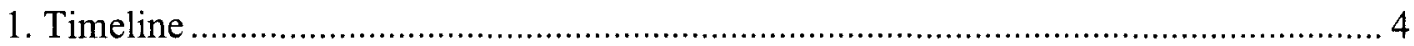

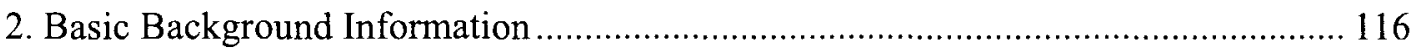

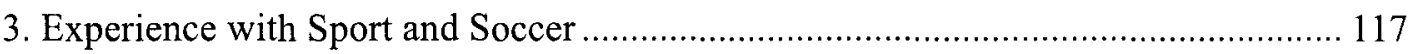

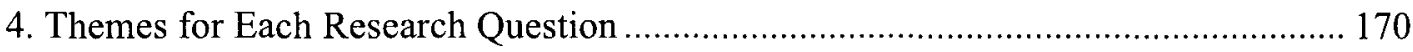

5.Themes Establishing the WUSA as a Social Movement Organization (SMO).......... 177 


\section{CHAPTER I}

\section{INTRODUCTION}

Mia munched on junk food and talked about her hopes for women's soccer. 'If we want to stay on top, we have to put a league together so players can play full time. Otherwise we' re going to lose our lead. It's that simple, really.'... The 1999 women's World Cup is over. The Women's National Team has made history. After the U.S. Men's National Team fared well in the 1994 FIFA World Cup, the United States Soccer federation agreed to form a professional league so our players could improve, could become world contenders. The players on our Women's National Team aren't just contenders. They are the champions. They deserve a league of their own. (Miller, 1999, p. 210)

On July 10, 1999, over 90,000 fans, the most ever to attend a women's sporting event, filled the Rose Bowl in Pasadena, California to be a part of women's sport history. After 90 minutes of the Women's World Cup Final, the U.S. Women's National Soccer Team remained tied, zero to zero, with China. The score stayed the same after an additional 30 minutes of sudden-death overtime. Not until goalkeeper Brianna Scurry saved one of the Chinese shots in the first round of penalty kicks did the end appear to be in sight. Finally, the United States sealed the victory as Brandi Chastain scored the winning penalty kick. After 120 minutes of soccer and ten stress filled penalty kicks, the United States team was the World Cup Champions and Brandi Chastain celebrated in style by ripping her jersey off, falling to her knees, and appearing in countless publications with a face of pure joy, forever endearing her and the team in the hearts of the American public and soccer fans worldwide (Longman 2000; Springer, 1999).

This event catapulted the team into the public's attention as the players became media darlings, leading to the creation of the Women's United Soccer Association 
(WUSA). The WUSA was founded as the first ever, wholly professional, soccer playing opportunity for women in the world and provided the highest level of soccer for women not only in this country, but globally. Attempting to build on this momentum following the 1999 World Cup, formerly largely anonymous women such as Mia Hamm, Brandi Chastain, and Julie Foudy became household names, worked their way into coffee break conversations and the mainstream media. Not only were these women media darlings, they became role models both on and off the field for little girls and boys throughout the country (Longman, 2000; Springer, 1999).

Southall, Nagel, and LeGrande (2005) put forward, "Build it and they will come?" John Hendriks was more than willing to take that risk. The founder of the Discovery Channel, Hendricks was willing to bet that he could make a successful go at the creation of what was ultimately to be called the Women's United Soccer Association (Southall et al.,, 2005).Hendricks' dream, as well as the dream of countless pony-tailed girls, came to fruition in February 2000 when the initial groundwork to form the WUSA was laid. The first season kicked off on April 21,2001, in front of over 35,000 fans at RFK Stadium in Washington, DC as Mia Hamm and the Washington Freedom hosted Brandi Chastain and the Bay Area CyberRays. The media in Washington DC fueled interest in the match and hundreds of Mia versus Brandi flags appeared on streetlight poles all over the city. While this game was surrounded in fanfare and played in front of over 35,000 fans, the league was unable to sustain itself and was forced to close its doors on September 15, 2003 (WUSA, 2003).

Many reasons can be offered for why this league rose so quickly and then experienced such a dramatic and resounding end. Many credit the success of the 1999 
World Cup as the mobilizing event that spawned the WUSA along with the U.S. National Team: "Their win was the most significant day in the history of women's sports, bearing the fruit of the passage of Title IX in 1972 and surpassing by a long shot that burn-yourbra night in 1973 when Billie Jean King beat Bobby Riggs" (Blumenthal, 2005, p. 113114). However, other events also played a role in the creation of the league as reflected in Table 1. The initial groundwork was laid in 1972 with the passage of Title IX and the issuance of guidelines for its implementation 3 years later. Title IX opened doors for women in athletics and from that time forward, women continued to stake their claim on the field (Blumenthal, 2005; Christopherson, Janning, \& McConnell, 2002; Liston, 2006; Spencer, 2000).

\section{Timeline of Events Related to the Organization of Women's Professional Soccer}

Many events set the stage for the development of women's professional soccer in the United States. Table I presents a timeline for these events, which are then explained in the section following the table. The Association for Intercollegiate Athletics for Women (AIAW) held the first women's collegiate soccer national championship in 1981. The following year the NCAA exerted its control over college sports and held the first National Collegiate Athletic Association (NCAA) Women's Soccer Championship. Repeated wins by the University of North Carolina, Chapel Hill continued to bolster girls' interest in soccer. Still, the first Women's World Cup was not held until 1991. Despite the U.S. victory, the members of the team and the sport in general garnered little attention as only one reporter met them on their flight back to the United States. 
Table 1

Timeline

Year

Event

1972

1975

1981

1982

1991

1993

1994

1995

1996

1996

1997

1999

2000

2001

2003

2004

2006

2007

2009

2010

2011
Title IX signed into law

Issuance of Title IX Guidelines

Only officially sanctioned AIAW soccer Championship (UNC defeated UCF)

First NCAA Women's Soccer Championship (UNC defeated UCF)

First Women's World Cup held in China (U.S won)

Establishment of MLS announced

Men's World Cup held in the United States

Second Women's World Cup held in Sweden (Norway won)

MLS kicks off

Olympic Games held in Atlanta, Ga.; Women's soccer debuts (U.S. won)

ABL debuts following success of women's sports in the 1996 Olympic Games

WNBA debuts playing a summer schedule

Women's World Cup held in the U.S. (U.S. won)

Creation of WUSA announced

WUSA kicks off with eight teams: Atlanta Beat, Boston Breaker, New

York Power, Philadelphia Charge, San Diego Spirit, San Jose CyberRays, and Washington Freedom

WUSA ceases operations in September after third season

Women's World Cup held in fall in U.S due to SARS outbreak in China (Germany won)

WUSA festivals held in summer (in Carson, CA and Blaine, $\mathrm{MN}$ )

Olympic Games in Greece (U.S. wins and Julie Foudy, Mia Hamm, and Joy Fawcett retire)

WSII Established to gauge potential for WUSA comeback

Plans for a new women's soccer league announced by WSII for the 2008 season

New league pushed to 2009 season

Women's Professional Soccer (WPS) launched with seven teams

Second season of WPS - LA Sol folded before the season started while two teams added before the season started (Atlanta and Philadelphia); St. Louis folded mid-season; FC Gold Pride closed its doors following its championship win.

Third season of WPS is set to start with six teams, including one new franchise (Western New York) 
It was not until the mid-1990s that soccer began to gain a more mainstream position in the sport market. It began with the announcement of the establishment of Major League Soccer (MLS) leading up to the 1994 World Cup, the first held on U.S. soil. Only 2 years later, women's soccer was added to the Olympic Games, which were also held on U.S. soil in Atlanta, Georgia. "The Title IX Olympics" showcased not only women's soccer, but also the plethora of successes of female athletes in the United States as the United States swept the team sports of soccer, basketball, and softball, as well as gymnastics and won numerous individual sport gold medals as well.

The successes of American female athletes led many to think the marketplace was ripe for women's professional sport leagues. The first off the block were the American Basketball League (ABL), in the fall of 1996 and the Women's National Basketball Association (WNBA), in the summer of 1997, each league hoping to benefit from the successes of the women's national team in Olympic Games. Two women's professional basketball leagues proved too much for the already saturated sport marketplace and the WNBA, backed by the NBA, was too big of an obstacle for the fledgling ABL. The WNBA continues to expand to this day, most recently adding a franchises in Atlanta, and Chicago, while simultaneously seeing franchises fold (Cleveland, Portland) and move (Oklahoma City) for a current 12-team league. As the WNBA continued to grow with the support of the NBA and David Stern, the 1999 Women's World Cup, soccer's premiere international competition, was hosted by the United States. Matches were held in a host of venues throughout the country and the U.S. Team continued to garner support at every stop while also gaining significant media attention. 
The United States loves a winner and the U.S Women's Soccer Team was no exception. From Brandi Chastain on the cover of Sports Illustrated to the entire team visiting the White House and President Clinton, these women were everywhere as they continued to play in "friendly matches" (warm-up games for the World Cup) throughout the country. As noted earlier, the enthusiasm and media attention led John Hendriks to believe he, combined with the 1999 Women's World Cup Champions, could form a unique partnership and create a professional league with teams in Atlanta, Boston, Carolina, New York, Philadelphia, San Diego, San Jose, and Washington. Each team was allotted two to three "founding players" from the World Cup Champion Team. Despite this seeming meteoric rise, by the end of the 2003 season a mere 3 years later, the WUSA announced it was ceasing operations. Immediately following its demise, the Women's Soccer Initiative, Inc. (WSII) was created to determine the feasibility of women's professional soccer in the United States. While it continued to explore options, two WUSA festivals were held in the summer of 2004 in non-WUSA team cities.

The attendance of the 2004 WUSA Summer Festivals was disappointing and gave little hope for the league's return, especially since many of the marquee players, such as Mia Hamm, Julie Foudy, Joy Fawcett retired at the end of 2004. The lack of success confirms the findings of Mahony, Nakazawa, Funk, James, and Gladden (2002). They found the longer an individual is a fan, the more likely they will become attached to a team and attend more games. In the context of women's professional soccer, at no time did any teams exist long enough to build a fan base.

The Mahony et al. (2002) piece dealt with the motives of the ticket purchasers for the professional Japanese soccer league, the J League. In another study, Funk, Mahony 
and Ridinger (2002) found "spectator interest in women's professional sports hit a high point in the United States during the 1999 Women's World Cup" (p. 34) laying foundation that fan support for women's professional sport would then continue to wane in the future. Additionally, Funk et al. (2000) examined the motivation of WNBA fans and found a host of factors that attracted them to games, including a wholesome environment, a factor rarely associated with men's professional sport, highlighting the need for more research on the motivation of women's professional sport fans (see also James, Kolbe, \& Trail, 2002).

After the disappointment of the WUSA Festivals, the WSII announced plans for a new professional soccer league to kick off in 2008 , a year later, the date was pushed to 2009. On March 29, 2009 the WPS launched with seven teams, two of which were part of the original WUSA (the Boston Breakers and Washington Freedom). The 2009 season proved minimally successful at best with several teams experiencing financial woes. As the WPS geared up for its second season, it announced the addition of two teams; however, shortly before the season kicked off, the LA Sol folded, followed mid season by St. Louis. Following another minimally successful season in 2010 , highlighted by the play of its championship team, the F.C. Gold Pride, again, the championship team was forced to close its doors to financial reasons. As the 2011 season begins, the WPS has only six teams competing.

Although the timeline lays the foundation of this analysis of the women's soccer movement, the greater women's sports movement also continues to grow and evolve. The social movement literature is especially useful in understanding this phenomenon. While an inadequatebusiness plan may be one reason for the WUSA's failure, it is just one of 
many reasons better analyzed through the lens of social movement literature. This dissertation addresses the call by Davis-Delano and Crossett (2008) for more research on sport as a social movement and more specifically the role of the women's sport movement as part of the larger women's movement.

\section{Social Movement Theory}

Social movement (SM) theory is a logical theoretical school of thought developed from the earlier works by Merton (1957) and Parsons (1951), who examined the factors related to the changes occurring in social structures. This early scholarship laid the foundation for social movement theory. The term social movement refers to a social phenomenon (Tilly, 2004) and "a distinct social process" (Della Porta\&Diani, 2006, p. 20). Social movements have been defined as "collective enterprises to establish a new order of life" (Gutterman, 2005, p. 14).

A social movement organization (SMO) is an organization working toward the goals of a specific SM. "SMOs are named groups of citizens who have, more or less, formally banded together to pursue or resist social change" (Edwards \& McCarthy, 2004, p. 621). Within SM theory, several schools of thought offer important ways to analyze the factors social movement theorists have considered critical to social movement organization success. Since treating the WUSA as a social movement organization (sometimes referred to as a social movement association) is at the core of this work, social movement theorists offer several ways to evaluate the resources of the WUSA in the context of their contribution of the rise and fall of the league.

Sport and social movements."The fact that there is no new social movement specific to sport does not diminish the relevance of this phenomenon" (Harvey \&Houle, 
1994, p. 347). In discussing new social movements, Harvey and Houle (1994) explained that though "There is no example of a sport-specific, organized, new social movement...sport has been deeply influenced by and has contributed to these movements" (p. 347). In examinations and reflections on "The Battle of the Sexes," a tennis match between the aging Bobby Riggs and heralded Billie Jean King, the lack of acceptance and inclusion of sportswomen frequently were touched upon: "[M] any leaders of the women's movement seemingly failed to comprehend the potential contributions that sportswomen could make” (Spencer, 2000, p. 396); “'You should use us more' King urged Gloria Steinem, the editor of Ms. Magazine. Steinem replied, 'Billie, this is about politics.' 'Gloria,' King replied, 'we are politics"' (Blumenthal, 2005, p. 51).

Sport frequently was omitted from coverage or perceptions of the women's movement: "In the early 1970 s, King was unsuccessful in persuading publishers of $M S$. Magazine to make better use of women's sports to bolster their aims in the women's movement" (Spencer, 2000, p. 396). However, in retrospect, many writers and feminists have credited King for her role in the successes of the women's movement (Spencer, 2000).

Few scholars have examined sport as a social movement or even included sport as part of the women's movement, making this unchartered territory for research. Because of this rarely discussed area of exploration of sport as a social movement, all three of the primary schools of social movement thought (resource mobilization, political opportunity structure, cultural cognitive) will be used to examine and analyze the WUSA as part of the women in sport movement. Additionally, in recent years there has been a push for more scholarship integrating the three primary schools of thought (McAdam, Tarrow, 
\& Tilly, 1997). The combination of factors, exploring a new SMO as well as the timing of this study of the WUSA, on the brink of efforts to create a new women's professional soccer league, allows this study to contribute to this trend of new literature.

Prevailing schools of thought in social movement literature. The first theory created by social movement scholars was resource mobilization (RM) theory. Soon after the development of RM theory, a theory focusing on political opportunity structure (POS) was advanced. The newest and least developed school of thought is the cultural cognitive or new social movement theory. Each of these theories offers specific factors critical to evaluating the successes and failures of social movements and social movement organizations. These three theories will be discussed in detail in the following sections.

Resource mobilization theory.Resource mobilization (RM) theorists focus primarily on more formal SMOs with a paid staff, articulated goals, and a defined membership base. Numerous RM theorists have listed factors they utilized when exploring SMs and SMOs (Feree\& Martin, 1995; McCarthy \&Zald, 1987; McGlen\& O'Connor, 1983). These factors include leadership, organizational base, administrative structures, communications networks, cooperation with like-minded organizations, competition for organizational space, means for acquiring resources and support, and critical mobilizing events. These factors all played a pivotal role in the evolution of the WUSA as a SMO and as part of the women's sport movement.

Resource mobilization theorists offer a lengthy list of factors, noted above, to explain the rise, establishment, and success and/or failures of SMs and SMOs. Not all of the factors offered by RM theorists are discussed in the literature review; only those most germane to the study of the WUSA will be analyzed. 
Political opportunity structure. After establishing that a SM or SMO exists by using the factors determined by resource mobilization (RM) theorists, political opportunity structure (POS) theorists use new, noninstitutional factors to examine the successes and failures of SMs and SMOs. Political opportunity structure has been described as "an asset of formal and informal political conditions that encourage, discourage, channel, and otherwise affect movement activity" (Campbell, 1995, p. 44) as well as a catch all term for defining SMs.

Many researchers have found certain factors within POS theory to be particularly important. However, established factors within POS theory can largely be synthesized to create an overarching list of four factors identifying a SM within POS theory (Brockett, 1991; Campbell, 2005; Kriesi, Koopmans, Duyvendak, \&Giuni, 1992; Rucht, 1996; Tarrow, 1994). The first of the four factors refers to the openness of the political system. The second factor evaluates the "stability or instability of that broad set of elite alignments that typically under gird a polity" (McAdam, McCarth, \&Zald, 1996, p. 27). The third factor underscores the relationship with elite allies, and the fourth factor explores the "state's capacity and propensity for repression" (McAdam et al., 1996, p. 27). These factors offer a new way to fully explore the SMs and SMOs.

Cultural cognitive/framing/new social movement theory. These three terms, while different, all describe a similar theory of SMs and SMOs. The basic premise guiding this theory is to emphasize the role of the participants' social and cultural context as well as the participants' personal values and beliefs, more commonly referred to as collective identity. According to Canglia and Carmin (1995), this theory provides "a further example of how ideas and concepts are used to understand the dynamics of social 
movements" (p. 205). The two primary factors used in this theory are: (a) the social and cultural context of the SM or SMO and (b) the collective identity of group members.

The factor social and cultural context describes the established beliefs, norms, and behaviors from which a SM arises. The collective identity factor refers to the way the members of a SM or SMO identify as a group in order to create change. These two factors within this newest school of thought are often used as a compliment to the theories of political opportunity structure and resource mobilization when examining SMs and SMOs.

\section{Success and failure of social movements and social movement}

organizations.Social movements, social movement organizations, social movement associations, and the success and failure of each have been studied by a legion of scholars since the turn of the 19th century (Abel, 1937; Banaszak, 1996; Costain, 1981; Disney \& Gelb 2002; McCarthy \&Wolfson, 1996; Minkoff, 1997; Zald\& Ash, 1977). As SMs, SMOs, and SMAs were recognized as critical actors in society both resulting from societal change as well as causing it, a host of definitions have been offered to explain each term as well as how to define successes and failures. Most researchers offer slightly different definitions of their terms, but each definition allows this study of the WUSA to be set clearly within a strong theoretical framework.

These three primary schools of thought within the social movement literature establish a host of factors necessary to explain SMs and SMOs and their successes and failures. Resource mobilization theorists offer a lengthy list of factors to explain the rise, establishment, and success and or failures of SMs, SMOs, and SMAs. Political opportunity structure theorists have attempted to refine the ideas of resource mobilization 
theorists, believing political power structures and the factors contributing to said structures such as access to political elites and cultural and environmental contexts cannot be ignored in the examination of SMs and SMOs. Luders (2006) explained, "Social movement success depends on expanding political opportunities" (p. 963). The passage of Title IX, for example, showed how women used a political opportunity that had tremendous impact on women and sports. Governments, especially school boards, were forced to reallocate money for female athletes as teams were added. Thus, POS offers an exciting and new way to more fully explore and understand the women's sports movement and the WUSA.

The most recent addition to social movement research, cultural-cognitive/new social movement theory helps to illustrate how the launching of the WUSA was framed and publicized, as well as how its leaders viewed their mission. These factors also enable the researcher to examine the WUSA in the context of the women's movement.

Taken together, all three schools of thought work together to create a new model of SMs, SMOs, and SMAs. None of the factors analyzed above are mutually exclusive and one can see the way factors crossover, both within one school of thought and to other schools of thought. While this crossover creates a challenge, it provides an opportunity for further research.

\section{Statement of Problem}

In 1999, it appeared there was sufficient interest in and excitement about women's soccer in the United States to justify the creation of a professional league. Record crowds attended women's games during the 1996 Olympic Games when the U.S. women won gold and then went on to win the next Women's World Cup in 1999. In 
addition, an entire generation of women had grown up playing sports as a result of passage of Title IX, and women's soccer was the fastest growing women's sport on both the high school and collegiate level (Fasting \&Pfister, 2000). Moreover, on Saturdays and Sundays all over the United States, playing fields were filled with young girls playing soccer. The problem then, is why, at a time that appeared especially auspicious to the launching of a women's professional league, did it, the WUSA, fail so quickly? In examining this phenomena, social movement theory is used to derive several research questions to determine what factors were critical not only to the start and development of the league, but also its demise.

\section{Research Questions}

The research questions can be summed up in one general question: How can the rise and fall of the WUSA be explained? This study contained three research questions to answer the general question of how the rise and fall of the WUSA can be explained:

1. How was the WUSA founded?

2. Why was the WUSA founded?

3. Why did the WUSA fail?

\section{Purpose of Study}

The purpose of this study is to examine the creation and demise of the WUSA, and to establish the league as a SMO within the context of the rich body of social movement literature. A new model for examining SMs will be established through this literature and will explore four primary areas: (a) the contributing factors that led to the creation of the WUSA, (b) the strengths of the WUSA, (c) the reasons the league was able to sustain itself for three seasons, and (d) the contributing factors that led to its 
failure. As more and more commentary suggests plans to bring the league (or some form of it) back, this dissertation will not only analyze the mistakes made in the creation of the WUSA, but also offer concrete suggestions based on theoretical work, that could be used to guide the creation of a new, more successful league.

\section{Significance of Study}

This study is significant to the social movement literature as well as to the women in sport literature.First and foremost, this study is one of the first scholarly examinations of the WUSA, other professional soccer leagues, and women's professional sport leagues in the United States. While there have been limited studies on these leagues, most researchers have had a narrow focus and have failed to look at the overall league as well as its social, cultural and historical place. The success of women's soccer in the United States and the creation and fall of the WUSA has been a recent phenomenon, thus allowing researchers little time to investigate its life cycle.

This study also contributes to social movement literature as it explores a nontraditional social movement organization through the qualitative design.By examining the WUSA in the context of SM theory, the definitions of SMOs are further enhanced and will provide a new model in which SMOs can be examined. Additionally, this study adds to the SM literature on the development and cycles of specific SMs: the women's movement, the sports movement, the soccer movement, and the women in sport and more specifically the women in soccer movement. While a number of studies have been conducted on various facets of the women's movement as well as a number of SMOs commonly associated with it, very few studies have explored the women in sport movement. This study reiterates the fact that the women in sport movement is an 
important part of the women's movement. As Harvey and Houle noted, (1994), "The study of new social movements is important in the study of sport" (p. 352).

Finally, this study added to the recent literature by integrating the three prevailing schools of thought within social movement literature. Early social movement literature focused on one of only two schools of thought, resource mobilization and political opportunity structure, until the recent addition of cultural cognitive/framing/new social movement theory. The literature integrating these three schools of thought is limited, making the study of the WUSA as an SMO in this light an important contribution to the social movement as well as women in sport literature.

\section{Delimitations}

The study has the following delimitations:

1. Only WUSA leaders, as defined by the researcher, were interviewed for this study.

2. Only individuals extensively involved with the initial planning or daily operations of the WUSA were interviewed. Individuals with ties to the WUSA and its member teams who were not in visible positions, as well as the various sponsors and vendors and the host of volunteers and fans, were not interviewed.

\section{Limitations}

This study is limited in the following ways:

1. Only leaders, as defined by the researcher, with the WUSA were interviewed for this study. Lower level team and league personnel, team volunteers, and members of teams not placed in leadership roles (as either founding players, captains, or other players that could provide unique perspectives due to their role with the team or league), each 
integral to the operation of the league and eight teams, were not interviewed for this study.

2. The researcher worked as an intern and seasonal staff member with two of the eight teams in the league, thus the possibility of bias is present.

3. The researcher has previous relationships with some of the interviewees, which may make them more or less open in the course of the interview(s).

4. Due to geographic locations and schedules, interviews were done in-person as well as over the phone, which may create differences in the interview.

\section{Operational Definitions}

Social movement (SM):The definition of a social movement provided by Rucht and Neidhardt (2002) is most prevalent throughout this study: "Social movements are mobilized networks of groups, which based on collective identity, participate in collective action to bring about social change" (p. 9).

Social Movement Organization (SMO):A definition provided by McCarthy and Zald (1987) will be used throughout this work. They define an SMO as a "complex, or formal organization, which identifies its goals with the preferences of a social movement or countermovement" (McCarthy \&Zald, 1987, p. 1218).

Social Movement Association (SMA): The term social movement association is a more recent term than social movement organization (SMO) and in most instances serves as an umbrella term in which a SMO can fall. The term SMA has also included for-profit groups working within a social movement (Knoke, 1986). 
Success of a Social Movement or Social Movement Organization:A social movement, social movement organization, or social movement association is deemed a success when it is able to meet its articulated goals in creating change in society.

Failure of a Social Movement or Social Movement Organization:A social movement, social movement organization, or social movement association is deemed a failure when it does not meet its original goals and/or is unable to gain a foothold in society and is forced to either stop its movement pushes or to close its doors. A SM, SMO, or SMA can also be seen as a failure after it has met its initial goals and is unable to reassert itself to establish new goals

Women's United Soccer Association (WULA): The WUSA was the first ever, wholly professional women's soccer league in the United States. Founded by investors and the members of the 1999 Women's World Cup Champion team, the league was comprised of the best players from throughout the world.

WUSA Leader:A WUSA leader can be: a founding player or investor, vice president or higher ranking league personnel, head coach, Board of Governors member, team captain, team general manager or other high ranking team staff member, and members of the reorganization committee. Other WUSA leaders include team members that were placed in a leadership role as either a "first," such as a first international allocated player, first drafted player, or first traded player, for the purpose of this research. 


\section{CHAPTER II}

\section{LITERATURE REVIEW}

For the most part, research bearing on the general area of sport and social movements has been rare. (Wilson \& White, 2002, p. 121)

This literature review is divided into three major sections. The first section of literature lays the foundation for social movement theory through some of the earliest forms of sociological research and the various factors given for change within society or social structures. The second section of literature grounds this study with social movement theory and includes a discussion of important terms including: social movements, social movement organizations, social movement associations, and social movement success and failure. The third section of literature is divided into three parts and presents the three prevailing schools of thought commonly accepted by social movement theorists: (a) cultural cognitive/new social movement theory, (b) political opportunity structure, and (c) resource mobilization.

Within each of these three schools of thought a host of factors have been used to explain the creation, rise, success, and failure of social movements and social movement organizations/associations. Together these three areas of literature will be used to lay the foundation necessary to explain the rise and fall of the Women's United Soccer Association (WUSA) and will work together in an attempt to create a new model to examine reasons of the failure of some social movement organizations and associations. 
By drawing upon the factors commonly associated with the various schools of thought within social movement theory literature and incorporating them, a new model will be developed to explain the rise and fall of the WUSA, as well as provide a new model others may use to examine how social movement organizations may develop and evolve.

\section{Early Sociological Studies of Culture}

The social structure is the overarching entity which allows movements and movement organizations to come to fruition. Many sociological scholars in the midtwentieth century wrote about societal structure and how it was able to evolve, while social movement scholars were doing the same.Merton (1957) focused on the term functional analysis in his study of social structures and continued on to elaborate on the factors contributing to social structure change. Merton elaborated on the term "functional analysis" of social structures and stressed two elements: (a) "culturally defined goals, purposes, and interests; and (b) the definition, regulation and control of "the acceptable modes of achieving these goals" (Merton, 1938, p. 673) as ways to explain social structures. Simply put, these two additions are cultural goals and institutional norms. This elaboration on functional analysis allowed him to "deal with problems of social and cultural change" (Merton, 1957, p. 122).

Beginning with functional analysis, Merton (1957) began by explaining the various concepts associated with the term "function." "Too often, a single term has been used to symbolize different concepts..." (p. 20) thus creating confusion among researchers. The concept or definition he used when describing the term function in function analysis stemmed from the original mathematical concept, also commonly associated with the hard sciences, and was described as "the vital or organic processes 
considered in the respects in which they contribute to the maintenance of the organism" (Merton, 1957, p. 21).

"Culture has always been important for the kinds of processes students of social movements study" (Swidler, 1995, p. 25). Even so, the importance of culture was not initially in the forefront of organizational and social movement research. Beginning in the mid-twentieth century, more and more scholars became interested in the role of culture in organizational and societal structure and later in social movements and social movement organizations. To better understand social movements and social movement organizations, it is important to look to the initial research on social structure as a foundation to the social movement scholarship.

Looking at the cultural goals and institutional norms allows a researcher to theorize about how a social structure functions and the influence(s) it may or may not have on individual members. Merton stressed the importance of cultural goals and norms in deviant behavior as well. His many works stressed the numerous factors contributing to social structure and its life cycle and his main area of exploration, cultural goals and norms, differ and change in their contribution depending on the structure (Merton, 1936, $1938,1945,1957)$

Around the same time Merton was working on social structure, Parsons (1938was also looking at the role of culture in societal behavior. Working from the two basic theories in the study of sociological culture, those of Weber and of Durkheim, Parsons attempted to merge the theories of Weber and Durkheim in creating the Parsonian theory (Parsons, 1938). 
Weber's (1958) theory attempted to explain the culture through the individual or specific analysis of entities, while Durkheim (1933) argued that culture was explained by "collective representations." Parson focused on the individual analysis of Weber in his creation of the Parsonian theory. This individual analysis referred to the way Weber explained how specific worldview of a group determined actions. The "collective representations" Parson focused on from Durkehim in his Parsonian theory included rituals and symbols, more tangible items than the worldviews or ideas associated with Weber (Davis, McAdam, Scott, \&Zald, 2005; Parsons, 1938; Swidler, 1995).

The combination of these traditions led to Parsons' theory, which referred to values. According to Swidler (1995), "Values are very general, abstract orientations of action, rather than the specific, historically grounded doctrines and worldviews that Weber thought shaped action" (p. 26). This theory never fully took off as a popular method for looking at social structure; however, it laid the groundwork for later scholars to examine culture and its role in creating a society and dictating the various directions it may take.

Parsons (1938) later reflected on three specific processes of social change: (a) institutionalized rationalization and "cultural lag," (b) ascendancy of the charismatic revolutionary movement, and (c) the adaptive transformation of a revolutionary movement. These three processes can be seen as a precursor to social movement theory, and the way scholars initially chose to examine SMs and SMOs. It is also of note, that some of SM research was going on simultaneously; however, there is little to no doubt it was influenced by sociologists including Parsons, Merton, and Weber. 


\section{History of Social Movement Theory}

Three main terms are commonly referred to in social movement literature: social movements (SM), social movement organizations (SMO), and social movement associations (SMA). In addition to these three terms, the success and failure of SMs, SMOs, and SMAs are often discussed. It is important to understand these terms to see the way the WUSA can be considered an SMO or SMA within the larger women's movement, and more specifically the women's sports movement.

Social movements. As early as 1850 , German sociologist Lorenz von Stein first introduced the term "social movement" into "scholarly discussions of popular political striving" (Tilly, 2004, p.5). As von Stein was writing, Marx and Engels recently had finished their Communist Manifesto, and sociologists began to see the need for explanations and a common set of terms. Von Stein's definition initially conveyed the notion of a "continuous, unitary process by which the whole working class gained selfconsciousness and power" (Tilly, 2004, p. 5).

Sociologists were quick to expand upon these works to call for examinations of what they termed social movements differentiating them by program, organization, and setting (Tilly, 2004). Noted sociologist Tilly, however, warned that many of those who studied movements in an historical perspective were quick to label isolated actions, whether collective or not, as social movements, when in fact, he believed those actions did not warrant being defined as social movements. He noted some historians concluded that women's actions in the 1700's were not part of a social movement. Yet, he argued groups such as the Daughters of Liberty, who existed in colonial times, were indeed part of a social movement. Tillyargued what he termed aspolitically complex social 
movements must have three components: (a) campaigns of collective claims on target authorities; (b) an array of claim-making performances including special-purpose associations, public meetings, media statements; and demonstrations; and (c) public representations of the cause's Worthiness, Unity, Numbers, and Commitment. The term WUNC serves as an acronym for Worthiness, Unity, Numbers, and Commitment (Tilly, 2004).

Tilly(1996) stressed that many contemporary social movement (SM) theorists failed to place their studies in a larger historical context, citing those who studied the civil rights and women's rights movements as notable exceptions. He noted what he called "one of the sharpest available statements on the subject" (Tilly, 1996, p. 45), sociologist Markoff's (1996) deft explanation of the problem:

Social movements as we know them today were beginning to flourish in England by the late eighteenth century and during the nineteenth century took root in Europe, North America, and elsewhere. To understand why, we need to consider many like changes: a strengthened government but a weakened king; a people organizing themselves to assert claims on that government; a political elite prone to claim that it ruled in the name of the people, transportation improvements and commercial relations linking distant people; the beginnings of widespread literacy and new conjunction media leading people separated in space to feel themselves moving to a common rhythm. (Markoff, 1996, p. 45) Still, both Markoff and Gamson, another noted sociologist who has made major contributions to the historical context in which social movements arise, failed to include women's movements in their examinations. 
Numerous additional social scientists have offered varied definitions of social movements. According to Rucht and Neidhardt (2002) "Social movements are mobilized networks of groups, which based on collective identity, participate in collective action to bring about social change" (Rucht\&Neidhardt, 2002, p. 9). Much earlier, Theodore Abel (1937) stated "A collective effort may only be called a social movement only if it operates within the medium of a community" (Abel, 1937, p. 348). He elaborated that a collective effort, or social movement (SM), falls under the general class of social phenomena and that it exists whenever a group, aims to win over the community while working toward a common goal. Frequently studied SMs include the Civil Rights movement, the various waves of the women's movement, and the more recent gay and lesbian rights movement. Abel, of course, was writing at the dawn of World War II at a time sociologists were trying to explain the rise of Nazism in Europe and the fledgling civil rights movement within the United States. More recently Tarrow defined a $S M$ as "collective challenges by people with common purposes and solidarity in sustaining interaction with elites, opponents, and authorities" (as cited in Jeydel, 2004, p. 22) and Koch and Leonard stated "The catalyst to all social movements is the perception that something is wrong and must be rectified" (Koch \& Leonard, 1978, p. 227). Tarrow and others focus on elites and their importance to group success.In describing women's movements in the United States, Mary Katzenstein (1987) noted these movements are a "political force that even in a single country ha(ve) broad ideological variety and a range of organizational expressions" (Katzenstein, 1987, p.182). Katzenstein's work was collectively concerned with the role of women within the Roman Catholic Church. Still, 
her reflections upon women's actions within such a male dominated institution are quite instructive for a study of women within the male dominated world of sport.

Katzenstein (1995) followed the development of a move for more power and recognition within the church, as well as the call for less discrimination to the "combined force of Vatican II and the dawn of feminism's second wave galvanized women" (Katzenstein, 1995, p. 37). Using an historical approach to the development of "churchwomen," she noted November 1975 was the first Women's Ordination Conference. Attendance exceeded 1200 and over 500 additional women were turned away. This conference brought women from all over the United States together, energizing their cause but wondering if their ultimate goal-permission to join the priesthood-was attainable.

Katzenstein (1995) carefully discussed the several tactics taken by what she called Church-Women, including a confrontation with the pope. While the actions ultimately brought little change to the church, Katzenstein concluded their actions brought about changes in the way the public viewed gender issues in the church, much in the same way the passage of Title IX led to the involvement of more women in sports and changes in public attitudes.

One study exploring sport as a social movement places great emphasis on how sport was able to evolve based on cultural factors such as the economic climate as well as religious and educational support. Wheeler (1978) noted how often sport was ignored as a social movement in his work. In discussing the development of the sports movement from an historical perspective, he noted how, in England, organized sport sprang from elite public schools such as Eton. 
Later, the churches played a critical role in encouraging the development of soccer leagues in the latter half of the nineteenth century. He found that only when workers began to work fewer hours were they able to have sufficient leisure time, money, and energy to devote to organized sport (Wheeler, 1978).

Around the same time Wheeler was studying the development in sport in England and placing it as a social movement, Koch and Leonard (1978) were exploring the National Collegiate Athletic Association (NCAA) as a social movement. In this work, Koch and Leonard discussed a catalyst, which they deemed necessary in defining a SM. They went onto argue there was a typical life cycle of a social movement and hypothesized these stages as: unrest, excitement, formalization, and institutionalization, and in some cases dissolution. By tracing the five stages in conjunction with the history of the NCAA, the researchers concluded the NCAA was a social movement.

According to the researchers, the NCAA was established in reaction to the numerous injuries and even fatalities taking place on the football field in the early $1900 \mathrm{~s}$ highlighting the stage of unrest. In response to these issues, President Theodore Roosevelt announced he would ban football if something was not done to stop the problem. Thus the next phase of a social movement life cycle took place: the excitement. In this case the excitement surrounded the potential abolition of football, a popular activity on college campuses. The third stage of formalization came in response to the President Roosevelt's threats as the Intercollegiate Athletic Association of the United States (IAAUS), the forerunner to the NCAA, was established at the end of 1905. Institutionality was the next phase, as the NCAA took its place as a formal institution shaped in a bureaucratic manner. The final stage in an SM is dissolution, or demise and 
although the researchers thought this could happen, the NCAA seems firmly entrenched as a social movement/social movement organization.

Koch and Leonard (1978) illustrated the NCAA as a social movement through the same kind of historical analysis used by Katzenstein (1995) tracing the development of "church women" and their push of ordination for women. In this context the NCAA is very clearly an SM or an SMO/SMA, and this research is part of a growing body of literature that understands and studies sport as an SM.

A later study explored the evolution of one specific sport organization, the National Rifle Association (NRA), as a social movement and the political and cultural climate that allowed the NRA to be studied through the lens of SM theory. Leddy (1985) looked at the development of the NRA from a simple sport organization into a hugely influential group and political player. The researcher explored this development through three forms of analysis. These methods included an historical analysis, a content analysis of the publication The American Rifleman, and an examination of the NRA's evolving group membership demographics.

The researcher found the success of the NRA to be atypical. The NRA fell prey to a faction increasingly aware of the politicking going on in regard to shifting the gun laws in the United States. Recognizing of the shifting political climate toward greater gun control, the NRA transformed into a politically invested and lobbying group, focused on ensuring its members the right to keep and bear arms. The ability of a sport entity to transition to a powerful lobbying group illustrated the potential other sport SMOs or SMAs can have in implementing change. 
Limited research explores the possibility of women's sports and other sporting entities as a social movement. While exploring ethics and moral behavior in sport, Corbett (2002) wrote, "Sport has a universal value, and is a social movement striving to contribute to the development of a peaceful and better world" (p. 168). Going one step further and exploring women in sport as a social movement, one of the earliest studies was conducted in 1981.

Ingram (1981) looked to publications about women in sport to assess the women's equity in sport movement. Through a review of 226 quantitative abstracts on the subject of women's athletics in the ERIC search engine, the researcher explored the cycles within this movement. Ingram's (1981) findings were twofold. First and foremost, the researcher found the women's equity movement in sport illustrated an increase in interest and participation from 1971 to 1981 . The researcher elaborated to conclude the social movement peaked in 1978 and at the time of her study was declining in intensity. The study also found publications on women in sport to be primarily journal articles followed by classroom materials, research reports, conference proposals, legal materials, and books, as well as a few additional publications. This early study laid the foundation defining the women in sport movement.

Later research narrowed in on women's soccer as a social movement, both in the United States and abroad. MarkovitsandHellerman (2003b) studied this evolution of women's soccer in the United States. They looked at women's soccer as an exception in the world. The United States is viewed as anomaly in the soccer world because the women's team has seen extreme success both on the field, as evidenced by their two wins in the World Cup (out of four) and two Olympic gold medals (out of three), and off the 
field as evidenced by their media popularity during the 1999 World Cup and in a variety of ad campaigns. Throughout the world, soccer (futbol or football) is the most popular sport and is dominated by men while in the United States it is a popular participant sport for both males and females; However it was not until the 1994 World Cup and then the 1999 Women's World Cup which were held on U.S. soil, that the sport was able to garner any of the public space, meaning support and a place in the sport space of the United States.

This study traced the evolution of women's soccer in the United States and explored why it had such success on and off the field. The study "is dedicated to the analysis of the reasons, origins, and present manifestations of this particular American sports 'exceptionalism"” (Markovits\&Hellerman, 2003b, p. 15). The investigators highlighted two key events in bringing women's soccer to the forefront of the U.S. media. The two events were the passage of Title IX in 1972 and the success of the Women's World Cup in 1999. The latter was the most popular event in the history of women's teams sports. It also had the highest television audience of any soccer game ever broadcast in the United States. The researchers even went so far as to tie the success of the U.S. team in endearing themselves to the U.S. public and media to the creation of the WUSA in 2001. While they remained hopeful and optimistic that the WUSA would become a mainstay (this article was published before the leagues demise in 2003), they understood the difficulty of a professional sport league having success when it did not come into existence in the pivotal 60 -year time frame from 1870 to 1930 when the "big three and one half," MLB, the NBA, the NFL, and the NHL, endeared themselves to the U.S. public. 
Later studies examined the opportunities women have had internationally in soccer and the evolution of opportunities for these female soccer players and illustrated the difficulties female athletes may encounter. Pelak (2005) explored the constraints encountered by female soccer players in South Africa. She explained the various experiences encountered by these women as well as how their opportunities changed during the evolution of women's soccer in the new (post-Apartheid) South Africa.

The researcher used a variety of data collection methods in this study, which was conducted in two separate, three month visits to South Africa in 1999 and 2000. The methods used in this study consisted of interviews, surveys, documents, and observation. These semistructured interviews were conducted with seven soccer players and 11 administrators active at the provincial and national levels and were selected through purposive sampling. The interviews consisted of questions about how the abovementioned individuals became involved in soccer, their experiences with the sport, and their views on the evolution of the sport. The interviews were than transcribed and coded with the help of the software, NUD*IST. Various documents were used to affirm the themes discovered from the interviews. The surveys were distributed by the author to the 14 teams in the league and were returned by 84 players from nine teams (for a $50 \%$ response rate). Besides the demographic information on the surveys, data were only used from two questions due to the difficulty with language barriers, age, and experience with surveys. Observations at games were also included as a part of this data collection and allowed the researcher to conduct informal interviews and gain rapport with the participants. 
The researcher found that the women in South Africa were denied opportunities to play competitive soccer in a variety of ways. Most of the reasons for the limited opportunities to participate in soccer at an elite level stemmed from the race and gender inequities permeating the landscape in the country. Even so the women were described by the researcher as agents of change "in the social institution of sports" (Pelak, 2005, p. 66).These women were tied as a collective group by their soccer playing experiences. Through this identification, the group was able to change the landscape of women soccer players in the new South Africa. The ability of this small group of women to influence the landscape of soccer in South Africa parallels the U.S. Women's National Teams role in changing the soccer and professional sport landscape in the United States.

Social movement organizations.In the early 1960s, a host of young sociologists began to advance more sophisticated, explicit, and political explanations for social unrest by concentrating on "collective action, social movements, and even social movement organizations" (McAdam\& Scott, 2005, p.6), moving away from an emphasis on collective behavior.According to leading resource mobilizations theorists, McCarthy and Zald defined a social movement organization as a "complex, or formal, organization, which identifies its goals with the preferences of a social movement or countermovement" (McCarthy \&Zald, 1987, p. 1218)

Tilly (2004) noted it was important to differentiate between social movements and social movement organizations. Gamson (1990) and his research associates devised a system to categorize political activities, social movement actions, and Worthiness, Unity, Numbers, and Commitment (WUNC) displays. Working his way through 75 historical analyses of these types of actions, he compiled a list of 4,500 organizations and then 
drew a random sample of 467 from which he and his colleagues did a more detailed examination of 53 organizations. These 53 organizations were chosen because they sought to mobilize a previously stagnant constituency and the relationship each had with an outside antagonist, countermovement, or mobilizing event.

This catalog of social movement events portrayed "a quickening and broadening of social movement activity in the United States doing the later $19^{\text {th }}$ century" (Tilly, 2004, p. 50). Many of these groups acted alone at times while others worked collectively with other groups allowing them to be categorized as social movement organizations.

Katzenstein noted not only did social movement organizations engage in the more traditional activities of the kind chronicled in Schlozmanand Tierney's (1983) quantitative study of Washington, DC based groups noted below, she also found groups engaged in what she termed discursive politics, the politics of meaning-making (Schlozman\&Tierney, 1983, p. 35). Meaning-making requires conceptual change through language, debate, the news media, and other forms of communication, quite similar to Tilly's WUNC. Katzenstein's (1995) work, based on interviews with women active within the Catholic Church, analyzed conferences held on women's status and found efforts at discursive politics largely failed. Nevertheless, she concluded groups working at the local level may be the most effective.

The range of activities and expressions in the arsenals of women's social movement organizations take a host of forms from traditional political lobbying, to creating social movement organizations, to working collaboratively with other groups for the good of all. Schlozmanand Tierney (1983), for example, in a mail survey to over 
1,000 of Washington, DC based interest groups found that groups participated in over 75 kinds of actions to further their goals.

Fereeand Martin (1995) noted their belief that feminist organizations were a special "species of social movement organizations" (p. 12). They often live with who many term their oppressors (men), and sex discrimination is rarely taken seriously by politicians or the courts. Still, Fereeand Martin (1995) held that "they do not view feminist organizations either as subtypes or as ideal types" (p. 9). Instead they view them "as the places in which and the means through which the work of the women's movement is done" (Feree\& Martin, 1995, p. 12). This was one of the initial attempts to remedy the fact that "feminist groups have largely been ignored by organizational scholars" (Feree\& Martin, 1995, p. 9). They noted scholars' tendency to examine larger, male-dominated associations and businesses and call for more study of women's groups and associations of every type to allow women to "develop new theory and discourse about feminist organization" (Feree\& Martin, 1995, p. 9). Thus, their definition included a full range of groups from feminist theatre groups to feminist art galleries. Surely, had the WUSA been in existence at the time they were writing, it would have also been included.

Social movement associations.In calling for a more open ended study of feminist organizations that would include consideration of associations as interest groups, Fereeand Martin (1995) reiterated a view first favored in 1952 by D. B. Truman in his classic political science treatise on interest groups, The Governmental Process. In chapter 2 , in particular, he underscored the key role that the use of the terms "group" "interest groups" or "associations," all are critical in understanding the role of organizations as well as social movements. His focus on associations was especially important for the 
present dissertation's emphasis on the WUSA as an association as well as a social movement organization and, as noted above, one with which Fereeand Martin (1995) would agree. Sociologists and political scientists often use the terms social movement organization and social movement association interchangeably. In the main, however SMOs are usually nonprofit and SMAs more frequently exist for profit, yet still work within the social movement milieu. For example, social movement associations or organizations such as the WUSA, may seek help from similar organizations, such as Major League Soccer (MLS) or the Women's National Basketball Association (WNBA) to succeed. Thus, it was not unusual to see WUSA marketers promoting tie-ins with groups such as the Girl Scouts, "Go Girl Go," and even groups such as the American Association of University Women and the National Council of Women's Organizations as it tried to expand its fan base and increase ticket sales.

Additional definitions for social movement associations include, "a formally organized named group, most of whose members... are not financially recompensed for their participation" (Knoke, 1986). Knoke (1986) elaborated to give examples of associations including labor unions, SMOs, professional societies, recreational clubs, and cooperatives, among others. With this definition of a SMA, it can be argued the WUSA is an SMA.

Success and failure of social movements. A variety of research explored the successes and failures of both social movements and social movement organizations/associations. In this research vein, researchers investigated a host of factors relevant to the success and failure of these entities and the cycles they display. Successes for SMs, SMOs, and SMAs can come in many forms. Obviously SMs, such as 
the first women's movement drive for the passage of the $19^{\text {th }}$ Amendment, the Civil Right Movement's passage of the Civil Rights Act of 1964, and even prohibitionists initial ratification of the $18^{\text {th }}$ Amendment outlawing the sale of alcohol in the United States, were all clear marks of movement success. However, with some successes come what some may see as failure. In the case of the suffragist movement, once the $19^{\text {th }}$ Amendment was passed, with no single goal to unite women's SMOs, this first wave of the women's social movement virtually disappeared and became a victim of its own success. Similarly opposition to prohibition proved to be so great that other SMAs were able to mobilize quickly against prohibitionists and were able to repeal prohibition with the passage of the 20th Amendment (Balkasak, 1996; Vose, 1972)

The failures of SMs, SMOs, and SMAs are slightly easier to define. For a movement to be deemed a failure it has little or no impact on creating change and/or is unable to sustain itself long enough to force change. Sometimes, such as in the case of the eugenics movement, favored by the Nazi party, ideas espoused by the movement fell out of favor with the general public (Vose, 1972). Other times competition within the movement lead to SMOs and SMAs competing for leaders, members, and resources. In the case of the National Organization for Women (NOW) for example, more conservative women split from NOW in 1967 to form their own group, the Women's Equity Action League (WEAL). Within WEAL, continued internal conflicts and an absence of strong leaders led it to having only a limited impact on any of the goals of the women's movement and its demise illustrated its failure (O'Connor, 1980).

Successes of SMs, SMOs, and SMAs can come in many forms. Minkoff (1993, 1994) tried to identify the survival prospects of various SMs and SMOs. Minkoff (1993) 
focused "on organizational survival as a success criterion and examines organizational characteristics and improve a group's legitimacy and thereby its bargaining position and continues activity" (p. 888). Elaborating on earlier research, Minkoff explored a variety of attributes associated with SMs and SMOs to see which attributes, if any, would influence their sustainability.

Minkoff(1993) collected information about "voluntary associations in the United States that are or were open to a national membership base and concerned with the status of women and racial-ethnic minorities" (p. 892). She used data collected on these organizations from the first 23 editions of the Encyclopedia of Associations. Initially 1,001 organizations were identified; however only 878 organizations were used. The dependent variable in this study was the disbanding of the organization, or inactivity. The independent variables used were (a) the main strategy(ies) employed by each organization, (b) the goals of the organizations, (c) targets of influence, (d) organizational structure, (e) membership composition, and (f) interorganizational affiliations. There were also four control variables: (a) membership size, (b) organizational age, (c) organizational change, and (d) constituency. All of these variables were explored thorough an event-history analysis with a focus on the structures, strategies, and goals associated with the movement or organizations.

The results from this study indicated that advocacy oriented groups were less likely to disband than service or cultural groups. Extremist groups were found to be more likely to disband than those movements with more moderate agendas. Minkoff (1993) also found the structures of these movement organizations to not play a significant role in the survival of these organizations. Survival rates of SMOs were found to increase after 
the 18th year and with an increase in membership size. Minkoff (1994) used data collected at the same time as her 1993 publication to examine the changes national membership organizations underwent and to explore what factors contributed to the shape and growth in the number of social movements and social movement organizations and how these factors allowed these movements to have success, or fail.

Differing from her earlier study, Minkoff (1994) examined these issues through four primary measures: (a) organizational founding, (b) density effects, (c) resources and opportunities, and (d) demand for action. Bivariate correlation was conducted "between internal density effects, cross-effects, and institutional and resource factors on the founding rate of protest, advocacy, and service organizations, respectively" (Minkoff, 1994, p. 954). These correlations allowed the researcher to explore the predicted influences on the growth and successes of SMs and SMOs.

Minkoff (1994) found the continued legitimization of advocacy as an alternate form of activity within SMs and SMOs. This was a shift from the original form of service as the main emphasis of activity. This time frame also saw an increase in the numbers of both. This increase in numbers was attributed to the perceived success of affiliated organizations contributing to the growth. These two studies found multiple factors contributed to the life cycle and growth of SMs and SMOs.McCammon, Campbell, Granberg, and Mowery. (2001) defined movement success as "political or policy outcomes" (p. 52). In concluding the women's suffragists' ability to gain the right to vote qualified it as a successful SM, the researcher examined what made this movement a success. 
Through an event history analysis the researchers were able to examine factors which contributed to the success of the women's suffrage movement in the time period from 1866 to 1919. Most of their data were collected from secondary sources pertaining to individual movements within each state. Archival research supplemented data. The data for 12 variables was then coded by three individuals through a content analysis and interrater reliability was assessed and ranged from .91 to .95 using Krippendorfer's alpha.

Multiple factors were found to contribute to the success of suffrage movements within the states where ratification by $3 / 4$ of voters was necessary for the amendment to pass. The presence of the new woman, a woman who was educated, professional, and active in society, passage of suffrage laws in surrounding states, fundraising abilities, and placing the reasoning behind granting them the vote in an "appropriate" gender context (i.e., the ability to protect their children) all contributed positively to the likelihood of movement success. The size of the movement was found not to affect success. The major finding in this study was "no single cause can explain women's suffrage success" (McCammon et al., 2001, p. 52).

In a later study, Disney and Gelb (2002) examined eight national level feminist organizations deemed as part of the women's movement. In trying to "identify particular characteristics of success and survival over time" (p. 39), the researchers found two characteristics, success and survival, did not necessitate the other. Their research consisted of 27 , two to three hour interviews with various executive directors and staff members within the eight organizations and an in-depth analysis of organizational documents and publications. Through this comparative study between the eight 
organizations the question: "What are the essential factors which contribute to feminist organizational success?" (Disney \& Gelb, 2002, p. 44), was asked.

Through these methods, Disney and Gelb (2002) found two primary factors contributed to the success of feminist organizations: (a) access to diversified funding and (b) organizational adaptability. Secondary factors were found to be (a) the renegotiation of the organizational structure and (b) the expansion of the feminist agenda.The factors or characteristics found to be indicative of successful SMOs within the women's movements, such as the new woman, an appropriate gender context, the ability to raise funds, and to adapt, can all be explored when examining the WUSA. Identifying additional factors which must have contributed to the initial success and almost immediate failure of the WUSA may help similar SMs, SMOs, and SMAs not face the same pitfalls.

Summary.Social movements, social movement organizations, social movement associations, and the success and failure of each have been studied by a legion of scholars since the turn of the 19 th century. As SMs, SMOs, and SMAs were recognized as critical actors in society both coming from societal change as well as causing it, a host of definitions have been offered to explain each term as well as how to define successes and failures. Each researcher offered slightly different requirements for their terms, but each definition allows this study of the WUSA to be set clearly within a strong theoretical framework and to be examined as a SMO within both the women's movement and the sports movement. 


\section{Prevailing Schools of Thought in Social Movement Theory}

Moving on from the above discussion of definitions, it is important to note that this section of the literature focuses on the extensive body of work surrounding interest groups and social movement organizations, in particular. It is divided into several subsections that will guide the analysis of the questions posed in Chapter 1 .

The three following subsections present literature from the three primary schools of thought in social movement literature: (a) cultural cognitive/framing/new social movement theory, (b) political opportunity structure, and (c) resource mobilization theory. A host of factors contribute to each school of thought. The most pertinent factors in seeing the WUSA as a SMO and part of the women's movement are included in the subsequent discussion.

Additionally recent scholarship has pushed for an integration of ideas across the three schools of thought. "We argue that a synthesis of the three major strands of research emerging from the main core of social movement research holds much more promise for theoretical progress than an endless disputation between rival schools" (McAdam et al., 1997, p. 14). The three main schools of thought are presented below, as well as the factors commonly associated with them and pertinent to establishing the WUSA as a SMO.

Cultural cognitive/framing/new social movement theory. The newest school of thought within social movement theory has been labeled differently by various scholars; however all of these scholars share the same basic premises. Whether one refers to this school of thought as cultural cognitive theory (Canglia\&Carmin, 1995), framing (Hunt \&Bensford, 1994; Hunt, Bensford, \& Snow, 1994; Sage, 1999) or New Social Movement 
Theory (Gamson, 1992), all extend past the most common schools of thought, resource mobilization theory and political opportunity structure, and emphasize the role of the participants social and cultural context as well as their personal values and beliefs more commonly referred to as collective identity. This view, sometimes called framing or frames, provide "a further example of how ideas and concepts are used to understand the dynamics of social movements" (Caniglia\&Carmin, 1995, p. 205) and "involves strategic efforts by activist and organizations to construct specific meanings and shape shared understandings in an effort to crystallize the targeted grievance or claim" (Sage, 1999, 127). In addition to helping understand the dynamics of social movements, "frames help to connect individuals to movements" (Caniglia\&Carmin, 1995, p. 205). Today many traditional Resource Mobilization and Political Opportunity Structure theorists are turning to framing as a way to enhance their respective theories.

The two primary factors explored in this school of thought are (a) the social and culture context and (b) collective identity of group members. While these two factors overlap to a certain extent, they each have distinct characteristics that differentiate them.

Social and cultural context.Social and cultural context describes the beliefs, norms, and behaviors in place as a social movement arises. In exploring the women's sports movement as well as the WUSA within this movement, understanding the social and cultural context of women's athletics as well as that of women athletes is vital and the ways they have been perceived. Many studies explored the ways female athletes as well as sports were viewed in society. One early study by Thirerand Wright (1985) explored the way America's youth see athletics as influencing their social position by examining the social status criteria of male and female youth in the mid 1980s. The 
researchers extended an earlier study by Eitzen (1976) as well as one by Coleman (1961) to see what, if any, changes had taken place in male and female youths regarding the factors that played the most significant role in their social status. They developed three basic research questions: (a) what is the basis for male adolescent popularity?, (b) what would male and female high school adolescents consider important to be remembered for from school?, and (c) what is the basis for female adolescent popularity?

Six hundred high school students $(n=600)$ from eight locations (rural, urban and suburban) were studied. They were distributed evenly by gender and grade. Each participant completed a questionnaire designed to assess his/her perceptions on being an athlete.

Differences were noticed among races, social class, parental education level, and school location, none of these factors however, were significant. "Being an athlete" was the highest indicator of what males and females believed made a male popular. In sharp contrast, the researchers found that females would most like to be remembered as a "brilliant student," (43\%) followed by "most popular" (40\%). Males preferred to be remembered as an "athletic star" (37\%) followed by "brilliant student" $(34 \%)$. It is not only interesting, but important to note in the context of Cultural Cognitive Theory, that the stronger majority of the younger males and females indicated a large majority would like to be remembered as an "athletic star." "Being in the lead crowd" was the next reported basis for female adolescent popularity and being an "athletic star" was given as fifth of the sixth choices among this same group. The shift from the older high school students to the underclass students illustrated a start in the shift toward greater acceptance of women athletes and the direction the culture is heading for women to be successful 
and accepted as athletes. While the children in this study illustrated a shift in their perception of women in sport, women participating at higher levels still deal with various stigmas surrounding their participation.

A later study looking at perceptions of girls and boys as athletes found similar stereotypes. McCallister, Blinde, and Phillips (2003) investigated the beliefs of young girls toward sport and physical activity. Spencer and McClung (2001) argued many events in the 1990's may have led to a shift in the belief system reported by Thirer and Wright (1985). With the publicity surrounding the 1999 Women's World Cup, McCallister et al. (2003) hypothesized that girls began to see women as successful athletes and being rewarded financially for this success. The researchers focused on three themes: (a) the "perceptions of the capabilities of boys and girls" (McCallisteret al., 2003, p. 85), (b) interactions with boys within sports, and (c) girl's internal beliefs about sport. In this qualitative study, the researchers used interviews as the primary data collection method. Interviews lasted 31 minutes and the interviewees were chosen from two elementary schools in rural southern Illinois. The majority of girls were White $(n=44)$; there was one Hispanic American and one African American. Areas of interest included demographics, preferences concerning sport activities, conceptualization of an athlete, similarities and differences between boys and girls, and participants reaction to conventional phrases about boys and girls in sport. The interviews than were transcribed and read by three independent researchers who identified three themes, all pertaining to sport and physical activity: perceptions of capabilities, interactions with boys, and internalized messages. 
The researchers found that when describing boys, girls were more inclined to use words focusing on physical qualities (stronger, tougher, etc.) while girls were described in socio-emotional terms (nicer, calmer, etc.) when relating them to each another. The girls also identified boys as being better at contact sports (football, soccer, basketball) while girls were described as being better at individual athletic endeavors (jumping rope, ballet, gymnastics). Their findings illustrated that even though women have made tremendous strides in rates of athletic participation, many stereotypes surrounding women in athletics still prevail.

Recently the literature exploring the culture of women and sport and has grown to provide research specifically women soccer players and their image. Harris (2005) keyed in on a theme of FédérationInternationale de Football Association (FIFA), the international governing body for soccer, "the future of football is feminine" (Harris, 2005 , p. 185). In recent years, women's soccer has grown dramatically throughout the world and has been one of the fastest growing sports for women. Participation rates have grown for women in soccer in the United States, England, and in other nations. Movies such as Bend it Like Beckham and its popularity are illustrative of increased interest in women's sport as well as the bias that still exists in football.

Harris (2005) collected data over 2 years. It consisted of field observations and in-depth semistructured interviews with "female football players at a college of higher education in the south of England" (p. 184). Observations took place at games as well as in the social settings of the participants (parties, pubs, etc.). Interviews were conducted with nine individuals. All of the individuals were White and most fell within the 18 to 21 year age group. Interviewees were diverse in terms of geographic and class background. 
The interviews lasted an average of an hour and a half and were recorded with permission of the interviewees. Harris's (2005) observations and interviews focused on the players' experience with outsiders' perceptions of their participation in football as well as their perceptions of the overarching image of women's football.

The researcher found the unfeminine, and more specifically, lesbian stigma continued to be associated with women football players. Some women in this study even quit the sport for a period of time because they were so afraid of the lesbian stereotypes they experienced. Many of the women who did not define themselves as homosexual saw the need to portray themselves as extremely feminine to counter socially constructed stereotypes. These same women also reported they experienced discrimination in women's football. The internal and external stereotypes that defined a female football player in this case study illustrated the difficulties female athletes often encounter.

Understanding the way female athletes were, and continue to be, treated is important to new social movement theorists in regard to understanding the cultural context. It is also important to note more specifically the cultural climate surrounding the more general sport climate.

Additional research exploring the role of media on the culture permeating women in sports has been conducted. This research field continues to increase in popularity as scholars are able to illustrate the different ways women in athletics are treated from their male counterparts.

Collective identity/personal values and beliefs. The importance of collective identity in the study of SMs and SMOs and SMAs by New Social Movement theorists is a critical factor of concern. While few studies focused solely on the role of collective 
identity, many did explore its impact on SMs, SMOs, and SMAs. Maddison (2004) conducted a study partially in response to the divide between the young feminists and their older counterparts. The older group felt the younger women lacked action and were complacent in their gender roles. The younger women argued they were active feminists. By examining two groups of young women, the researcher was able to explore the way these groups identified themselves and the role each age cohort played in the larger feminist social movement.

Two case studies were conducted using Australian organizations comprised of young women to assess the role of personal values. The first group, Young Women Who Are Parents Programme (YWWAPP), was based just outside of Sydney, Australia and was part of a women's health center. The center was a part of the feminist women's health movement and focused on helping young mothers by increasing "the current and future opportunities and choices of young women who are parents and to address the social, individual, and political barriers experienced by young women who are parents" (Maddison, 2004, p. 240). The second case study was done of the Cross Campus Women's Network (CCWN). The CCWN was a network of women from a variety of college campuses. This network was a part of the larger student union movement and focused on its catch phrase, "Bombing a patriarchy near you!" (Maddison, 2004, p. 244).

Maddison (2004) found the two SMOs differed significantly in the way their respective members collectively identified. In the case of the YWWAPP, the young mothers identified first as young mothers, which gave the entire group commonality. From this commonality, the women were able to act to make changes in the way young parents were treated. In this organization, women were given the opportunity to learm 
and grow into themselves and as a collective group to "speak with a unified voice" (Maddison, 2004, p. 244). In the case of the CCWN, the women created a collective identity through the goals they set for the organization to be part of the women's liberation movement. "The primary goal for the women in the CCWN is not to achieve policy reform but to politicize other women and encourage them to become more politically active as feminists" (Maddison, 2004, p. 248). This group had an intense passion for what it was doing. Maddison, however felt many of the women would burn out when it became clear that large scale changes were still in the distant future. The women of the YWWAPP would not encounter a similar fate as they were targeting a niche market. The researcher ended by describing the ability of both groups to adapt to the contexts in which they were placed and reiterated the role collective identity played in their ability to create change.

The factor of collective identity is important in allowing an SM or SMO to establish itself effectively as illustrated by the work of Pelak (2002), a collective identity theorist. Pelak (2002) examined the creation and cycle of a collegiate club ice hockey team at a Midwestern university as a case study in an attempt to explain how one part of social movement theory, collective identity theory, can be used to force change in one area of male dominated sport (ice hockey). Collective identity theory explores how a group creates its identity and includes defining the group, creating a group consciousness, and mobilizing to implement change, all factors affected by who is at the top.

Pelak's (2002) study spanned a 6-year time frame, from 1993-1996 and 19981999. The researcher collected data via participant observation.Additional data included semistructured interviews with six members of the club ice hockey team and five 
university staff as well as documents from the men's and women's club ice hockey teams, newspaper articles, communications between the women's club and the university, and web pages from the various parties involved. The purpose of using these various documents was to gain a better understanding of the culture of the club as well as to better situate the relationship of the club with the ice hockey rink, the university, and other ice hockey teams at the university.

The researcher found the club was created because of a few individuals who had an ice hockey background, which coincided with social movement theorist's belief that there needs to be a network of informed individuals for a social movement to emerge. In this study, the individuals had a background in creating greater opportunities for women to play ice hockey. The researcher also found being able to situate the women's ice hockey club in its setting relative to other entities at the university as well as the ice hockey rink allowed these women to establish a collective identity. Through this collective identity the women on the team were able to mobilize and challenge the status quo. As the team began to demand more equitable treatment, the players rallied together to formalize these requests. Through the ties with one volunteer coach, a law student, they began to push for the addition of a varsity women's ice hockey team at the university. Because of the political climate pressuring on schools to abide by Title IX, the university accepted the request and began to fund the club team as it headed toward varsity status. The collective identity of this team as female ice hockey players challenging the status quo, allowed these women to implement social change.

Summary. The early scholarship on social structure and the role of ideas or background can be seen as laying the foundation for this newest approach offered by 
which to analyze SMs and SMOs/SMAs such as the WUSA. The notion of cultural context is of special utility in this study as women in sport is an new area of scholarship within the study of the women's movement. The framing of the league's creation and development, its publicity, as well as how its leaders viewed their mission are key aspects of the exploration of the WUSA as part of the women's movement. Additionally, the culture surrounding women in sports and female athletes is a key factor in understanding the rise and fall of the WUSA within the within the cultural context of social movement theory.

The next theory in social movement research continues to add factors in which the success and failure of the WUSA can be explored. While there is some overlap between these two theories, each has its distinct characteristics and factors. The overlap and distinct differences illustrate the benefits of integrating the schools of thought within social movement scholarship.

\section{Political Opportunity Structure/Political Processes}

Frustrated with some of the limits of resource mobilization theory, political opportunity structure (POS) theorists began to explore the successes and failures of SMOs using new, noninstitutional factors to enhance their ability to understand SMs. Campbell (2005) described political opportunity structure as "an asset of formal and informal political conditions that encourage, discourage, channel, and otherwise affect movement activity (Campbell, 2005, p. 44). Sage (1999) referred to POS as "changes in the institutional structure of a political system that either encourages or discourages the formationof collective actions" (p. 207). Other theorists described political opportunity structure as being a catch all for defining social movements. In the early 1990's, four 
different groups of scholars (Brockett, 1991; Kriesi et al. 1992; Tarrow, 1994; Rucht 1996) established a list of necessary factors in their conceptualization of political opportunity structure theory: Openness of the political system, elite alignments, elite allies, and the propensity for repression (context). Only two of these factors are explored in depth here: (a) access to political elites and (b) cultural and environmental contexts. There were many similarities among the factors put forward by the theorists. Brockett (1991), Kriesi et al. (1992), Rucht (1996), and Tarrow (1994) can be synthesized across the board to create an all-encompassing list of four factors they collectively offer. The first factor explored the openness of the political system. The second factor attempted to evaluate the "stability or instability of that broad set of elite alignments that typically under gird a polity" (McAdam et al., 1996, p. 27). The third factor underscored the relationship with elite allies, and the fourth factor explored the "state's capacity and propensity for repression" (McAdam et al., 1996, p. 27). Later political opportunity structure theorists moved past the political structures and their resultant opportunities (Jeydal, 2004) to explore the cultural and environmental context in which social movements arise (Canglia\&Carmin, 2005; Davis et al., 2005; Klanderman\&Staggenborg, 2002). Critical to the case of the WUSA as an SMA and as part of an SM, factor three, access to political elites the newest factor emphasizing the role of the cultural and environmental context, will be explored in greater detail.

Access to political elites. According to Jeydel (2004) this course of inquiry is useful when examined political phenomena, such as the case with Jeydel's analysis of the three waves of the women's rights movement over time. She used extensive archival data on women's movements available at the Library of Congress, election data, and 
public opinion poll data to conclude social movements groups or associations must have access to political leaders or other elites to be successful. Jeydel (2004) underscored the need to use both political opportunity structure and resource mobilization theory to offer a complete picture of the creation, rise, successes and failures of the SMOs she studied. In O'Connor's (1980) work on women's organizations in the courts (to be discussed later), for example, adding a political opportunity variable to her analysis did much to enhance her findings.

Stevenson and Greenberg (2000) offered a very sophisticated analysis of the usefulness of the POS model to explain social movement group behaviors. They attempted to explain the "successes and failures of actors in a network of relationships trying to influence policies on environmental issues in a small city" (Stevenson \& Greenberg, 2000, p. 651) in this study.

The researchers examined this relationship in an exploratory study of environmental policy issues in a northeast city. "Individuals acting as agents of organizations were the unit of analysis" (Stevenson \& Greenberg, 2000, p. 662). The researchers used quantitative and qualitative methods in this study, which was derived from archival data. Supplemental, structured interviews of 28 individuals were conducted, exploring the interviewees relationship through event structure analysis.

Stevenson and Greenberg (2000) found the influence of these individuals to be positively correlated with their ability to affect change. This confirmed the most important finding to the researchers, "position in the network matters" (Stevenson \& Greenberg, 2000), reiterating the importance of elites in creating successful social movements. 
These works support the positive relationship the WNBA has had with its parent organization the NBA. Created and supported by an established and successful professional organization with a structure already in place, allowed the women's professional basketball league the opportunity to have ups and downs in its early years and has provided it the financial backing necessary to stay afloat in an evolving economic market. The MLS was fortunate enough to have deep financial backers as it strives to turn a profit and find its niche in the American sport marketplace and never created a strong relationship with the WUSA in many of the markets in which both played.

A later study examining the transfer of patent rights of the drug, RU-486 ("the abortion pill") in the United States had similar findings (Jackman, 2002). The Feminist Majority Foundation (FMF) was the primary SMO leading the movement. This study incorporated a 12-year participant observation. The researchers gathered data via formal and informal meetings, conversations about the patent transfer, as well as with advocacy groups and various officials, interviews with the President and Board Chair, and the review of media reports, notes, fact sheets, and other internal and external documents.

Jackman (2002) found the "importance of insider/outsider alliances" (p. 96) to be of great importance in the success of bringing RU-486 to the United StatesShe illustrated this by highlighting the relationships the FMF and other organizations established with the leaders of the two companies in France holding patent rights to the drug. SMOs such as the FMF were also able to have success in bringing RU-486 to the United States by establishing relationships with various government officials from the state and local level to the federal level. In this study, the researcher also found public opinion, media, and various pressures to contribute to the success of various social movements. The success 
of the various SMOs in the women's movement through their alliances with elites

illustrates the necessity of establishing these relationships in order for a SMO to survive and prosper.

Cultural and environmental contexts. While this factor has recently been added to many of the political opportunity structure theories, it was discussed in greater detail in the previous school of thought, cultural cognitive/framing/new social movement theory. Even so, there are some instances, which focus on this factor within the context of political opportunity structure or the political process. One of the most prominent studies relating the culture and political context to the political structures was conducted by Anheirer, Neidhardt, and Vorthamp (1998). Research on the rise to power of the Nazi party has intertwined both Political Opportunity Structure and Resource Mobilization theorists, illustrating how the party was able to capitalize on both. Anheier, Neidhardt, and Vortkamp (1998) explored the rise of the Nazi party (National Socialist German Workers Party, NSDAP) as a social movement and more specifically how it used the Political Opportunity Structure to come to power. These researchers traced the movement cycle of the party from 1925 to 1930 , when it came to power. Looking to previous research on social movements and movement cycles as well as the transformation of the Nazi party during this time frame, they examined a few themes: the facilitation of the transformation to this new party, the factors that contributed to this transformation, and opportunities that emerged to enable the Nazi party to appeal to more of the population.

The researchers studied the announcements in the official publication of the NSDAP (the Nazi Party), the $V B$, to find the frequencies, topics and themes announced 
for meetings. The data consisted of all announcements in Munich that were in two sections of the $V B$ : "From the Movement" and "Associations and clubs." From February 1925 through September 1930, 8,670 announcements were found (with some appearing more than once). Sorting through the announcements, the researchers found 3,146 party events and 1, 329 events held by outside organizations. These announcements fell into three categories: internal party events, talks and speeches by party members, and events organized by other groups. Eighty-two percent of these announcements were of activities by the NSDAP in Munich.

Anheier, Neidhardt, and Vortkamp (1998) categorized the years studied into three phases based on the frequency of announcements. Phase 1 had the greatest frequency of announcements, while Phase 2 saw a decline, and Phase 3 had an increase in activity. These phases were found to mirror political and economic changes going on in the country and world. References to the NSDAP also became more noticeable from the first phase to the third. The shift in popularity of the Nazi party was due in large part to the shift of the messages it was delivering, reiterating the importance of resource mobilization. The ability of the Nazi party to infiltrate the mainstream culture shows the importance of resource mobilization and political opportunity structures.

Pfister (2003) investigated the history of the women's soccer and athletics in East and West Germany from the 1800's into the present. Focusing on the political, social, and environmental climates of the two countries Pfister was able to examine how the factors contributed to the success of women's soccer. From the 1800 s women were given minor roles in physical education, which only "allowed" for a minimal role. Sport was considered unacceptable for women, however moderate exercise was tolerated for 
women's health and well being of this group in Germany. As the 1900 s came and went, women became interested in soccer, and in 1921 there were a number of women's soccer clubs abroad; however the numbers of teams and the acceptance of women as soccer players remained nil in Germany. Following the Second World War, women began to push for opportunities to play soccer and their success was eventually rewarded. This brief look at the history of women in German soccer hopes to answer two questions: "Why have the women had to overcome so many obstacles just because they wished to play football?"(Pfister, 2003, p. 128) and, "Were women football players living in socialist systems confronted with the same problems as like-minded women in capitalist systems?" (Pfister, 2003, p. 128).

This research consisted of a comparative study tracing the history and development of women's participation in sport with an emphasis on soccer in the Federal Republic of Germany and the German Democratic Republic (West and East Germany). Pfister(2003) recapped the developments, challenges, and role of the state in each location in the development in soccer. Various sorts of publications were used in compiling these descriptions.

Pfister's(2003) major finding was the two countries had a similar progression of acceptance for women as soccer players. Even so, there were still significant differences between the development of soccer in each country. The major difference found was West Germany officially recognized women's soccer as a top-level competitive sport through inclusion in a formal sport association. The opposite happened in East Germany, because there were no perceived gains for the country (financial and recognition) and the government saw no reason to support the female soccer players. This major difference 
between the development of women soccer players falls in line with the beliefs of the two governments. This evolution of women's soccer in Germany showed how the social movement of women in sport and more specifically in soccer can evolve in different fashions due to the political constraints placed upon a group.

Summary. In the main, POS theorists have attempted to refine the ideas of resource mobilization theorists believing political power structures and the factors contributing to said structures such as access to political elites and cultural and environmental contexts cannot be ignored. Luders (2006) explained, "Social movement success depends on expanding political opportunities" (p. 963). The passage of Title IX, for example, showed how women used a political opportunity that had tremendous impact on women and sports. Governments, especially school boards, were forced to reallocate money for women athletes as teams were added. Thus, POS offers an exciting and new way to explore more fully and understand the women's sports movement and the WUSA.

Political opportunity includes factors that illustrate how the WUSA was able to come to fruition and the very early steps that contributed to the cultural climate discussed in the cultural-cognitive theory. The final popular theory in social movement research is resource mobilization theory. These three schools of thought are able to combine to create a new model for social movements to be explored.

\section{Resource Mobilization Theory}

Resource mobilization theorists focus primarily on more formal social movement organizations with a paid staff, articulated goals, and a defined membership base. McCarthy and Zald (1987), for example, argued that "movements, if they are to be 
sustained for any period of time, require some form of organization: leadership, administrative structure, incentives to participation, and a means for requiring resources and support" (p. 6). Thus the four factors McCarthy and Zald(1987) deemed necessary to define a social movement were (a) leadership, (b) an administrative structure, (c) participation incentives, and (d) ways to acquire resources and support. These four factors excluded the role(s) the environment may play in a social movement (Davis et al., 2005).

Other resource mobilization social movement theorists, especially those such as McGlen and O'Connor (1983), considered a similar set of four factors important in defining a social movement. The four factors they listed were (a) leaders and organizers, (b) extra-group inputs and preexisting organizations, (c) communications networks, and (d) critical mobilizing events (McGlen\& O'Connor, 1983). They used these factors to explain the rise (and fall) of what they viewed as the three women's movements: the initial battle for suffrage, 1848-1875; the second effort that included garnering the vote and wage and hour protections, and the third, the effort to win the ERA (1966-1982) (McGlen\& O’Connor, 1983).

The first factor according to McGlen and O'Connor (1983) focused on the requirement of having experienced individuals, called "leaders" or "entrepreneurs" ready, willing, and able to initiate action to mobilize a movement. The second factor, emphasized the role of an organizational base in order to mobilize (i.e., a constituency group to mobilize). The third factor stressed the importance of having appropriate communication avenues in place to mobilize and expand the constituency group. The fourth factor referred to the term "critical mobilizing event" (McGlen\& O'Connor, 1983), 
which focused on an event or group of events, exciting the group into action. Oberschall (1973) noted these crises, which he termed "precipitating conditions," can be a series of events or a single happening. These pivotal events are a vaulting point inspiring social movement organizations to flourish out of various social movements or in some cases sparking a new social movement altogether.

According to sociologists Feree and Martin (1995), who took a very different perspective from McGlen and O'Connor (1983), a different set of four factors must be present for women's social movement organizations to succeed, or of course, in their absence, fail. They were in turn: (a) institutionality, (b) their relationship to feminist groups in the movement, (c) the affect of tensions growing from the multidimensionality of the larger women's movement, and (d) the tensions growing from within the multidimensionality of the women's movement. These factors were geared exclusively toward the examination of women's associations and may offer additional insights (Feree\& Martin, 1995).

Feree and Martin (1995) defined institutionalization as "the development and routinized relationships with other organizations" (p. 6). They elaborated on the relationship of feminist organizations to the women's movement by arguing close associations with like groups gives women's SMOs access to new members and the ability to publicize their agendas with minimal costs. Mansbridge (1995) called this accountability, a "set of changing, contested aspirations and understandings that provide conscious goals, cognitive backing, and the emotional support for each individual's evolving feminist identity" (p. 27). Understanding the tensions growing from the multidimensionality of the larger women's movement is also of importance. With so 
many issues at stake and the number of feminist women pulled in so many directions (not even to mention what Pepper Schwartz calls the second shifi-an issue that clearly contributed to the failure of female supporter's availability to get their sons and daughters to yet another after school event) it becomes more and more difficult to be engaged in a variety of social movement organizations. Critical here, according to Staggenborg (1995, p. 9) were the questions, "What are the short-and long-term effects on policy, mobilization potential, and the surrounding culture," and of feminist social movement organizations?

As illustrated by these three sets of factors by three groups of resource mobilization theorists, a number of factors are necessary for a social movement to exist. While many of the theorists overlapped on some of the factors, each set was unique. The most critical factors in the case of examining the WUSA as an SMA within the larger women's movement are: leaders, organizational base, administrative structures, communication networks, cooperation with like-minded organizations, competition for organizational base, and critical mobilizing events, and will be analyzed in further detail.

Leadership.Both McCarthy and Zald (1987) as well as McGlen and O'Connor (1983) expressed the importance of leaders and leadership in establishing a successful social movement, social movement organization, and social movement association. The leader(s) of a SM, SMO, or SMA dictate the direction and success of these entities. Among some of the key questions resource mobilization theorists grappled with was how and why groups are formed, especially the role of leaders and outside resources in group formation. Having experienced individuals, called "leaders" by a host of social scientists and "entrepreneurs" by others, ready, willing and able to initiate action to mobilize a 
movement has been found to be critical in the success of SMs and SMOs. Walker's (1983) classic study was one of the first to test empirically how groups form and to note the role of leaders. He sent a mail survey to 913 interest groups around the country. Walker used a very broad definition of interest groups including trade groups, business groups and corporations, as well as more traditional nonprofit groups. Still, he omitted public interest law firms, university based centers, and lobbying bodies for state and local governments.

His first task was to create a typology of groups. Thus, he divided his sample into one group requiring members to possess certain qualifications and another in which anyone could join. Walker found only $20.7 \%$ of his groups were nonoccupational citizen groups, the rest were occupational with the nonprofit sector accounting for $36.6 \%$ of his respondents, $11.9 \%$ were mixed sector groups, and $31.7 \%$ were occupational-profit sector.

In additional to adding these typologies to the literature, Walker is most famous for his examination of the support needed for groups to form. Citizens groups, for example, relied most heavily on outside sources of support ( $89 \%$ ), while even $33.9 \%$ of his profit groups received outside sources of support (Walker, 1983, p. 398). Moreover, in the period from 1946-1980, which saw the largest growth in social movement organizations, profit sector groups relied on individual gifts $(19.8 \%)$, foundation grants $(2.2 \%)$, other associations $(3.5 \%)$, and government grants $(5.8 \%)$. These numbers were much higher for citizen groups with individual gifts $(68.4 \%)$, foundation grants $(39.2 \%)$, other associations (22.8\%), and government grants (10.1\%). (p. 399). Walker called those who provided these start-up costs "patrons," and noted individuals were far more 
likely to be patrons as groups start up, as well as being the source of continued funds for maintenance over time. The majority of research supporting resource mobilization theory explored public interest movements. This research found the majority of SMs could be traced to dynamic entrepreneurs or leaders (Berry, 1977; McCarthy \&Zald, 1987; Robnett, 1996). Berry (1977) found through a survey with public interest organizations that a majority of SMOs were established by enthusiastic entrepreneurs/leaders and others followed in his footsteps investigating the role(s) of leadership in SMs and SMOs.

Staggenborg (1988) studied leadership in women's organizations with an emphasis on pro-choice organizations. In her 1988 study, she explored the emergence of leaders who made their livelihood as SM leaders. She explained a variety of different movement organizations, participants, and leaders. The purpose of her study was to analyze the role of leadership in the structures of pro-choice organizations.

To investigate this relationship, Staggenborg analyzed case histories of 13 prochoice national and local organizations, as well as interviews with 50 individuals, including leaders and activists. She classified the changes these organizations underwent in three time periods, divided the SMOs into two different groups, and finally explained the leadership styles each organization encompassed.

The researcher found professionalization to be a trend in the formalization of SMOs. Even so, she explained further that this was not at the cost of informal SMs and SMOs and the informal SMOs were instrumental in mobilization efforts. The data collected by Staggenborg indicated new, professional managers have the ability to provide greater stability for the organizations as well as increase the coalition building efforts. These coalitions enhanced the ability of the SM to mobilize effectively and lobby 
for change. These formal leaders were also more likely to set articulated goals and follow through with them. In this study by Staggenborg, one can see individuals making a career out of leading SMOs or SMAs were frequently able to be more effective and successful than SMOs or SMAs run by other, less experienced individuals, either volunteer, or merely those lacking appropriate qualifications.

Vose (1955) also noted the tremendous importance of professional leaders to the success of a group. Vose's classic study of the NAACP's Legal Defense Fund from its creation in 1939 and the role Thurgood Marshal played as its Chief Counsel was critical to the eradication of the separate but equal doctrine. Vose used NAACP internal documents, court filings, personal interviews, and writings by and about the NAACP as Marshall tried to change the political and legal climate to facilitate wins in the Court. As a brilliant leader, Marshall was able to convince the Supreme Court, through a series of test cases, to outlaw discrimination in housing and then in education.

Cooper (1992) illustrated the pivotal role passion and enthusiasm played in leadership in her analysis of the marathon movement in the United States. The 1970's saw a large increase in the number of marathons throughout the country, from 40 in 1969 to over 200 in 1977. The number of racers also increased dramatically in this time frame. One individual was given credit for this turn of events, mainly in the New York City Marathon. Lebow looked to corporate sponsorships and new runners as a way to increase the coverage of his sport and race.

Through this historical analysis, the researcher traced the changes Lebow made to the New York City Marathon, beginning with publicizing the demographic information of the Road Runners Club, which illustrated the high educational attainment, and more 
importantly, the high socioeconomic status of the majority of the members. These facts, tied with the increase of interest in women's athletics, allowed Lebow to create additional running events and increase sponsorship opportunities. Lebow's passion for running and the running community events illustrated the difference an energetic and passionate leader can have on the success of an organization. Lebow not only had the energy and passion necessary for organizational success, he also had a strong business plan and products that benefited sponsors, participants, and fans.

Robnett (1996) was another scholar who explored the importance of leadership in SMs. Specifically she examined the role of African-American women in the Civil Rights movement with an emphasis on the leadership roles they played throughout the movement. The Civil Rights movement preceded the women's rights movement, thus women had yet to hold in many leadership positions. Because of this lack of equality, many African-American women were not put in formal leadership roles.

Through analyzing life histories, archives, interviews, and additional qualitative sources, Robnett (1996) investigated the role gender played in leadership within the Civil rights movement. Many of the interview contacts were made by the researcher using snowball sampling to make sure the most relevant individuals were interviewed.

The researcher found very few African-American women in formal leadership roles within the Civil Rights movement or within various Civil Rights movement organizations. She did come to the conclusion, however that many women fit the role of a bridge leader. A bridge leader was described by Robnett (1996) as an informal leader who is able to bridge the gap between the public SMOs or SMAs and private constituencies. Being able to bridge two or more SMOs/SMAs is imperative for an 
SMO/SMA to be successful as the cross-over between the Civil Rights and women's rights movement illustrated.

Pelak (2002), a collective identity theorist, also noted the critical role of leaders in her study on a collegiate ice hockey team explained in greater detail earlier in this literature review. She explained how the leadership presented at the inception of this club, as well as later leadership, allowed the team to establish a new, elite athletic opportunity at its university for women as well as educating the institution and region that women could be ice hockey players. While collective identity was the main focus of this study, the researcher continued to stress the role and importance of leadership in establishing a successful social movement organization.

Organizational base.McGlen and O'Connor (1983) theorized the necessity of preexisting organizations or an organizational base for an SM or SMO/SMA to develop. They noted, for example, how the abolitionist movement provided a base for the first women's movement. A similar factor can be seen in the political opportunity structure within social movement theory. Here again was another example of how much overlap existed between the factors explored by resource mobilization theorists in their research. For example, Searles and Berger (1987), in one of the earliest social movement studies investigating women in any sort of athletic endeavor, explored the women's selfdefense movement. This movement is a faction within the feminist antiviolence campaign under the larger umbrella of the women in sport movement as well as the women's movement. This self-defense movement worked to stop violence against women in the form of rape, incest, and pornography to name a few. The lone part of this campaign aimed at prevention, over victim services, was self-defense. Still, it was able to 
grow because it built on the preexisting organizational base and a political opportunity structure open to crime prevention.

The Searles and Berger (1987) first surveyed college and university bulletins to identify the number of self-defense course offered for women. Focusing on 211 institutions that granted over 30 physical education undergraduate degrees per year, they found $39.7 \%$ offered some form of martial arts instruction, $28.4 \%$ offered self-defense courses, and only $6.2 \%$ offered women's only self-defense courses. Over half of the women-only courses were offered in California. Three additional sources were used to supplement these numbers and the researchers found there to be 54 or 55 additional women's self-defense organizations in 16 or 20 states, respectively.

A case history then was completed on the Women's Self-Defense Council (WSDC), which was based on a feminist model and offered courses and workshops on self-defense. This case history was created from participation observation, teaching materials, and organizational correspondence, and traced the addition of a for-profit arm of this movement, Victim Prevention, Inc. (VPI).

Searles and Berger (1987) found that while opportunities for women in selfdefense increased, they did not grow at the same rate as other branches of the feminist anti-violence movement. Even with a set of organizational bases, such as physical education departments, various courses, and organizations teaching self-defense, the movement was unable to utilize this base effectively. Its leaders were also unable to coordinate with similarly situated SMOs to advance this cause. Though this movement has not seen the growth other parts of the antiviolence movement have, the researchers note changes and ended their study by stating "this more gradual development may go 
hand-in-hand with a greater ability to retain its initial purpose and feminist vision" (Searles\& Berger, 1987, p. 71).

Another study also revealed a crossover of factors. Poster (1995) examined the differences between two women's movement organizations, one with a membership base of primarily White, middle to upper class women and the other group with members who could be classified as women of color and of a low socioeconomic class. The researcher chose these two groups from within the Bay Area of California to address the lack of diversity within the upper echelons of the women's movement and the prominent social movement organizations they encompassed. She hoped to identify if and how these organizations differed in terms of structure, ideologies, and the ways they tried to implement change to see how they created a more effective coalition supporting all of the women's movement. The researcher explored a number of variables in this study relative to these two organizations. The ties to other organizations, either at the national or state level, could also be seen as imperative in the perceived successes of each organization.

This study was a qualitative comparative case study of these two organizations, Low-Income Women (LIW) and Corporate Women (CW). For these two case studies the researcher used semistructured, in-depth interviews with members and leaders of each organization (a total of 12 within the two organizations), participant observation, (consisting of attending events and member meetings), as well as reading organizational literature.

The researcher found the members of the LIW organization addressed issues related not only to gender discrimination, but also to racial and class discrimination. The members of CW addressed only gender discrimination based on their place of greater 
privilege. Poster (1995) also found the members of LIW took nontraditional routes to try to implement change in that they structured their organization as a collective democracy so everyone had a voice, while the women of $\mathrm{CW}$ structured their organization in a more traditional, hierarchical bureaucracy enabling it to work within the status quo and elite patriarchy it was working toward breaking through. The successes of the $\mathrm{CW}$ organization and the way it marginalized the experiences of the LIW members to try to generate change illustrated the role elites play in social movements. It also illustrated the way in which ties to other organizations can affect the way an SMO operates. In this specific case the ability of $\mathrm{CW}$ to operate with national organizations enabled it to implement greater changes.

Additional studies examined strong, initial foundations and the role they played in the creation of SMOs. Two studies took place in Louisville and Lexington, Kentucky and traced the evolution of the passage of the Faimess Ordinance, a successful SM in these two cities. Through the use of organizations already in place, strong communications networks, and planning each city was able to see the Fairness Ordinance pass. Grise-Owens, Vessels, and Owens (2004) investigated the cumulative events that led to the passage of an ordinance giving gay, lesbian, bisexual, and transgender (GLBT) rights in housing, employment, and public accommodation in Louisville, Kentucky. Over a period of nearly 20 years, the GLBT population in Louisville made tremendous gains in acceptance, however it took a strong and organized grassroots movement and the work of a multiple organizations for the ordinance to pass.

This article explored the establishment of a grassroots social movement organization in Louisville, KY. Not only is Louisville the largest city in the state of 
Kentucky, it is also one of the most liberal and diverse cities in the state. A variety of religious groups are present in the city. African Americans make up 33\% of the population and Whites make up the remaining $67 \%$. This case study looked at the specific GBLT social movement and the way it not only came to fruition, but the process the movement used to the pass the Fairness Ordinance. The researchers created this case study through interviews with leaders of the movement, public media outlets, and other relevant documentation.

This case study led Grise-Owens et al. (2004) to conclude six lessons could be learned. They were small steps can lead to great strides; great change necessitates "systematic intervention," (p.12); "the personal is political and the political is personal," (p. 12); adaptation, patience, planning, etc. and a lucky break are necessary for success; the importance of continuing action in order to maintain success; and the importance of staying focused on one's goals. These six goals were derived from the process of the LGBT social movement toward passing the Fairness Ordinance. The findings of importance, even though learned in the context of a political study, underscored the importance of an organizational base, communication networks, and goal setting in the success of a social movement and social movement organization.

A similar study was done later in Kentucky exploring the process in which the same ordinance was passed in Lexington, Kentucky. This study reinforced that one social movement organization can build on and work with similar SMOs. Otis (2004) studied the evolution of the lesbian, gay, bisexual, and transgender (LGBT) movement in one town/county. Looking to the increased acceptance of the LGBT group in many societies as well as the increase in their protection though legislative avenues, the 
researcher explored how one organization, the Kentucky Fairness Alliance (KFA), in one city, Lexington, $\mathrm{KY}$, was able to further change and campaigned for the passage of the Fairness Ordinance, which "added protection based on real or perceived sexual orientation or gender identity, to existing civil rights protection related to housing, employment, and public accommodation"(p. 20).

Otis (2004) explained this case and illustrated the role of the initial ordinance passed in Louisville. KFA-Bluegrass used the momentum and support of the Louisville ordinance to inspire it to a whirlwind grassroots effort to pass the Fairness Ordinance in Lexington. In a four-week span, the KFA-Bluegrass organization mobilized, via e-mail and telephone trees, and utilized all of its strengths to formulate and communicate a strong, unified message. It also networked and coalesced with three large groups, a common trend according to social movement literature. The three groups it communicated with were the religious communities (a very important group in this region of the country), the business community, and social justice organizations. Lobbying through these three groups enabled the KFA-Bluegrass group to gain support once the media got wind of the movement. The KFA-Bluegrass chapter was able, with much patience and methodical organization, to lead a strong grassroots campaign, which led to the Fairness Ordinance being passed in Lexington by a vote of 12-3.

The ability of the Lexington group to learn from the Louisville group illustrated the importance of seeking out similar groups and using strategies that worked for it as well as working with successful organizations to ensure the new group or social movement organization has a better opportunity for success. These latter two studies also 
reiterated the importance of the administrative structures of these social movements in having success.

Administrative structures. McCarthy andZald (1987) considered the administrative structure of an organization imperative in defining it as an SM and explained a successful SM must have an established and effective administrative structure. Early efforts by some left leaning women's movement organizations stressed nonhierarchical structures and refused to have leaders. Nearly all of those groups died quickly without one or a few persons to speak for or lead the group (Freeman, 1975).

Barasko (2006), in an extensive study of NOW, examined all of the bylaws and minutes of every annual meeting as well as newsletters to conclude its loose configuration of membership structure has caused it to lose members and political clout. Because state affiliates often have different priorities than the national office, NOW does not always speak in one voice, minimizing its successes.

Membership groups often have greater difficulties than nonmembership based groups. Thousands of women, for example, contribute to Emily's List every year making it an effective force in electing pro-choice, Democratic women. Its wealthy president, Ellen Malcolm, makes all of the decisions for the group and runs its larger staff with a tight fist (Barasko, 2006).

Communications networks. The McGlenand O'Connor (1983) model of SMOs emphasizes the role of communication networks in their development. Newspapers, the publication of $M s$., and annual conferences of activist women lawyers all contributed to these communications as did publications such as Susan B. Anthony's weekly newspaper, The Revolution, in the late 1860s. Similarly, O'Connor's (1980) study of 
women's litigating groups found the creation of the first women's rights law journals, as well as the start of an annual women and the law conference, facilitated cooperation and coordination and communication that led to successful challenges of discriminatory laws. She used interviews with all of the living lawyers who argued sex discrimination cases before the Court on behalf of women's groups to reach that conclusion.

While communication networks commonly refer to how groups communicate with members, they can also address the way messages are communicated to the public. Gamsonand Modigliani (1989) elaborated on this factor and set the stage for the role of the media in public opinion, which can prove instrumental in the creation of a social movement and social movement organizations. In this study, the researchers reviewed the interaction of public and media discourse and the role the two played in creating culture. Through an analysis of all nuclear power material in TV, magazine, and newspaper news the investigators reviewed the media discourse surrounding this subject.

A content analysis of network evening news, Time, Newsweek, U.S. News and World Report, editorial cartoons, and syndicated columns in ten newspapers were used in this study. With a three-digit code and subcodes, two coders went through the content. Any material not receiving $80 \%$ reliability was thrown out. An additional survey was conducted to evaluate the public perception towards nuclear power (positive, negative, or ambivalent; Gamson\& Modigliani, 1989).

The researchers found public opinion concerning nuclear power can only be understood if it is rooted in the cultural context, which is imperative in understanding the communications networks necessary in an SM. Rohlinger (2002) followed suit: "For social movement organizations that can get their messages into mainstream media, there 
is the potential for great rewards... [it] can energize a movement by mobilizing a population" (p. 479). The researcher compared the ways two opposing SMOs got media coverage during various events during the abortion debate and the ways each went about packaging its message.

This study was done by examining two SMOs involved in the abortion debate, one on the pro-choice side, the National Organization for Women (NOW), and the other on the pro-life side, the Concerned Women for America (CWA), and the ways each chose to package its messages to the media. By following the media coverage of three momentous court cases in the abortion debate, one of which was considered a success for the pro-life movement and two seeming to be a wash, the researcher investigated four areas: (a) the preferred way each SMO chose to package its organization during these critical events, (b) the strategies used by each, (c) the way the packaging of the media messages did or did not change during these critical events, and (d) media coverage outcomes in the mainstream media. The media packages of each SMO were established by the researcher reading all articles related to abortion in the publication of each organization. She found there to be two frames and 24 preferred packages used between the two. Additionally, the researcher conducted interviews and explored archival files. A content analysis was then conducted in four national publications following each of the court cases mentioned above (Rohlinger, 2002).

Rohlinger (2002) found "the media strategies that SMOs use to influence coverage matter" (p. 500). NOW was found to view the media as a way influence change and made doing so a primary objective, while the CWA considered the media to be be hostile to its pro-life messages and chose to focus on grassroots efforts over the 
mainstream media. "The lesson, then, is that both strategies and perceptions of media matter" (Rohlinger, 2002, p. 504). Formulating a media message and a way to get it into the mainstream proved pertinent to the success of NOW and the CWA. These studies set the stage for a variety of studies exploring the perceptions of women in athletics and the role they have played in the cycle of SM and SMO development (Gamson\& Modigliani, 1989).

While women have been making greater strides as athletes and on breaking down barriers based on their cumulative "team" effort, the media have played a part in the greater awareness and acceptance of these female athletes. The role of the media in the 1999 Women's World Cup was unprecedented; however it was short lived. Both before and as a response to this success, researchers began to look at the greater emphasis and exposure of female athletes with a focus on both print and televised media.

One of the most popular advertising campaigns for women in sport has been the Nike, "If you let me play" print and television commercials. Nike was been applauded for empowering young girls and bringing many of the positive traits that can be derived for these young women "If you let me (them) play." This campaign won many awards for the seemingly positive message it sent to the girls in the United StatesAn additional popular, empowering ad campaign by Nike for young women was its "There is a girl being born in America" campaign. Both commercials sent positive messages about female participation in sport and clearly showed girls thriving in athletic pursuits, as did one of the "Fun Police" ads starring NBA players. Lucas (2000) argued that these advertisements superficially empowered women and they actually hindered the development of women in sport. 
The researcher critically examined the text and images in each of three commercials with a primary focus on the power relationships illustrated in these two outlets. Lucas also explored the historical and socio-cultural context in which each ad came to light.

The researcher argued by saying "If you let me play" indicated these girls are asking permission to participate in sports and that if they are not "allowed" to play, they will fall victim to weaknesses. The images accompanying the text also were seen as being racist, sexist, and classist from this critical examination. This ad was seen as indicating these girls had no control over their person and needed others such as Nike and their parents in order to be successful. The "There is a girl being born in America" campaign illustrated a choice a girl "must" make - to be either an athlete or a beauty and again the author argued the text going along with the images removed the choice from these girls and indicated the girls choice dictated by the environment. Finally the "Fun Police" campaign, took male, NBA players to empower these girls to have fun and play sports. In all three cases the girls needed external factors to empower their sport participation because they were unable to participate without this support. Lucas argued similar ads would never appear with boys and these ads perpetuated the myth that females needed someone else in order to be successful. These Nike ads were just examples of women athletes being exploited for the mighty dollar.

Weardenand Creedon (2002) moved one step further in exploring gender portrayals in commercials. In this study, the researchers analyzed the commercials shown during the first season of the WNBA in 1997 for signs of sexism. At the time this study was conducted the NBA was trying to figure how the WNBA would fit into the 
marketplace. It looked to target the female fan and the selection of commercials and sponsors were paramount in this. The purpose of this study was to see that if sexism in commercials differed by network, sponsor, and/or product category as well as to see the prevalence conventional beauty standards played in the commercials.

In this study, 19 games were videotaped on four networks: Lifetime, NBC, ESPN, and the Madison Square Garden station (MSG) for comparative purposes. The 1,632 images from 591 commercials were analyzed through content analysis with the coding process being derived from the Consciousness Scale of Sexism (CSS), which defined the roles of women in action into five categories. Two additional factors were added to the coding procedure, which placed the women in age and beauty categories.

The researchers first gave basic descriptive data: $53 \%$ of the commercials analyzed were from the five major sponsors of the league, Sears, Champion, Nike, Bud Lite, and Lee with the additional commercials being categorized generally. The most negative coding level in the CSS was Level 1, which displayed a commercial putting down a woman. The researchers found $22 \%$ of the ads fell into this category, second only to Level 5 (just over $59 \%$ ), which were ads not showing any stereotypes.

Commercials "putting down" women were more likely to have attractive, young women. Seven percent of the commercials fell into Level 2, which were described as keeping woman in her place. Part of the research also found the models used in the majority of the analyzed commercials fit the conventional definition of beauty. Unconventional models were most common in the ads for Sears and in the sporting goods category. The ads seen as perpetuating sexism were also more likely to be found on Lifetime and ESPN (which were the same broadcast), and least likely to be on NBC and the regional station, 
MSG. While the WUSA was able to fill all of its ad time and secure sound sponsors with an emphasis on marketing to women, even its ads perpetuated the myths of women as the weaker sex.

Advertising toward women athletes both in commercials and through sponsorships, even if somewhat sexist, illustrated a shift in perceptions of women as consumers of sport. This trend has continued into various media sources such as broadcasting games and the creation of new publications targeted solely to female athletes. "Women's sports magazines were launched during the mid-to-late 1990's as a response to the growing women's sports movement in the U.S." (Hardin, Lynn, \&Walsdorf, 2005, p. 105). Hardin, Lynn, andWalsdorf (2005) looked to three of these magazines: Sports Illustrated for Women, Real Sports, and Women's Sport and Fitness in response to the publicity surrounding their publication. The first two magazines emphasized they would follow a more traditional sports magazine model with less emphasis on beauty and fitness and more emphasis on sport. The researchers wanted to see exactly how these three magazines, as well as Shape, a popular women's health and fitness magazine, portrayed women in their editorial pictures. It was also expected the magazines would pioneer an additional way for women interested in sport to learn more about various opportunities.

To examine the images in these four magazines, the researchers decided to examine only editorial photos. All images were derived from six issues of each magazine from the spring of 1999 to the summer of 2000 . The resultant 4,989 images were coded for gender and only pictures with women were coded further. Additional coded items included the angle from which the pictures were taken, the women's activity level, the 
sport type, and sport category. The coding was done by 12 sport management graduate students and was found to be reliable over $90 \%$ of the time.

Almost $90 \%$ of the images were taken from a parallel angle with ten percent from above, a traditional angle for degrading women. However, when the photos with the downward angle were analyzed, most of them were from above the rim, action shots taken in basketball games. Active motion images were found in just over half on the images (53\%) with the majority of these images being in Sports Illustrated (SI) for Women and Real Sports. These two magazines also had higher percentages of team sport images than Shape and Women's Sport and Fitness. Significant associations were found between all variables and the two types of magazines in which they were found. SI for Women and Real Sports never had the circulation of the other two magazines (and Real Sports was not even sold on the newsstands) and were unable to sustain themselves. The two other magazines were still in circulation. The apparent necessity of the media to conform to expected gender norms illustrated one of the many factors that may have contributed to the inability of the WUSA to be successful. SI for Women was an initial sponsor in the WUSA; however the magazine failed midway through the second season thus providing even less coverage to the league.

More mainstream media outlets and publications have figured even more into perpetuating the inequitable treatment and exposure of women in athletics. One of these publications, Sports Illustrated, has postured itself as the preeminent sports magazine in the United States covering a wide range of sports and athletic endeavors. Even so, the magazine has continued to marginalize the accomplishments of female athletes. Bishop (2003) followed up on a study conducted in the 1970's, which explored the coverage of 
women in feature articles in Sports Illustrated. Bishop (2003) explained women athletes recently made successful forays into sports, most notably the success of the 1999 WWC championship team as well as the WNBA's continued building of a fan base. However the media has not followed this shift with the attention it deserves.

To track any changes in the coverage of women in Sports Ilhistrated, Bishop (2003) analyzed the first issue of the magazine each month from 1980 until 1996 and tracked the feature articles in each issue. "A feature article was defined as one that was described at length in the issue's table of contents" (Bishop, 2003, p. 188). Each of the issues was tracked in five categories: the number of feature articles, the number of pages for each article, the sex of the athlete in the feature, the sport covered, and the number of photographs per article. Descriptive statistics were reported, as were the results of a t-test comparing the findings with, Bishop's (2003) earlier study, which looked at feature articles during the Olympic years from 1956 to 1976.

In total, 569 articles covering 2,919 pages were reviewed. The coverage of women in feature articles in Sports Illustrated increased through 1994. Even so, the increase was not statistically significant from the coverage charted in the earlier study in regard both to the number of articles as well as the pages devoted to each sex. While the increased coverage of women was not significant, it was still noted. Bishop (2003) also found decreased coverage of women from 1992 and 1994 to 1996, a year which saw one of the most successful Olympics for women in history. Bishop (2003) also found decreased photo coverage in the articles concerning women from the 1980's into the 1990's. In the same vein, the researcher noted that in pictures, including men and women, women almost always were displayed in a supporting role. The lack of coverage 
of women in the most widely circulated sports magazine in the United States illustrated the inequitable treatment of women in the sports world as well as the mountain that needing to be climbed by women athletes to gain legitimacy and recognition.

More specific research exploring media coverage of soccer in the United States was conducted. Markovits and Hellerman (2003a) focused on soccer as a social movement as they explored the evolution of the World Cup in the United States. In this study the researchers first touched on the increased participation and coverage of soccer in the last two decades. They then continued to highlight this point by exploring the media coverage of the 2002 World Cup.

MarkovitsandHellerman (2003a) studied the media coverage of this World Cup through a "systematic study of 32 daily newspapers" (p. 1536). The newspapers they looked were in cities which hosted either a World Cup game in 1994, had an MLS franchise, or was home of a WUSA team. Two additional cities were added due to their demographic base and history of supporting soccer. USA Today was also included in this study as a national paper with a history of strong soccer coverage. The study began 11 days before the World Cup began on May, 20, 2002, and lasted through July 4, 2002, four days after the gold medal game.

The researchers found a total of 1, 403 articles written by newspaper staff, not from a wire service. The Los Angeles Tribune led the way with 209 staff written articles, while the Detroit Free Press had none.Each paper ran articles on the opening day of the World Cup and continued to keep tables on the Cup through the weekend. Coverage nearly doubled as the United States was set to take on the highly favored Portugal. When the United States upset Portugal, they were on the front page of every newspaper in the 
study and there was a high of 52 staff written articles spread between the 32 papers. When the U. S. team advanced to the second round of the tournament, all 32 papers publicized this on the front page or at a minimum on the front page of the sports page. When the American team beat Mexico in this round, the media coverage bettered itself once again with 72 staff written articles among the papers. Through this study, the researchers concluded people in the United States have an increased interest in soccer, at least during the World Cup, and that the grassroots movement of soccer participation, the success of the 1999 Women's World Cup, and the recent success of the U.S. Men's team have all contributed to this recent social phenomenon. Both the MLS and the WUSA tried to pull from the momentum of the World Cup in the summer of 2002. The MLS was able to have greater ties with the Cup since their players were participating in the event, while the women were still 14 months away from their Cup and a hopeful momentum swing.

A vast amount of research has been conducted looking at the television coverage of female athletics as well. Because the Olympic Games provide comparable opportunities and timing for men's and women's coverage, it is commonly used in this area of research (Bernstein, 2002; Higgs, Weiller, \& Martin, 2003; Tuggle\& Owen, 1999). Tuggleand Owen (1999) analyzed the coverage given to the women competing in the 1996 Centennial Olympic Games. The researchers offered five hypotheses when exploring the coverage provided by NBC: (a) the coverage of women would focus on individual events; (b) male coaches, competitors, etc. would be quoted more frequently than their female counterparts; (c) women's events would be edited more frequently than men's, especially in team events; (d) power and contact sports would cover males more 
frequently than females; and (e) the number of on-air male reporters would be greater than those of females.

To investigate these five hypotheses, Tuggleand Owen (1999) analyzed the prime time coverage of the Games from July 20-August 4, 1996. This included 72 hours of videotape. The content of the tapes then was coded for the following variables: sport, length of segment, presentation, sex, live/edited presentation, focus of commentary, team/individual event, role of interviewee (if necessary) and contact level as well as the role of the speaker and his/her sex. Intercoder agreement was also performed between the two coders.

Four of the five hypotheses were confirmed. Women were covered more frequently in individual sports, while men had greater coverage in team sport. Men were significantly more likely to be quoted than women in broadcasts, more likely to be covered in power and contact sports, and more likely to be announcers in the broadcasts, proving Hypotheses 1,2,4, and 5 correct. The only hypothesis not proven was that the women's events would be edited more frequently then men's. These findings indicated that while women were gaining exposure as athletes, it was still primarily in "acceptable," individual sports. Furthering this thought and relating it to the television coverage of the WUSA, the U.S. Women's National Soccer Team received only 1,773 seconds in prime time air, which came to just under 30 minutes of coverage enroute to the U.S. National Team's Olympic victory.

Higgs et al. (2003) elaborated on the study by Tuggleand Owen (1999) by analyzing the coverage of female athletes in the 1996 Olympic Games as well as comparing the coverage from 1996 to the coverage in 1992 . They looked to compare the 
amount of coverage of women and the quality of coverage between male and female athletes in the same sport. With the increased success of women athletes in the Olympic Games, the researchers looked to answer the question: "With such a heightened focus on women's sports, and on women athletes, was the television coverage of the 1996 Games less stereotyped and gender hierarchical than the coverage in 1992?" (Higgs et al., 2003, p. 53)

The researchers examined over 150 hours of Olympic Games coverage on NBC to study both quantitatively and qualitatively. A content analysis was conducted on all segments that had a male and female counterpart. After the content analysis, 60 hours of video were randomly selected. A content analysis was done again on these 60 hours. The researchers assured randomness by drawing from all time slots during the day. Quantitative analysis was done to find the amount of time spent on male and female sports, length of segments, use of slowmotion and replays, and use of onscreen statistics. Qualitative analysis was done on the narrative comments during these segments, focusing primarily on the adjectives used to describe the athletes as well as story lines.

Thirty hours and 28 minutes (of the 60 hours) covered same-sport activities. This included both team and individual sports. The researchers found the coverage of women's sports increased from the 1992 to 1996 Games in six of the eleven sports analyzed. The coverage of men's sports felt this effect as a decline was found in four of eleven sports. The increase in television coverage for women's sports was most dramatic in basketball and volleyball, with statistically significant increases of $26 \%$ and $69 \%$, respectively. The researchers also found the coverage of women's sports made tremendous strides from the 1992 to 1996 Games. The gender marking, commentator 
adjectives, and slow motion replays were balanced for the most part (four per game for the men and three per game for the women).

This study also found women made tremendous strides in earning the commentator's respect. In the 1992 Games strength descriptors were used in describing basketball (158 times for men and 68 for women); in the 1996 Games there was almost balance ( 52 for men and 47 for women). While there was a shift toward balance between the coverage of men and women in team sports, there were still sexist overtones in some of the individual sports, most notably gymnastics, with swimming and diving a distant second. While female gymnasts saw greater television coverage than their male counterparts, they were still continually feminized and weakened. The women competing were frequently called by their first name ( 177 times to men being called by their first name only 16 times) and 42 strength and 100 weakness descriptors were used to describe these females. The term "girl" was also commonly used to describe these athletes. While women are making strides in equitable media coverage, the public and media still insisted on weakening women and placing their athletic endeavors second.

A later study by Carty (2005) investigated the portrayals of female athletes in various forms of media (print, television, etc.). She noted since the passage of Title IX, the participation rates of women and girls in sport have increased dramatically. The increase of participation rates of women in sport, have led to a greater exposure of this group. Carty investigated two perspectives, the radical feminist perspective and the postfeminist perspective. The radical feminist perspective argued patriarchical structures constrained women in the male domain and reinforced the idea of male domination over women. The post-feminist perspective empowered women to do with themselves (and 
their body) as they pleased and allowed them liberation. Post-feminists viewed themselves as exploiting the system rather than being exploited by it.

The researcher used a content analysis of textual portrayals of female athletes in the media to identify themes. Carty (2005) utilized television commercials during the 1996 Olympic Games, 1999 Women's World Cup, the 2001 NCAA Women's Basketball Toumament, and WNBA games from the 2001 and 2002 season. These events were televised on ESPN, ESPN2, and NBC. The events were chosen because the researcher assumed there would be ads, which would highlight women as athletes. Print ads were also analyzed and were drawn from: Gear, Sports Illustrated, Women's Sport \& Fitness, and The National Sports Review. These media outlets, dates, and times were utilized because the researcher thought they were extreme cases of sport and print media and provided examples of popular media perceptions and portrayals. This is a necessary requirement in exploratory research.

Carty (2005) began her findings with a critique of two well-known Olympic athletes, Brandi Chastain and Jenny Thompson, both of whom posed in minimal clothing in Gear and Sports Illustrated, respectively. While both women claimed to be proud of the body they had trained and worked hard for, allowing them to become elite athletes, they were criticized for their choices. When investigating the commercials, Carty found many of them had contradictory messages throughout the print media on in a commercial. This media would commonly have an empowering or positive voice message paired with images that did not match (displaying women as passive, etc.). Even when trying to send an empowering message about women, Carty illustrated that the advertisers obviously were not comfortable with empowering women completely (both in word and image). 
Carty also found most of the advertising to highlight a woman's femininity and heterosexuality (showing with a husband, as a mother, etc.). The adjectives that were used during these events also illustrated the role that race played in descriptors chosen: White women were usually defined with more feminine words associated with their grace, beauty, etc, while African Americans were described in more physical ways, strength, muscles, etc. In essence, while women have made gains in the acceptance of their athletic participation and prowess, their femininity was still an issue and was highlighted in advertisements and the descriptors used in print and on air media.

Bernstein (2002) preceded Carty (2005) and argued that though women was continuing to gain ground and acceptance in the male world of sport, sexism still pervaded the entire domain. Bernstein (2002) focused on the print media surrounding two popular female athletes, Marion Jones and Anna Kournikova. Her study indicated sexist thoughts still existed towards female athletes. Her focus on the media portrayal of female athletes underscored the role the media plays in defining our cultural norms. She elaborated by saying when women are portrayed in the media their appearance and attractiveness were highlighted over their athletic successes.

The researcher chose not to look at television broadcasts because she felt they were more cognizant of the gender disparities. Both athletes were covered heavily throughout 2000, Jones leading up to the Olympic Games and Kournikova during the Grand Slam tournaments.

Bernstein (2002) found Jones to be described in most publications as being arrogant and boastful and the limited images of her displayed her strength and muscular physique. Even though Jones claimed she would win five gold medals and was one of 
the greatest track athletes the United States had ever seen, she was not the most photographed athlete during these Games. Rather, a 6'2" blonde, model/high jumper was the "winner of this award" most photographed. From those findings, it was not surprising to the researcher that Kournikova got such extensive media coverage and was the most photographed athlete during Wimbledon 2000 . While Kournikova was certainly an elite tennis player, ranking as high as eighth in the world 2002, she never won a singles title. This small case study illustrated the focus the U.S. media places on appearances and sends "a message that sport is in essence a male activity, in which women play only a subordinate and/or sexualized role" (Bernstein, 2002, p. 426). Supporting her conclusions, Dave Letterman described the U.S. Women's National Team as "Soccer Mama's" emphasizing their attractiveness during the course of the 1999 Women's World Cup (WWC).

Many SMOs associated with the women's movement have had little success remaining in the public eye for sustained periods of time. Most of the media attention these organizations are able to garner usually have a negative slant about controversy and even more frequently the demise or failure of said SMOs:

Whatever media leaders' reluctance to chronicle the rebirth of the feminism in the 1960 s and early 1970s, they had no such hesitation in reporting its demise...Despite some periodic reprieves, press postmortems have continued with stunning regularity (Rhode, 1995, p. 691).

Rhode (1995) continued in her analysis to add the way in which the press describes the "failed" organization and/or movement: "In these autopsies of the movement, most authors come to bury rather than praise their subject" (p. 691). Her discussion of the role of the media in creating and perpetuating cultural perceptions reiterated the role the media can have in the failure of SMs and SMOs. 
Cooperation with like-minded organizations. Feree and Martin (1995) discussed the role coordination with like minded organizations can have on one another. This factor was related to factors posed by McGlen and O'Connor (1983) as well as one from McCarthy and Zald (1987). The necessity of preexisting organizations was similar to Feree and Martin's model and relate to the means of acquiring resources and support explained in the McCarthy and Zald's (1987) model. While all three models are different, most of their factors are related.

Costain $(1980,1981)$ has consistently found the cooperation between women's organizations to be imperative in the creation and success of women's movement organizations. In her initial study, Costain (1980) studied the development of the national women's lobby. Through interviews with representatives from 14 women's groups, Costain was able to find what the groups deemed important to its successes as well as how each organization could be most effective. Costain also explored the most effective lobbying tactics by various women's organizations.

Thirteen of the 14 interviewees stated the importance of lobbying in pushing for legislative change. These representatives also explained the importance of coordinating their efforts with other like-minded organizations. Through this coordination each organization was able to specialize and be more informed on its specific goal within the umbrella of the women's movement. Costain also found these alliances to be imperative to the perseverance of these SMOs. She continued on to explain the strength of the women's equality lobby was its ability to encompass a variety of tactics through the coordination of the various groups and how each of the main lobbying efforts of the women's movement was supported by at least two SMOs, but usually six on average. 
Her later research looked to answer the question of "What factors determine the success or failure of movements that try to gain access to the political system?" (Costain, 1981, p. 100). The researcher looked to the women's movement as her point of interest. The women's movement has the potential to yield tremendous power since the group encompasses half of the population as well as covering the geographical scope. Even so, this social movement has tremendous perils because it is such a vast group encompassing an array of races, ethnicities, socioeconomic classes and a variety of other subgroups with differing viewpoints and ideologies.

Her study of the women's movement and its ability to lobby the political system was conducted through 65 interviews between the fall of 1974 and the summer of 1977.These individuals questioned represented organizations that were active in lobbying for women's issues and in campaigns as well as. Additional interviews were conducted with members of Congress or their staffs.

Three factors affecting the ability of the women's movement to gain access to the political system were identified by the researcher. These factors were (a) changing the views of the movement so that the membership did not oppose lobbying, (b) securing additional groups willing to assist the movement in lobbying, and (c) locating sympathetic members of Congress to help with lobbying efforts. The findings from these two studies illustrated the importance of establishing alliances with similar groups in order to succeed. Phillips (1991) continued to look at the coordination of SMOs with each other. Basing her research on the theory of social movements being created by networks of actors, she explored the national women's organizations in Canada. The 
purpose of this study was to map the social movement network making up the Canadian women's movement and explored the collective identity the movement created.

A social network analysis was conducted on the 33 national women's movement organizations identified by Phillips based on four criteria: (a) the primary purpose was advancing the status of women, (b) voluntary membership was based on similar interests, (c) the organization was engaged in policy advocacy, and (d) had a national membership or served as a national representative. Interviews then were conducted with the president of the SMO or another high-ranking leader. Two questions were asked: (a) list four present advocacy projects and other groups they worked with on those projects and (b) organizations the group normally works with in advocacy activities. In the first question, ties were listed as either weak, when only mentioned once, or strong, when the SMO was mentioned two or more times.

Phillips (1991) found 29 of the 33 organizations to be connected within a single network. The two of the four groups not in the network were professional, feminist groups, while the other two had different views on gender roles. The ties between these organizations were found, in most instances, to be weak, which Phillips explained as being important and necessary for changes and innovations to occur within an SM. She elaborated to say the number of weak ties were actually a strength of this network and allowed the associated individuals to be involved in a number of other organizations. These varying memberships allowed the SMOs to enhance their visibility and legitimacy and enabled them to effect greater change. Had the WUSA been able to more effective in coordinating with other women's sports, women's movement, and/or soccer movement, it may have been able to have greater success. Seeing how the ties in the case of Canadian 
women's organizations enabled them to encourage greater change reiterated the importance of networking both at the individual and organization level.

Competition for Organizational Space. Competition for organization space was noted as an important factor for the creation of SMs and SMOs. The idea of organizational space has also been explored by sport management and sport sociology scholars (Tomlinson, Markovits, \& Young, 2003) and by tying these two academic areas, the influence of organizational space on the women in sport movement is apparent.

Taylor (1989) looked to the competition for organizational space as an explanatory variable for the continuity of SMs. The women's movement is one movement that explained distinct ebbs and flows within its cycle. The emphasis in this research was on the abeyance processes of this movement focusing on the fact the movement never ceased to exist but that it lost members or enthusiasm until a need for reorganization or revitalization occurred. The movement simply underwent holding patterns and the researcher focused on what happened to allow the movement to take greater action as well as what forced it to go into abeyance.

Data to examine feminist activity between 1945 and the early 1960 's were collected in two ways. The first was from archival data from various women's organizations including the National Woman's Party and the League of Women's Voters. Additional documents from various public and private collections were also included in this archival data. The second source of data came from 57 open-ended interviews, which were semistructured in nature. These interviews were tape recorded and conducted between 1979 and 1983 . The women interviewed were leaders and central 
members in many of the key women's organizations. The data enabled the researcher to explore the cycle of the women's movement after it won suffrage rights.

The findings in this study were twofold. First, Taylor (1989) identified five characteristics which enabled an SM to be in abeyance: temporariness, purposive commitment, exclusiveness, centralization, and culture. These five factors, according to the researcher, appeared "to be the ideal combination of factors necessary to hold a movement at a standstill until the external forces make it possible to resume a more massbased challenge" (Taylor, 1989, p. 770). Taylor than advanced her research to decipher what enabled the women's movement to become active again. She elaborated and suggested three factors contributing to this process: preexisting activist networks, a collective identity, and existing goals and tactics. Following suit she stated the founding of the National Organization for Women (NOW) was pivotal in the women's movement coming out of abeyance.

Exploring the various factors enabling a movement to come out of a dormant phase was important in exploring the ways in which organizations and movements were able to compete for space. Allowing a movement to be in abeyance and come out of this phase illustrated the importance of a movement having the ability hold its place in the organization's space and being able to capitalize on the cultural climate most beneficial for its resurgence.

Stern (1999) noted how all groups competed for what she terms "social space." She argued SMOs competed with each other for members and the importance of finding a niche in order to grab more members. In this study, Stern (1999) "examines the competition between social movement organizations" (Stern, 1999, p. 91). Stein used 
membership data on all members from two local SMOs in Hallsta, Sweden, IOGT, a more established SMO, and SAP, a newer addition to the SMO landscape, from 1915 to 1934. Stern (1999) measured the organizational niche of each SMO through the variables of age and social status, which was based on the member's occupation and were estimated through a time-series analysis.

Stern found the growth or addition of the SAP SMO had a negative effect on the membership of IOGT. This finding illustrated the role competition can play in the success of an SMO. She reiterated by stating, "the success of social movements does not depend solely upon their own actions, but is also affected by the actions of other organizations in the market" (Stern, 1999, p. 100).

Means for acquiring resources and support. McCarthy and Zald (1987) listed the means and ability of acquiring resources and support as being instrumental in creating a SM and SMO. Many studies of SMOs in the women's movement reiterated this sentiment (Disney \& Gelb, 2002). In regard to women in sport it is easy to make this correlation since women have had difficulty gaining access to the sports space. In recent years, researchers explored the ways women gained access and support to enter sport. McGinnis, McQuillan, and Chapple (2005) investigated why golf has maintained the status of a "man's game." Even though women have gained access in many areas formerly limited to just men, recreational golf has not been an area inundated by women, where other recreational sports have had greater access. Women are still viewed as tokens on the golf course and continue to be discriminated against when they tee up. Due to this anomaly in behavior, especially with the increased participation rates of women in other recreational sports as well as traditional male careers, these researchers looked at 
two issues, discrimination and tokenism, in golf. They posed the following questions: "What barriers and constraints to participation do women experience on the course and what strategies do women use to negotiate playing and persisting in golf?" (McGinnis et al., 2005, p. 314).

The data collection consisted of 10 semi-structured interviews. These interviews were conducted in a 1-year period with women golfers, beginning in the spring of 2000 . All of the interviewees resided in the Midwest, which is where the primary researcher was based as well. Snowball and purposeful sampling were utilized to secure a broad range of golfing experiences. These interviews were described as being long and indepth. The purpose of this study was not to generalize to the public, but to gauge the "depth of experience" (p. 318) of women involved in the sport.

McGinniset al. (2005) found the women interviewed felt they were tokens and because of the positioning they were constantly singled out. They were stereotyped on and off of the course as being weaker, not as good, etc. Due to these stereotypes, most of the women felt they were "picked on." According to the literature this is a normal perception when one is viewed as a token (McGinnis et al, 2005). These women also discussed the idea of role entrapment. A term coined by Kanter (1977), this meant women were unable to get away from the stereotypes placed upon them. Other issues of discrimination in golf brought up by these women dealt with the limited merchandise and equipment available to them, maintaining their femininity, and absence of role models.

These are just some of the issues holding women back in the world of golf as well as from success in other athletic endeavors. The inequities in golf mirror those in other sports as illustrated in Scraton, Fasting, Pfister, and Bunel (1999) who focused on the 
international women's football (soccer) movement. These researchers focused on the way women in Europe gained access to participation in soccer and their opportunities to play. While soccer has been the most popular sport in the world for men and in Europe for many years, women's participation and interest was very low. In recent years, soccer became one of fastest growing sports for women in Europe. Due to the popularity of soccer throughout these countries, it is commonly associated with men and masculinity. Women and girls wishing to play soccer "have had to challenge dominant notions of 'appropriate' female sport' (Scraton et al, 1999, p. 101).

Scraton et al (1999) conducted ten in-depth interviews with women from England, Germany, Norway, and Spain to learn about the experiences these women had playing soccer. Each interviewee was described as being a "top footballer" meaning she played in the highest league in her country and possibly for her national team. Each interview covered six main themes: her sports background, social networks, daily life, body, gendered identities, and sport and life plans.

The researchers found the women from England, Germany, and Norway began playing, on average, between 4 and 6 years old and were encouraged to play by the men in their lives (fathers, brothers, friends), while the women from Spain did not start playing until they were 11 years old and usually began playing due to encouragement by their female friends. All the women faced barriers when they began to play or tried to play in primary school and were encouraged to play more appropriate sports for girls. They were continually described as tomboys in an attempt to discourage their participation. Many of them did not have opportunities to play soccer formally until they were 14,18 , and in one case, 22 years old. The researchers also found the barriers 
increased as they entered adulthood partly because men controlled their national soccer programs. Women in Germany and Norway were found to have fewer barriers (as illustrated by their international successes as well) than the women playing in England and Spain. The successes of women in football challenged the traditional, binary opposition of masculinity and femininity and can be deemed a hindrance to the acceptance of women in sport.

Critical mobilizing events. McGlen and O'Connor (1983) stressed the importance of a critical mobilizing event(s) in the construction of a SM or SMO. The women's sports movement came to fruition from the implementation of Title IX, which required schools to provide opportunities for women in and off the playing field. "Title IX is considered one of the most enduring contributions of the U.S. women's movement" (Taylor, 2005, p. 358). As a result of Title IX, many high schools and colleges added soccer programs and club leagues flourished for women. The best of these women were members of the gold medal winning U.S. Women's National Team in the 1996 Olympic Games and the 1999 WWC, which has been defined as one of the most important events in the women's sport history. Since the implementation of Title IX, the perception of women in athletics has taken a positive shift. Women still face opposition however, as they do in many other facets of their lives. Interestingly, recent studies indicated public support of Title IX was actually far greater than politicians thought (Sigelman\& Wilcox, 2001). After seeing how politicians and lobbyists pushed for the weakening of Title IX, Sigelmanand Wilcox (2001) explored various polls concerning the public attitudes and thoughts toward this act. Through the observations of these polls the researchers hoped to answer the following questions: (a) Is the general public support of Title IX? (b) Is 
there public support for gender equality in funding? (c) Who supports equality in college athletics?

Sigelman and Wilcox (2001) looked at nine national opinion polls conducted by Gallup, Roper, Harris, and CBS News for organizations such as the Knight Commission, Feminist Majority Foundation and the Charles F. Kettering Foundation. Some of the information derived from the polls was simply answers to questions asking opinions toward equality in athletics. However, some of the polls had more demographic information, allowing the researchers to conduct greater statistical analysis.

Four polls were explored looking specifically at the public's view toward equitable funding of men's and women's athletics. These polls were conducted in 1974, 1979,1985 , and 1997. In all of the polls a majority of those surveyed agreed there should be equal funding for both, though there was a dip in acceptance in the late 1970's to the mid-1980's, with highs in 1974 of $88 \%$ and $86 \%$ in 1997 agreeing men and women should receive equal funds in high school and college athletics. An additional poll in 1990 showed $85 \%$ of the public supported women getting the same athletic opportunities as men. Further analysis revealed age and gender, however were significant predictors in agreeing with this thought. Younger individuals and women were more inclined to agree women should have the same opportunities as men. The researchers also reported $70 \%$ of the public opposed the weakening of Title IX in 1995, this concluding politicians and lobbyists have effectively skewed the false perception that the general public does not support Title IX and equality in athletics. This 2001 study illustrated public opinion does not necessarily mirror public perceptions. While the public may act as though it supports 
something such as the WUSA, its actions may say something different as indicated the inability of the WUSA to get fans in the seats.

Markovits and Hellerman (2003b) also studied the evolution of women's soccer in the United States. They looked at women's soccer as an exception in the world. The United States is viewed as anomaly in the soccer world because the women's team seen extreme success both on the field, as illustrated by its two wins in the World Cup (out of four) and two Olympic gold medals (out of three), and off the field as shown by the team's media popularity during the 1999 World Cup and in a variety of ad campaigns. Throughout the world, soccer (futbol or football) is the most popular sport and is dominated by men while in the United States it is a popular participant sport for both males and females. However, it was not until the 1994 World Cup and then the 1999 Women's World Cup, which were held on U.S. soil, that soccer was able to garner any of the public space within the professional sport domain.

This study traced the evolution of women's soccer in the United States and explored why it had such success on and off the field. The study "is dedicated to the analysis of the reasons, origins, and present manifestations of this particular American sports "exceptionalism"" (Markovits \& Hellerman, 2003b, p. 15). The investigators highlighted two key events in bringing women's soccer to the forefront of the media in the United States. The two events they keyed into were the passage of Title IX in 1972 and the success of the Women's World Cup in 1999. The latter event was the most popular event in the history of women's team sports. It also had the highest television audience of any soccer game ever in the United States. The researchers even went so far as to credit the success of the team in endearing themselves to the U.S. public and media. 
The researchers remained hopeful and optimistic the WUSA would become a mainstay (this article was published before the league's demise in 2003), they understood the difficulty of a professional sport league having success when it did not come into existence in the pivotal 60-year time frame from 1870 to 1930 when "the big three and one half," according to Markovits and Hellerman (2003a), [Major League Baseball (MLB), the National Basketball Association (NBA), the National Football League (NFL), and the National Hockey League (NHL)], endeared themselves to the U.S. public. Not only did this research explain the importance of events such as Title IX and the 1999 WWC, it also explained the competition existing in the sport space in the United States and the difficulties, which may lie ahead for any new professional sport leagues.

Summary. As the above discussion makes clear, resource mobilization theorists offer a lengthy list of factors to explain the rise, establishment, and success and or failures of SMs, SMOs, and SMAs. While not all of the factors in resource mobilization theory offered are discussed above, those most germane to the study of the WUSA are analyzed and illustrate the many ways the WUSA should be seen as a social movement organization in the many views of resource mobilization theorists.

The more recent schools of thought, Cultural Cognitive/Framing/New Social Movement Theory and Political Opportunity Structure, were established in a response to later scholars filling in perceived gaps and shortcomings of resource mobilization. And, while RM theorists provided a solid starting point for social movement theory, the addition of later schools of thought have only enhanced social movement theory. 


\section{Summary}

The three schools of thought within social movement theory highlighted by the the early works of Merton and Parsons relating to social structure, illustrate the level of overlap and ambiguity existing among the three. While each school of thought has defining characteristics setting it apart from the others, virtually all of the factors can be

related back to the early research of Merton and Parsons on the role of culture (as well as the definition of culture).

While the three schools of thought do overlap to a certain degree, they are also able to work together to allow this researcher to create a new model of SMs, SMOs, and SMAs that is more inclusive and open to the numerous factors integral to the formation of a social movement and its organizations. As alluded to earlier, none of the factors analyzed above are mutually exclusive and one can see the way factors crossover, both within one school of thought and to other schools of thought. While this crossover creates a challenge, it also makes creating a new model, blending the three schools together, necessary to continue to advance the literature on social movements.

Even though the initial reaction of social movement theorists was to examine SMs and SMOs through only one school of thought, recent scholarship encourages the blending of the various schools as a way of better understanding SMs and SMOs. The host of factors listed above from Cultural Cognitive/Framing/New Social Movement, Political Opportunity Structure and Resource Mobilization camps within social movement theory all work from early scholarship examining social structures to create a new, integrated model for examining SMs and SMOs. This new, integrated model 
illustrating the WUSA as a SMO in the women's movement, sports movement, and women in sport movement, will provide an important contribution to the literature. 


\section{CHAPTER III}

\section{METHOD}

Both the 1999 Women's World Cup and the creation of the WUSA were pivotal moments in women's sport history (Chistopherson et al., 2002; Markovits \& Hellerman, 2003b).This moment however, as well as others in women's sport history, such as the "Battle of the Sexes" and the passage of Title IX, are often omitted from studies of the women's movement. Omission of these critical events appears to be a conscious decision by leaders of the women's movement. In combination, the WUSA should be seen as part of women's sport history as well as a player within the women's movement. "For the most part, research bearing on the general area of sport and social movements has been rare" (Wilson \& White, 2002). More recently however, research on sport and social movements has become an area of greater interest by various scholars (Harvey \& Houle, 1994; Leonard, 1998; Sage, 1999; Wilson \& White, 2002).

\section{Study Purpose}

The purpose of this study is to look at the creation and demise of the WUSA as a social movement organization within traditional social movement literature.

\section{Research Questions}

The above discussed design was used to answer the three research questions:

1. How was the WUSA founded?

2. Why was the WUSA founded?

3. Why did the WUSA fail? 


\section{Study Design}

The design used is a case study design from a historical analysis perspective.

This study is grounded in social movement theory: "Movement scholars have used a variety of methods to investigate interactions between SMOs and their environments and the ways in which organizational structures affect tactics, mobilization, and outcomes" (Klandermans \& Staggenborg, 2002, p. 322). The lack of inclusion of sport in the women's movement, along with the recent trend of examining sport in the social movement context, allowed the researcher to examine the specific case of the WUSA within the women's movement.

For this examination of the WUSA, a historical case study is the most appropriate research method to employ. Through examining numerous conceptual works on case studies, Snow and Trom (2002), indicated that this design included (a) an analysis of some social phenomena, (b) the generation of "thick elaboration of the phenomenon studied," (p. 147), and (c) the use of multiple methods. "Case studies are in-depth and detailed explorations of single examples of an event, process, organization, group or individual" (Rossman \& Rallis, 2003, p. 104). A case study, which is "when the object of research is distinctly "singular" in character (an individual person, an individual local community, or an individual institution)" (Nowak, 1977, p. 21) is often the method used Since most studies of social movements derive their data from research on a particular movement or a stretch in time in a movement's career, one could conclude that the case study method and the study of social movements are almost one and the same. (Snow \& Trom, 2002, p. 146) 
Qualitative analysis enabled the researcher to trace the rise and fall of the WUSA as a SMO requires in-depth interviews from the perspective of insiders. "Qualitative research methods are used to understand some social phenomena from the perspectives of those involved" (Glesne, 2006, p. 4). A social movement is also a social phenomenon and a SMO is an agent of a SM; therefore, a qualitative design makes sense as the WUSA will be examined as an SMO, an agent of a social phenomenon, through the perspectives of leaders within the league. Additionally, qualitative data are known for "their richness and holism, with strong potential for revealing complexity" (Miles \& Huberman, 1994, p. 10), which is ideal for the study of the host of factors indicative of a successful or failed SMO.

Interview was the primary form of data collection used in this qualitative case study from a historical perspective. It was used because it is "the most straightforward way researchers get to know an SMO" (Lofland, 1996, p. 43) and is the closest in "proximity to a SMO under study" (Lofland, 1996, p. 29). The additional methods used to collect data in this case study of the WUSA included (a) examination of historical archives and internal documents from the WUSA, (b) WUSA publications, and (c) secondary publications, such as newspaper and magazine articles, as well as books on women's soccer in the United States and abroad, soccer in the United States, and the changing roles of women in sport. Similar to Sugden and Tomlinson's (1996) case study on the 1994 World Cup, "the range of methods used in this analysis is not justified in the basis of any model of triangulation, as multimethod approaches have been by methodologists...rather, the multimethod approach employed...embodies the authors' commitment to a critical investigative sociology" (p. 241). 
Finally, as indicated by Snow and Trom (2002), the use of multiple methods, referred to as triangulation, is critical to establishing the trustworthiness of a case study. In the study of SMOs, "extensive and diverse forms of data are collected on the case" (Lofland, 1996, p. 23) which include "historical reports...direct observation and interviewing, surveys of SMO members, or extensive reading of each SMO's literature" (Lofland, 1996, p. 23). The historical method will be a part of this multi-method approach. This method "refers to the means of identifying how some phenomenon has changed or has remained the same" (Thomas, 2003, p. 17). The ties of the historical method to social phenomena or social movements were beneficial to the explanation of the WUSA as a SMO. These various methods of data collection are necessary as the case study has a "particularistic focus" (Rossman \& Rallis, 2003, p. 105).

This varied data collection allowed the investigator to succeed in addressing the purpose of this study as well as to successfully answer the three research questions.

\section{Participants}

The participants in this study were leaders within the WUSA. The sample size of eight, was chosen based on other case studies on social movement organizations. Many of these studies consist of interviews with between five and 20 individuals (Costain, 1980; Pelak, 2002; Poster, 1995) key to the SMO being investigated; some however involved many more individual subjects, many of which did not conduct as in-depth interviews (Banaszak, 1996; Costain, 1981; Staggenborg, 1988).

The research participants were selected based on a stratified purposeful sampling strategy, which "illustrates subgroups; facilitates comparisons" (Miles \& Huberman, 1994, p. 28). The stratification in this sample consists of the various groups of leaders 
within the WUSA, players (founding and/or captains), high-ranking league personnel, high-ranking team personnel, head coaches, investors, and members of the reorganization committee - the Women's Soccer Initiative, Inc. (WSII). Within these stratified groups, purposeful sampling will be conducted, meaning the researcher has "reasons (purposes) for selecting specific participants" (Rossman \& Rallis, 2003, p. 137). The purposes of targeting the above mentioned groups were to get variation in perspectives and experiences with the rise and fall of the league, geographic location, and success of the team. Additionally, the "snowball sampling" strategy will be used to increase the number of interviewees and to ensure "completeness" and "the principle of similarity and dissimilarity" suggested in Blee and Taylor (2002). This strategy is described as obtaining "knowledge of potential cases from people who know people who meet research interests" (Rossman \& Rallis, 2003, p. 35). The final interviewees were receptive and willing to be interviewed during the process. Additional potential interviewees were contacted, however were unable to commit to the time commitment.

\section{Access and Entry}

According to Lofland (1996), interviewing members of an SMO is the best way to learn about them and it "is actually quite easy and pleasant...researchers...normally find early contacts and interviews quite cordial and even fun" (p. 43). The leaders of the WUSA were willing to be interviewed. The initial interviewee aided in this process and opened many doors to additional leaders, as did other individuals that were initially contacted and interviewed.

The interview process began with gaining approval from the Institutional Review Board at the University of Louisville. Next, two leaders of the WUSA agreed to be 
interviewed and assist in contacting additional interviewees for this study. These two individuals helped contact many of the additional interviewees so they would be more open to being interviewed. Once interviews were confirmed, each interviewee was sent a letter explaining the study, its purpose, and the role of the interviewee. Once at the interview location, each interviewee was given an informed consent form, a requirement from the Institutional Review Board.

\section{Data Collection}

While the primary data collection method in this case study was the in-depth interview, additional collection methods were used. The interviews took place in 2008 and 2009 and lasted between 45 to 90 minutes each. Demographic information, including gender, age, race, role with the league, role in soccer, geographic location, and team(s) associated with, were collected from each interviewee during the interview process and were completed by following the outline used in earlier examinations of the

success and failure of SMOs (Banasazak, 1996). Secondary data collection consisted of internal documents, various websites, and newspaper articles. These secondary documents were examined to complement the interview data.

Interview. Semi-structured, in-depth interview was the primary data collection method in this study as suggested by Blee and Taylor (2002): "In the field of social movements, semi-structured interviewing is useful in studies where the goals are exploration, discovery, and interpretation of complex social events and processes and when combined with participant observation and/or documentary methods" (p. 93). Blee and Taylor (2002) further noted semi-structured interviews to be "particularly useful in research on loosely organized, short-lived, or thinly documented social movements" ( $\mathrm{p}$. 
93). As the WUSA fits the latter of the two categories, short-lived and part of a thinly documented or overlooked social movement organization, this method is the best way to solicit initial data.

The interview protocol was based on the literature cited in chapter two (see Appendix A for interview protocol). Each interview began by collecting demographic information. It continued on to examine the rise and fall of the WUSA from the perspective of each interviewee based on the factors associated with successful and failed social movements and social movement organizations. Additionally, each interview covered topics such as events leading to the creation of the WUSA, the timing of the creation of the WUSA, and the successes and eventual failure of the WUSA. The final part of the interview probed the interviewees' thoughts about the future of women in sport, professional sport, and soccer. The interview was organized in this fashion as a way to ease into the interview and engage each interviewee before probing into their thoughts on the league. Each interview was recorded and transcribed in full with additional notes taken by the researcher during the course of and following each interview.

The interview protocol (see Appendix A) was modified from those used in an examination of the role of women within the federal government in the women's movement. Many of the women interviewed for this study by Banaszak (1996) were instrumental in founding the National Organization of Women (NOW), a social movement organization. The researcher modified the questions to place them in the context of the women's sport movement as well as the WUSA. The research protocol was modified throughout the interview process as additional questions were added and 
some were omitted to the initial interview protocol to ensure the interview process was securing the necessary information.

Document mining. Newspaper articles were reviewed at key points in the life cycle of the WUSA: (a) during the course of the 1999 Women's World Cup, (b) February 2000 (when the league was established), (c) April 2001 (when the league kicked off), (d) throughout the lifespan of the WUSA (April 2001 to September 2003), and (e) the fall of 2003 (when the WUSA suspended operations and throughout the course of the 2003 Women's World Cup). These articles were drawn from USA Today and reviewed to gauge the coverage of the WUSA and chart when, if ever, more coverage was given to the league. These articles were used to confirm themes derived from the interviews. USA Today was used "because it is a national newspaper but for its superb sports coverage, traditionally quite inclusive of soccer" (Markovits \& Hellerman, 2003a, p. 1537).

WUSA documents. Various WUSA documents were examined in order to enhance the context of the league's formation. These documents include (a) internal WUSA published marketing and operations guidelines, $(b)$ team and league media guides, and (c) championship programs.

\section{Data Analysis}

The data analysis in this study used the framework of a case study design from an historical analysis perspective, which relies primarily on in-depth interviewing (Glesne, 2006). The interview schedule is provided in Appendix A. Each interview was transcribed and coded deductively using a code grid that was modified throughout the interview processes as well as during the data analysis (Appendix B). The analysis of the 
interview data was examined throughout the data collection, as suggested by Blee and Taylor (2002) as constant comparative analysis. This analysis consisted of the "coding, categorizing and analyzing" (Blee \& Taylor, 2002, p. 112) of the transcribed interviews until data saturation was achieved.

Constant comparative analysis compares fresh data with current or set configurations of categories (see Appendix C). "The purpose of the constant comparative method of joint coding and analysis is to generate theory more systematically" (Glaser, 1965, p. 37). Glaser further goes on to list the four stages of constant comparative analysis: "(1) comparing incidents applicable to each category, (2) integrating categories and their properties, (3) delimiting the theory, and (4) writing the theory" (p. 439). These four stages comprise the constant comparative analysis method and enabled the researcher to add structure throughout the interview process as well as aid in any changes to the interview protocol.

The constant comparative analysis works hand in hand with the historical analysis perspective used here to examine the place of the WUSA in history. According to Goldstone (2003) historical analysis "aim[s] to determine the causal sequences and patterns producing outcomes of interest in those specific cases" (p. 42). Using historical analysis in conjunction with constant comparative analysis enabled the researcher to achieve analytic generalizations (Miles \& Huberman, 1994), meaning generalizations that can be applied to other SMs and SMOs.

The additional sources of data, internal and external documents, complimented the data from interviews and can also be placed into the categories with the coded interviews for greater analysis. This process of data mining allowed the researcher to 
examine data "that endure over time and enable researchers to compare the past with the present" (Talley \& Keedy, 2006, p. 428).

\section{Trustworthiness}

Trustworthiness is also referred to as research validity and according to Glesne (2006), and should be considered throughout the entire research process. She identified eight ways trustworthiness and validity can be established and preserved. Five of the most useful in this research of the WUSA are (a) data saturation, (b) triangulation, (c) peer review and debriefing, (d) member checking, and (e) thick description.

Data Saturation. This process also allowed for data saturation which is when the "data you have seem complete and integrated" (Glesne, 2006, p. 152). The multiple interviews with key informants enhanced this data saturation. Once the data collection and coding were completed, the codes were then highlighted in categories. The categorization allowed the researcher to view the coded data to derive conclusions.

Triangulation. The use of triangulation in this study added to its trustworthiness and was established through the use of multiple research methods, including in-depth interviews, additional interviews with key informants, and the mining of various internal and external documents. Use of these multiple methods enhanced the researcher's ability to see not only the way WUSA leaders viewed the league, but the way the league was situated in society.

Peer review and debriefing. Members of this dissertation committee provided input throughout this project. They contributed significantly in the layout of the research as well as gave input throughout the analysis portion. Additional social movement scholars were consulted throughout the process and gave input on additional questions 
that were asked in the interviews, ways of categorizing and coding the data, as well as how various thoughts fit into establishing the WUSA as an SMO.

Member checking. Preliminary categorization, as well as any reports on what the researcher seeing is the first part of the member checking process (Glesne, 2006). For the few key informants who will be interviewed a second time, member checking was conducted to ensure the researcher is making the appropriate analysis and not drawing inaccurate conclusions. The addition of member checking to this analysis of data enhanced the overall trustworthiness of this project.

Thick description. The thick descriptions used here enhance the reader's ability to understand the context of the founding of the WUSA as well as the varied leadership roles of those interviewed. By giving the reader as much detail as possible about all areas of research and the findings, this study is seen as having greater trustworthiness.

Additionally, the data collected in the interviews were seen as having greater trustworthiness as they were modified from an earlier interview schedule conducted on the roles of women in various policy changes as well as their role(s) in the founding of NOW. The parallels between the creation of these two SMOs in the women's movement made the initial interview questions used for the NOW founders a logical choice when interviewing the leaders and founders of the WUSA.

The use of these four procedures as well as the previously used interview questions, enhance the overall trustworthiness of the data collected and, more importantly, in the analysis and findings. 


\section{CHAPTER IV}

\section{RESULTS}

The two purposes of this study were to examine the creation and demise of the WUSA, and to establish the league as a social movement organization within the context of the rich body of social movement literature. This was examined by answering the question "How can the rise and fall of the WUSA be explained?" and included the following three research questions:

1. How was the WUSA founded?

2. Why was the WUSA founded?

3. Why did the WUSA fail?

Interviews were conducted with eight individuals meeting the definition of a WUSA leader by the researcher. Each individual participated in one interview lasting approximately 45 to 90 minutes. Additionally, one interviewee, deemed a key informant, was interviewed an additional time to (a) clarify some of the findings through the interview process and (b) elaborate on themes that had been identified throughout the previous interviews. Each interview consisted of a series of questions encompassing three major areas: (a) background information including sport history and involvement in soccer as well as the role or roles each individual had in the WUSA, (b) looking to answer the overarching research question "How can the rise and fall of the WUSA be explained?" by examining the WUSA as a SMO, and (c) the future of women's professional soccer in the United States. 
This chapter is organized into several sections:

1. An introduction to the eight interviewees, which will include a brief biography for each individual including his/her sport background and role within the WUSA;

2. Establishing the WUSA as an SMO within the women's movement and more specifically the women's sport movement, highlighted by connecting the interviews with the factors associated with the three social movement theories: resource mobilization, political opportunity structure, and new social movement theory;

3. Responding to the three research questions: how was the WUSA founded?, why was the WUSA founded, why did the WUSA fail?;

4. A summary combining the answers to "how can the rise and fall of the WUSA be explained by examining the WUSA as a SMO?"

\section{Interviewee Biographies}

Eight individuals were interviewed. All eight individuals defined as WUSA leaders and encompassed a variety of roles with the league and/or their respective teams, which included, but was not limited to the player representative on the WUSA Board of Governors, founding players and team captains, and general managers. These eight individuals represent five of the eight teams that comprised the WUSA. Additionally, there is representation from one of the two southeast teams (Carolina Courage), one of the two teams from the Atlantic region (Washington Freedom), one team from the Northeast region in (New York Power) and both of the West Coast teams, the San Diego Spirit and San Jose CyberRays.

This section on the biographies of the eight interviewees is separated by interviewees and includes information in three main parts for each. The first part 
includes the basic background information for each of the individuals, including facts such as their gender, ethnicity, college, WUSA affiliation and role(s) within the league, as well as their current employment status. The second part deals more specifically with each individual's sport and soccer background. The third part focuses on each interviewee's roles and responsibilities within the WUSA and with her specific team.

Interviewee biographies. The eight interviewees were all women and hailed from throughout the United States and Brazil. They attended a variety of different types of universities and played for or worked for five of the eight different WUSA teams. Additionally, due to their background, each had unique early exposure to sport. Growing up throughout the United States and Brazil from the 1950s through the 1970s, all of these women were exposed to sport, experiencing both positive and negative attitudes toward their sport participation, which helped them become leaders within the WUSA. Below are two tables with the basic information of each interviewee and is followed by a more thorough background of each interviewee. Table 2 highlights the basic background information for each individual and Table 3 highlights each interviewees experience with sport and more specifically soccer. 
Table 2

Basic Background Information

\begin{tabular}{|c|c|c|c|c|c|c|}
\hline Name & Gender & $\begin{array}{l}\text { Race/ } \\
\text { ethnicity }\end{array}$ & College & $\begin{array}{l}\text { WUSA } \\
\text { atfiliation(s) }\end{array}$ & Position(s) & Current position \\
\hline Kaley Baker & $\mathrm{F}$ & $\begin{array}{l}\text { White } \\
\text { Caucasian }\end{array}$ & $\begin{array}{l}\text { Mid-size, } \\
\text { Catholic, mid- } \\
\text { Atlantic, } \\
\text { NCAA D-I } \\
\text { school }\end{array}$ & $\begin{array}{l}\text { Southern } \\
\text { WUSA team }\end{array}$ & $\begin{array}{l}\text { General } \\
\text { manager }\end{array}$ & $\begin{array}{l}\text { Policy and External } \\
\text { Relations Ofticer at a } \\
\text { large, international } \\
\text { nonprofit }\end{array}$ \\
\hline $\begin{array}{l}\text { Margaret } \\
\text { Barnstable }\end{array}$ & $\mathrm{F}$ & $\begin{array}{l}\text { White } \\
\text { Caucasian }\end{array}$ & $\begin{array}{l}\text { Sinall NAIA } \\
\text { school in the } \\
\text { Southwest }\end{array}$ & $\begin{array}{l}\text { West Coast } \\
\text { WUSA Team }\end{array}$ & $\begin{array}{l}\text { General } \\
\text { manager }\end{array}$ & $\begin{array}{l}\text { Founder/CEO } \\
\text { Women's } \\
\text { Organization/nonprotit }\end{array}$ \\
\hline $\begin{array}{l}\text { Brittany } \\
\text { Churchill }\end{array}$ & $\mathrm{F}$ & $\begin{array}{l}\text { White/ } \\
\text { Caucasian }\end{array}$ & $\begin{array}{l}\text { Mid-size, } \\
\text { Catholic, West } \\
\text { Coast NCAA } \\
\text { D-I school }\end{array}$ & $\begin{array}{l}\text { West coast } \\
\text { WUSA Team }\end{array}$ & $\begin{array}{l}\text { Founding } \\
\text { player, team } \\
\text { captain }\end{array}$ & $\begin{array}{l}\text { Founder Women's } \\
\text { Organization/nonprofit, } \\
\text { player West Coast } \\
\text { WPS Team }\end{array}$ \\
\hline Jenny Frazier & $\mathrm{F}$ & $\begin{array}{l}\text { White/ } \\
\text { Caucasian }\end{array}$ & $\begin{array}{l}\text { Mid-size, } \\
\text { private, West } \\
\text { coast, NCAA } \\
\text { D-I school }\end{array}$ & $\begin{array}{l}\text { West coast } \\
\text { WUSA Team. } \\
\text { WUSA Board } \\
\text { of Governors }\end{array}$ & $\begin{array}{l}\text { Founding } \\
\text { player, tean } \\
\text { captain }\end{array}$ & $\begin{array}{l}\text { Founder Women's } \\
\text { Organization/nonprofit, } \\
\text { soccer business owner, } \\
\text { Sport Television } \\
\text { Analyst }\end{array}$ \\
\hline $\begin{array}{l}\text { Isabelle } \\
\text { Kramer }\end{array}$ & $\mathrm{F}$ & $\begin{array}{l}\text { White } \\
\text { Caucasian }\end{array}$ & $\begin{array}{l}\text { Mid size, west } \\
\text { coast, State } \\
\text { University }\end{array}$ & $\begin{array}{l}\text { West coast } \\
\text { WUSA Team }\end{array}$ & $\begin{array}{l}\text { Director of } \\
\text { operations }\end{array}$ & $\begin{array}{l}\text { General Manager West } \\
\text { Coast WPS Team }\end{array}$ \\
\hline $\begin{array}{l}\text { Margot } \\
\text { MacMillan }\end{array}$ & $\mathrm{F}$ & $\begin{array}{l}\text { White/ } \\
\text { Caucasian }\end{array}$ & $\begin{array}{l}\text { Large } \\
\text { Southern State } \\
\text { University, } \\
\text { NCAA D-I } \\
\text { socer }\end{array}$ & $\begin{array}{l}\text { Southern } \\
\text { WUSA team }\end{array}$ & $\begin{array}{l}\text { Head coach, } \\
\text { Asst. GM }\end{array}$ & $\begin{array}{l}\text { General Manager } \\
\text { Midwest WPS Team }\end{array}$ \\
\hline $\begin{array}{l}\text { Theresa } \\
\text { Michaels }\end{array}$ & $\mathrm{F}$ & $\begin{array}{l}\text { White/ } \\
\text { Caucasian }\end{array}$ & $\begin{array}{l}\text { Mid-size, } \\
\text { Catholic, West } \\
\text { Coast NCAA } \\
\text { D-I school }\end{array}$ & $\begin{array}{l}\text { Northeastern } \\
\text { WUSA team }\end{array}$ & $\begin{array}{l}\text { Founding } \\
\text { player, team } \\
\text { captain }\end{array}$ & $\begin{array}{l}\text { Player West Coast } \\
\text { WPS Team }\end{array}$ \\
\hline Shanna & $\mathrm{F}$ & Brazilian & & $\begin{array}{l}\text { West coast } \\
\text { WUSA Team }\end{array}$ & $\begin{array}{l}\text { International } \\
\text { player, } \\
\text { occasional } \\
\text { captain }\end{array}$ & $\begin{array}{l}\text { Assistant Coach/Player } \\
\text { West Coast WPS Team }\end{array}$ \\
\hline
\end{tabular}


Table 3

Experience with Sport and Soccer

\begin{tabular}{|c|c|c|c|c|}
\hline Naine & $\begin{array}{l}\text { Youth sport } \\
\text { experience }\end{array}$ & $\begin{array}{l}\text { High school sport } \\
\text { experience }\end{array}$ & $\begin{array}{l}\text { College sport } \\
\text { experience }\end{array}$ & $\begin{array}{l}\text { National team/prolessional } \\
\text { soccer experience }\end{array}$ \\
\hline K. Baker & $\begin{array}{l}\text { Played } \\
\text { many } \\
\text { sports }\end{array}$ & Played many sports & $\begin{array}{l}\text { Varsity soecer was } \\
\text { established in the } \\
\text { spring of her } \\
\text { freshmen year; } \\
\text { member of varsity } \\
\text { team }\end{array}$ & NA \\
\hline $\begin{array}{l}\text { M. } \\
\text { Barnstable }\end{array}$ & $\begin{array}{l}\text { Athletic: } \\
\text { primarily } \\
\text { traditional } \\
\text { women's } \\
\text { sports. }\end{array}$ & $\begin{array}{l}\text { Played "traditional" } \\
\text { women's sports }\end{array}$ & Varsity Tennis & NA \\
\hline B. Churchill & $\begin{array}{l}\text { Played a } \\
\text { variety of } \\
\text { sports; } \\
\text { soccer was } \\
\text { always first } \\
\text { love. }\end{array}$ & $\begin{array}{l}\text { Played a variety of } \\
\text { sports; primary focus on } \\
\text { soccer. }\end{array}$ & $\begin{array}{l}\text { Played at a large state } \\
\text { university before } \\
\text { transferring to a } \\
\text { smaller school } \\
\text { leading the team to } \\
\text { two Final Fours }\end{array}$ & $\begin{array}{l}\text { Member of U.S. National Team } \\
\text { for over } 15 \text { years winning World } \\
\text { Cup Championships and } \\
\text { Olympic gold medals; played } \\
\text { and served as captain of her } \\
\text { WUSA team; played in the WPS } \\
\text { lor one year. }\end{array}$ \\
\hline J. Frazier & $\begin{array}{l}\text { Played a } \\
\text { variety of } \\
\text { sports. }\end{array}$ & $\begin{array}{l}\text { Focused primarily on } \\
\text { soccer, juggling playing } \\
\text { for her high school and } \\
\text { club teams as well as } \\
\text { with the U.S. National } \\
\text { Team }\end{array}$ & $\begin{array}{l}\text { First ever scholarship } \\
\text { player on the Varsity } \\
\text { soccer team; led team } \\
\text { to first College Cup }\end{array}$ & $\begin{array}{l}\text { Member of U.S. National Team } \\
\text { for over } 15 \text { years winning World } \\
\text { Cup Championships and } \\
\text { Olympic gold medals; played } \\
\text { and served as captain ol her } \\
\text { WUSA team and of the National } \\
\text { Team }\end{array}$ \\
\hline 1. Kramer & $\begin{array}{l}\text { Played a } \\
\text { variety of } \\
\text { sports. }\end{array}$ & $\begin{array}{l}\text { Helped establish a girl's } \\
\text { varsity soccer team at } \\
\text { her high school }\end{array}$ & NA & NA \\
\hline $\begin{array}{l}\text { M. } \\
\text { MacMillan }\end{array}$ & $\begin{array}{l}\text { Played } \\
\text { many } \\
\text { sports }\end{array}$ & $\begin{array}{l}\text { Participated in many } \\
\text { sports throughout high } \\
\text { school. }\end{array}$ & $\begin{array}{l}\text { Won three NCAA } \\
\text { Championships }\end{array}$ & $\begin{array}{l}\text { Member of U.S. National Team } \\
\text { for two years. }\end{array}$ \\
\hline T. Michaels & $\begin{array}{l}\text { Played } \\
\text { many } \\
\text { sports } \\
\text { throughout }\end{array}$ & $\begin{array}{l}\text { Three sport athlete in } \\
\text { high school }\end{array}$ & $\begin{array}{l}\text { Full scholarship } \\
\text { Varsity soccer player }\end{array}$ & $\begin{array}{l}\text { Member of U.S. National Team } \\
\text { for over } 15 \text { years winning World } \\
\text { Cup Championships. }\end{array}$ \\
\hline Shanna & $\begin{array}{l}\text { Played } \\
\text { many } \\
\text { sports } \\
\text { informally. }\end{array}$ & $\begin{array}{l}\text { Focus became soccer at } \\
\text { high school age. }\end{array}$ & NA & $\begin{array}{l}\text { Member of the Brazilian } \\
\text { National Team for the first three } \\
\text { Women's World Cup } \\
\text { Championships and two } \\
\text { Olympic Games. }\end{array}$ \\
\hline
\end{tabular}

Kaley Baker. Kaley Baker grew up in the Northeast United States in the late 1970 s and 1980s, before going to college in the Mid-Atlantic region. When Baker

arrived on campus she was content to be a member of the club soccer team until in only her second semester on campus the athletic department chose to add women's soccer in 
an attempt to comply with Title IX. From the spring of her freshmen year until her graduation, Baker was a member of the varsity women's soccer team.

Baker was one of the first general managers to be hired by the WUSA and played a key role in the early stages of the league. Due to her close proximity to Hendricks and the Discovery Channel base of operations, she played a key role in many of the early league and team decisions, even assisting as other team and league personnel were being hired. Additionally, due to her early hire, Baker was able to get ahead on getting her team up and running, securing one of the best offices and practice set-ups in the league. Prior to working in the WUSA, Baker played NCAA Division I soccer at a midsize Catholic university in the Mid-Atlantic region, interned and worked in the Presidential Administration. Baker now works for a major charitable foundation.

Margaret Barnstable. Barnstable grew up in the upper Midwest in the 1950s and 1960s before heading to the Southwest for college. Growing up she played many sports informally with her siblings and once in college began to focus primarily on tennis. While she played tennis competitively, she did not receive tremendous support from the university and in her surroundings. Barnstable went on to coach at the collegiate level at her alma mater, and was named the NAIA Coach of the Year for her successes.

Barnstable moved on to athletic administration as an assistant athletic director where she was able to continue to improve opportunities for female athletes.

Margaret Barnstable was the General Manager for the one of the West Coast WUSA teams for its entirety. She was one of the last hires in the role for the league and one of the last to leave as she stayed on board with the league as she continued to work as a member of the reorganizing committee. Prior to taking the position with the WUSA 
team, Barnstable served as the Senior Woman Administrator at a university in California. Previously she had served in a similar role at another university while also coaching the women's tennis team. As previously stated, Barnstable was one of the last general managers to be hired, so as soon as she accepted the job officially she hit the ground running, securing practice fields, office space, and a stadium, in addition to hiring a staff that embraced her vision for women's soccer in their competitive market area.

Barnstable was active at league meetings and on calls and was one of the last two general managers to stay on with the WUSA after it ceased operations. She worked diligently with a host of others to set up the Women's Soccer Initiative, which was created in tandem with the WUSA final event of the 2004 Summer Festivals in Southern California and Minnesota.

After the WUSA suspended operations, Barnstable teamed up with Brittany Churchill and Jenny Frazier to establish a nonprofit in the Bay Area that establishes programs and partnerships through which women athletes bring health, hope and wholeness to the Bay Area community. She currently serves as the Founder and as the CEO of the nonprofit.

Brittany Churchill. Brittany Churchill is a native of the Bay Area in California. She and her younger brother grew up playing soccer together and being involved in the Northern California soccer community. Churchill began her soccer career at a Division I university in California where she was named the Soccer America Freshmen Player of the Year before transferring to another university for her final two seasons where she helped lead her new team to consecutive NCAA tournament appearances. 
Churchill is one of the most recognizable women's soccer players. She played a pivotal role in the success of the United States in the 1999 Women's World Cup. Following the success of her team and the publicity she helped garner with her teammates, she became a founding member of the WUSA and played all three seasons for one of the two West Coast teams. Additionally, she played for the National Team in the 1991 and 2003 World Cups and the 1996, 2000, and 2004 Olympic Games in addition to the famous 1999 World Cup. Churchill also was a member of a franchise in the Women's Pro Soccer League (WPS) near her residence in its initial year, and continues to make numerous appearances and is involved in multiple service and soccer endeavors as well as various media appearances and promotions.

Brittany Churchill was one of the most popular and visible founding players and most teams saw a spike in ticket sales when she came to their venues. She was a fan favorite on and off the field as she completely embraced the responsibility of being a founding player. She was frequently the most highly demanded player from her team for charity events and worked as many events as she could. She was also commonly the last player to leave the autograph zone following games, win or lose, as she understood what it meant to all the children waiting for her.

Jenny Frazier. Jenny Frazier was a founding player of the WUSA as a member of the one of the West Coast teams. She played for said team for all 3 years of its existence while serving as a team captain. Additionally, she was a prominent member of the U.S. Women's National Team from 1987 until 2004, participating in four World Cups and three Olympic Games serving as a spokesperson throughout her tenure with the National Team. Not only did Frazier play for a WUSA team, she served as one the 
players' representatives on the WUSA Board of Governors, giving the players a voice at the league level, something rarely, if ever, encountered in professional sport organizations. Simultaneously during her soccer career, Frazier served as the President a national women's social movement organization, served on various national policy committees, testified before Congress, and created and a wide array of soccer camps and leadership opportunities for young women. She is also a frequent television commentator on soccer events as well and has continued to be a key advocate of ensuring the current Title IX legislation remains intact.

Frazier played a host of team sports from a young age with her older siblings. She began playing soccer at recess in first grade, but could not join a formal team until she was 7. From her seventh birthday on, soccer was her main focus and in high school she began playing for the National Team, juggling her national team commitments with her high school responsibilities. After being offered numerous soccer scholarship opportunities for college, Frazier opted instead to attend a university that did not offer any soccer scholarships when she first enrolled. Shortly before her senior year, Jenny Frazier was awarded the first ever soccer scholarship for her final year of college play, achieving one of her childhood goals to attend dream university on a soccer scholarship. Throughout college, she maintained her position on the U.S. National Team and continued to play for the squad through multiple World Cups and Olympic Games before her retirement.

Jenny Frazier was the leader of the founding players and also the most vocal in virtually everything they did as a group. When player allocations were being decided, Frazier teamed up with her U.S. teammate, Carla Overbeck, to try to come up with the 
best fit for everyone. She frequently played diplomat between the league and the players as the lone player representative on the WUSA Board of Governors; however, by her own admission, she "wouldn't have wanted it any other way," even though it forced her to think more in terms of the big picture rather than just her team or her fellow founding players. Additionally she had responsibility to her team and her fans.

Isabelle Kramer. Kramer played a host of sports in her youth and throughout high school. She actually petitioned her high school to establish a girls' soccer team before she graduated and she was a member of that team. In college and following college she continued to play soccer recreationally.

Isabelle Kramer was a WUSA leader within her organization. She worked as the Director of Operations, which oversaw many parts of the day-to-day operations of the team, dealing with numerous contracts and arrangements for stadiums, practice locales, and overseeing a large volunteer staff. Additionally, she played a role overseeing equipment and aiding with the operational side of sponsor fulfillment. As a Director in the team organization she was also involved on conference calls and league meetings dealing with game operations and overall fan experience on a weekly and monthly basis. Additionally, in her capacity as the Director of Operations, Kramer handled all game logistics, worked on the stadium contracts, and played a pivotal role in the day-to-day operations of the organization. Prior to her work with the WUSA, she worked with the American Basketball League (ABL) and with the 1999 Women's World Cup Organization in the United States. Kramer most recently served as the General Manager for one of the WPS franchises. 
Margot MacMillan. MacMillan grew up in Northern Virginia and had ample opportunities to participate in sports from the time she was a child. She participated in a multitude of sports throughout her high school years before focusing on soccer at highly successful Division I university. MacMillan went on to become a collegiate assistant and head coach before entering the professional ranks as a head coach.

Margot MacMillan was a head coach in the WUSA. Her desire to coach in the league emerged from learning the fact that no women had been hired throughout the league. She led the team from a worst place finish in the first season to the WUSA Championship during her time as head coach. After leading her team to the championship, MacMillan switched gears and moved in to the front office the following year as the assistant general manager of the organization where one of her primary responsibilities was to oversee ticket sales and help increase team revenue.

Prior to her career in the WUSA, MacMillan served as the head coach at three successful, large NCAA Division I soccer programs in major conferences, had a successful college playing career winning multiple national championships, as well as a short career with the U.S. National Team. Currently, MacMillan is the General Manager of a franchise in the WPS and works with the U.S. National Team and the National Soccer Coaches Association of America (NSCAA).

Theresa Michaels. Michaels began playing all sports from the time she was a child as her mom encouraged participation from an early age. In high school she was a three sport athlete and only began focusing on soccer once she attended university on a soccer scholarship, though she thought about being a dual-sport college athlete. Following her collegiate career, Michaels went on to play professionally overseas as well 
as starring on the U.S. National team. She returned overseas when the WUSA suspended operations in 2003 and made her final appearance with the national team in 2006 , reaching her elusive $100^{\text {th }}$ goal.

Theresa Michaels was named one of the founding players of the WUSA after leading the team in goals on the way to the championship at the 1999 Women's World Cup. Michaels was allocated to a team in the Northeast United States where she took the reins of the team as the captain and was thrust into the spotlight and leadership role for the first time since her college career. Michaels thrived in the situation both on and off the field, earning numerous league-wide accolades while also embracing her new role as a leader and face of her team. Michaels understood that player appearances in the community and any appearances with media outlets were all opportunities to showcase her team and the league and she relished the challenges and opportunities granted to her in her new role as the captain of her WUSA team.

Additionally, Michaels was a member of the U.S. National Team from 1993 to 2006 earning over 200 caps (competition appearances) in that time span and representing the team in the 1995, 1999, and 2003 World Cups as well as in the 1996, 2000, and 2004 Olympic Games. She currently stars for WPS club, winning numerous personal and team accolades, after not being drafted by any club and only being offered two tryout opportunities in 2009.

Shanna. Shanna grew up playing sports breaking the mold of traditional gender roles in Brazil. When she joined the Brazilian National Team, she starred and led the team to international success in Women's World Cup Tournaments, winning numerous personal awards as a player 
Prior to joining the league, Shanna was a standout international player, starring for Brazil. In the 1999 World Cup, she led her team to a semifinal appearance and third place finish as the Golden Boot (scoring the most goals in the tournament) and Silver Ball (awarded to the second most valuable player). During the Cup she was regarded as one of the most talented midfielders to ever step on the field. Shanna also served as a captain of her team at times during her career with the WUSA.

Shanna was one of the first international players allocated/drafted in the WUSA. She, along with one other Brazilian, was allocated to a West coast team (while two of her Brazilian National Teammates were allocated to the Washington Freedom). As a foreign player with a limited background in English, Shanna immediately embraced English as her new language as well as embracing the United States culture she was thrown into. Her attitude toward her new team and teammates served as a great inspiration for the other international players throughout the league as it was commonly held that no other international players integrated as well and as early on as the two Brazilians at this West Coast franchise. Led by Shanna, the two Brazilians served as inspiration for many of the other international players so much so that in the second year they were joined by a third Brazilian teammate. Not only did Shanna understand the role she had to play as a sometime captain and one of the most famous international players in the league, she embraced everything that was thrown at her. She excelled working in the community, especially with children as she coached numerous camps and clinics, volunteered with a host of children's charities, and in many ways used her way as a WUSA player to interact with children and showcase the her team and the WUSA. 
She has recently coached and played in the WPS and continues to coach at youth level, play semi-professionally, while also continuing to serve the community through various humanitarian efforts.

Summary. These biographies provide basic information about each of the eight interviewees and shed light on their roles within the WUSA and various teams throughout the league. Each had unique backgrounds and experiences, which led to being involved with the WUSA when it kicked off in 2001 and when it suspended operations in 2003. The interviews provided each WUSA leader an opportunity to share what they felt about their experience with the WUSA and aided in examining the WUSA as a social movement organization.

\section{Examining the WUSA as a SMO}

The purpose of this study was to answer the question of "How can the rise and fall of the WUSA be explained?" As stated earlier, it is being examined through the lens of social movement research. Below are a host of the factors highlighted in chapter 2 , which are commonly associated with the three primary schools of thought in social movement research. Many of the factors in the differing schools of thought overlap and complement one another and will be elaborated on below.

Critical mobilizing events/social and cultural contexts. One of the critical defining factors attributed to establishing a social movement is the critical mobilizing event or events (CME) that preceded the movement or movement organization. A critical mobilizing event as defined in resource mobilization theory also explains and lays the foundation of the social and cultural contexts described as a factor by social movement theorists in both political opportunity structure as well as new social movement theory 
(Canglia \& Carmin, 2005; McAdam et al., 2005; McCallister et al., 2003; McGlen \& O'Connor, 1983; Spencer \& McClung, 2001). In this examination of the WUSA as a SMO within the women's sports movement, a movement rarely studied and overlooked according to Billie Jean King and mentioned in the interview with Jenny Frazier, all interviewees answered questions about the event or events that led to the creation of the WUSA. Examining the event or events that led to the creation of the WUSA establishes the social and cultural context that was necessary for the WUSA to establish itself.

All eight individuals described the 1999 Women's World Cup as a key CME that led to the creation of the WUSA. Shanna elaborated even more to highlight the final game where the United States defeated China in the Rose Bowl Stadium on the famous goal by Brandi Chastain in the shoot out, "especially in the final when I saw-oh my gosh! It was-I think everything changed..." The 1999 Women's World Cup Final held throughout the United States in the summer of 1999 is commonly thought of as the catalyst for sparking interest in establishing the WUSA; however, as evidenced by the interviewees, it was the final piece of the puzzle in showcasing women's soccer and allowing individuals and businesses to believe the United States was ready for a professional women's soccer league.

While the 1999 Women's World Cup was one of the first CMEs mentioned by all of the eight WUSA leaders interviewed, all eight individuals also mentioned some level of significance of the 1996 Olympic Games. "It was another step, bigger than most," said Mia Hamm of the first women's soccer Olympic debut. "Maybe it will help start a league, give girls who want to play soccer something to look forward to" (Becker, 1996, p. 12C). In an event that showcased the success of female athletes in the United States as the 
women's soccer, basketball and softball teams captured gold in addition to numerous other individual female athletes. "It's a real watershed for women's athletics," said Schultz. And I'm hoping it will help move women's sports to the next level," (Becker, 1996, p. 12C). Theresa Michaels elaborated as she listed the Olympic Games as one of the main events that led to the creation of the WUSA when asked, "the 1996 Olympics for sure, where the Olympics were in your backyard...the Atlanta Games were the Olympics of the women." She elaborated to describe them as "the seed planted." The success of the women's teams at the 1996 Games also highlighted the importance and signaled victory of Title IX. "You're seeing the first generation of women who've had a lifetime opportunity to play," said Women's Sports Foundation executive director, Donna Lopiano. What you see is the female athlete as a rule, not the exception" (Becker, 1996, p. 12C).

Two of the interviewees, Kaley Baker and Margot MacMillan, named Title IX as the initial CME leading to the eventual creation of the WUSA almost 30 years later. "It was Title IX. It was getting girls involved in sports," said Kaley Baker as her immediate response when asked, "What events do you think led to the creation of the WUSA?" Margo MacMillan also mentioned Title IX in two parts: (a) "you could obviously look to Title IX" when asked about events that led to the creation of the WUSA and (b) "Title IX is the cool thing that has helped to create the base of athletes" in elaborating on the events that led to the creation of the WUSA.

Although all eight interviewees highlighted the importance of the 1999 Women's World Cup and it being held on United States' soil with such fanfare as the primary event leading to the creation of the WUSA, over half of them also mentioned the 1996 Olympic 
Games, also held on U.S. soil, as laying a significant piece of the foundation and showcasing that society could support women athletes in large numbers. Additionally, two individuals mentioned the importance of Title IX in laying the foundation of creating athletes able to support a league as well as opportunity for them to play. These CMEs intertwined greatly with setting up the social and cultural context allowing the WUSA to get off its feet. The CMEs highlighted by the eight interviewees played a pivotal role in the next factor discussed, leadership. Many of these interviewees were direct products of leadership opportunities initially established by Title IX and these events also led the early leaders of the WUSA to believe in the ability of the WUSA to be a successful venture.

Leadership. In examining the factor of leadership, three key themes arose. First and foremost was the role of the founding players (i.e., the U.S. Women's National Team) in creating the product. Second, another leader, John Hendricks, saw the potential to establish a league for women's soccer. Third, the league and team leadership were also brought up by many of the interviewees as both positive and negative factors contributing to the rise and fall of the WUSA.

Founding players. All eight interviewees mentioned the founding players as being the key leaders of the WUSA both prior to its inception and throughout its 3-year existence. The founding players were unique to professional sports in that they not only worked together to allocate themselves to the eight franchises, but they had an actual ownership stake in the league and a voice on the Board of Governors. These twenty individuals, usually through the voice of their player representative or her backup, had a place at the table in establishing how the things such as league operations, salaries, and 
key hires, both at the league and individual team level. Not only did these founding players lead off the field, they were looked to lead on the field as captains of their teams and key members of the outreach team both in their communities and on the road.

More so than just the organizational leadership they provided, this group of women were viewed by outsiders as leaders of the women's sports movement, while also as a truly unique and amazing group of women. All eight interviewees described the hold this group had and the role these women played in creating the WUSA, though the founding players definitely downplayed it. "I don't think it would have worked with just any group of players. I mean, you've met them and they were perfectly positioned to take advantage of this in a way...They didn't take anything for granted. They had no sense of entitlement...and they just had fun, smart personalities," described Baker. MacMillan explained how the core group of founding players also took on the "weight and responsibility for the success [of women's soccer]" preceding the Women's World Cup when they went on strike to guarantee equitable treatment to the men's national team, it "was a very strong move to professionalize." Their political involvement with U.S. Soccer and the clout they carried enabled and prepared them to play a significant role in the creation of the WUSA.

All of the interviewees understood the importance of the founding players in establishing the WUSA; however, outsiders also understood how pivotal this group of women was in making the WUSA a reality. "Yet no one denies the WUSA's driving force: The U.S. players who won the Women's World Cup - and the nation's collective heart—in 1999," wrote Weiner (2001, p. 1C). Individual players such as Mia Hamm, Julie Foudy, and Carla Overbeck were singled out as being leaders on this quest and 
being unlike most others in professional sport prior as they pushed one another and demanded fair and equitable salaries and benefits for all players (Brewington, 2000e Weiner, 2001).

John Hendricks. Joining the founding players, John Hendricks, or "Saint John," as the founding players group preferred to call him, established the WUSA. Hendricks had a vision following the Women's World Cup that he hoped could help with the various programming needs of the cable networks he was connected with. "I was intoxicated by what I witnessed in the 1999 World Cup and all the sponsorship surrounding that event..." Hendricks said (Longman, 2003, p. 314). In her interview, Churchill described Hendricks as someone "who was really passionate about it [the WUSA/women's soccer] and had a lot of influence and knew a lot of people who also could...make an impact", and was credited by Frazier as "the one who spearheaded it all and really made it happen." Five of the eight interviewees highlighted his leadership as being paramount to establishing the WUSA and this group included both of the general managers, Margaret Barnstable and Kaley Baker, as well as the coach/assistant general manager Margot MacMillan, and two of the three founding players in Jenny Frazier and Brittany Churchill. MacMillan explained how integral the support of John Hendricks was in establishing the WUSA, describing him as "somebody who had a deep belief and was willing to take the lead." She proceeded to explain how he led the charge in establishing the league in its early stages, saying "all of the initial owners were cable companies... he had strong role not just in buying his own team but gathering in those resources. That was huge." Frazier elaborated, "John was willing to take a chance and sent on a proposal to a lot the fellow cable operators." All of the initial investors were brought together 
through Hendricks' numerous contacts in the cable television industry, enabling the league to have connections to television viewers from the initial start of the WUSA (Longman, 2000).

On February 15, 2000, John Hendricks announced over $\$ 40$ million had been secured for the WUSA. Through his multiple contacts in the cable industry, Hendricks had done what many thought was impossible-securing such a significant amount of money in a short period of time. Additionally, Hendricks secured commitments from all players on the World Cup Champion team to play for his league, the WUSA, putting a damper on a proposal being thrown about by the MLS (Brewington, 2000c, 2000d). "We have put all the fundamentals together. We cannot imagine anyone trying to stop our progress," said Hendricks" (Brewington, 2000c, p. 16C). The entrepreneurial spirit and leadership of Hendricks was pivotal in getting the WUSA up and running.

Churchill described the players and John Hendricks as "those two things kind of colliding at the same time together with the same feelings and wanting to go in the same direction," when asked about what played the biggest role in establishing the WUSA. The leadership of the founding players and John Hendricks teamed together to create the WUSA and announce its inception in the spring of 2000 , before kicking off the league in the spring of 2001 .

Once the league kicked off, Hendricks continued to play a major role in the WUSA organization, however his main focus was on the team he was most invested in, the Washington Freedom. A few of the WUSA leaders (players and rival team administrators) perceived that the Freedom was able to utilize his deep pockets, where other teams did not have as beneficial of a relationship. 
The dynamic leadership of the founding players and Hendricks were thought of as major strengths of the WUSA. A strength described by over half of the WUSA leaders also involved the leadership of the individual teams as well as the some individuals at the league level: however it was also described as a weakness, which will be discussed in the examination of why the WUSA failed. The third theme of leadership, the leadership of the teams and the league will be examined under the administrative structure heading. This dynamic leadership group of the founding players and John Hendricks was able to forge relationships with like-minded organizations as well as gain access to political elites enabling the WUSA to have momentum as it kicked off in 2001.

Like-minded organizations and access to political elites. Working with likeminded organizations and access to political elites are two additional factors associated with social movement theory that can also be linked when examining the WUSA as a social movement organization. All interviewees answered questions about any cooperation and/or collaboration with like-minded organizations or leaders that could be deemed political elites or leaders in outside organizations. The examination of these factors intertwined throughout the interviews and overlapped as well.

Like-minded organizations that were discussed primarily included youth soccer organizations at the local level, Major League Soccer (MLS), U.S. Soccer, and the WNBA. The Women's Sports Foundation (n.d.) was also mentioned and crossed lines as both a political elite and a like-minded organization, especially when put in the light with many of its key members such as Billie Jean King. Additionally, virtually all of the interviewees discussed the role of sponsors in the league. These corporate sponsors encompassed both like-minded organizations in that many of the companies supported 
and believed in what the WUSA was doing and stood for as well as being political elites of sorts as they had access to various groups, media, and most important, money.

Half of the interviewees mentioned the lack of cooperation with the other soccer organizations. This includes the relationship between the National Governing Body (NGB) of soccer in the United States, U.S. Soccer, and the WUSA. All of the founding players mentioned similar issues with U.S. Soccer throughout the process of trying to establish the WUSA, possibly because of the tumultuous history between the founding players and U.S. Soccer. For example, the women's team went on strike in the 1990s in a successful effort to gain greater financial support, more in line with their men's counterpart.

U.S. Soccer was an integral component in establishing the MLS and once the women said they wanted their own league separate from the MLS, U.S. Soccer in essence seemed to turn its back on the idea of a league for the women. While none of the interviewees discussed the tumultuous relationship with U.S. Soccer in great detail, the founding players and two of the general managers mentioned it in passing and the disappointment they felt not having strong support for the sanctioning body of soccer in the United States. As Baker explained,

There was a whole rift during that formation period where the players basically publically announced they would not play for an MLS owned league, and I think U.S. Soccer was frustrated by that...that process wasn't easy and we didn't get as much support as we hoped for, and I don't think that relationship ever really healed between U.S. Soccer and the WUSA. 
This statement illustrated the rift that occurred early on in establishing the league and the effects that lingered throughout the 3 years of league operation. The tumultuous early relationship between the MLS and WUSA stemmed in large part from the desire for the WUSA to be the league sanctioned by U.S. Soccer. For a brief period of time, MLS discussed establishing a sister league similar to the relationship between the NBA and WNBA. Eventually MLS agreed not to submit a rival league to U.S. Soccer as the WUSA made concessions and the two leagues also made plans to work together. "This is mutually beneficial,' said WUSA founder John Hendricks, head of Discovery Communications" (Brewington, 2000d, p. 13C). Even though the two leagues and U.S. Soccer were saying the right things and promoting a healthy, mutually beneficial relationship, tensions between the WUSA and both U.S. Soccer and the MLS continued throughout the existence of the WUSA (Berkowitz, 2003; Brewington, 2000b, 2000d). The rift between U.S. Soccer and the MLS with the WUSA was best explained by Churchill:

What do you call that when there's a conflict of interest, because U.S. Soccer really had a big stake in the MLS and not really in us and I think that people saw that, you know, I think the players recognized that. I don't think there was as much of an interest in us doing well as the MLS doing well.

The lack of a trusting relationship between U.S. Soccer and the WUSA was seen as having at least a minor role in the difficulty the WUSA had gaining a foothold in the American sports market, specifically the soccer market.

Playing off the thought from Churchill leads into examining the more direct relationship between the men's professional soccer league in the United States, the MLS, 
with the WUSA and the individual teams. This relationship was disheartening to most of the interviewees as well. The fact that the individual who created the initial WUSA business plan took a leave of absence from the MLS and guided the WUSA leadership group to use an ill-conceived business plan, highlighted many of the problems that would permeate the relationship between the WUSA and MLS. While the interviewees spoke very little about the individual who created the business plan for the WUSA, one explained that he was suggested by MLS and US Soccer personnel and had played a role in the formation of the initial MLS business plan. Why an individual from the MLS was used was not elaborated on by the interviewee with the most information, however, it can be inferred it was someone that the WUSA leaders felt confident would have the best interest of the future league in mind.

Additionally, the relationships between the WUSA and MLS were highlighted in specific markets where there were deemed to be "competing" franchises as two WUSA teams shared facilities with MLS teams, the Washington Freedom (shared with DC United) and the San Jose CyberRays (shared with San Jose EarthQuakes), and another two teams, the New York Power and Boston Breakers shared markets. Little bestpractice sharing and collaboration appeared to take place at the league level. The two teams sharing markets with the MLS seemed to view the WUSA as competition according to Frazier, "I think on both sides you just see each other as competition rather than trying to build the sport together...I don't think they [the MLS] were thrilled when we [the WUSA] were successful." This sentiment was echoed by the majority of the interviewees, most notably those whose teams shared facilities directly with an MLS team. 
Additionally, in the two cities where facilities were shared the relationship seemed even less than cordial at times, as indicated by the league personnel working in those two facilities. Kramer described the relationship her organization had with its MLS counterpart when sharing a stadium:

There's also a hierarchy I think in the world of soccer. The men's game is more important, and so the MLS team sets their dates first...we're piggybacking off somebody else's institution and so all the dates are secondary to us.

The relationship in Washington was better than the one in San Jose; however, it was far from great throughout the cycle of the WUSA: "We got off to a little bit of a rough start... but gradually it became more collaborative, with some exception," stated Baker.

In the first year of the league only the Washington Freedom combined with its MLS counterpart (DC United) to host doubleheaders. The two doubleheaders held at RFK Stadium significantly increased the attendance for both teams and were deemed a success by media outlets. A rift still seemed to exist between the two leagues, most notably when the Freedom insisted on announcing a separate attendance figure from DC United. This created some initial friction but the two teams were able to move forward toward a second doubleheader in the first year, "WWe worked out those kinks and there aren't any animosities,' DiCicco said" (Lawlor, 2000, p. 8C). Based on the success of the doubleheaders in the first year in DC, other cities (Boston and San Jose) followed suit in the 2002 and 2003 seasons. While the relationship between the MLS and WUSA was strained, the WUSA did forge positive relationships with other sport organizations, while continuing to work on improving its relationship with the MLS. 
The relationship with two other sport organizations was mentioned by multiple interviewees as well and included minor collaboration with the Women's National Basketball Association (WNBA) as well as with youth soccer in the individual markets. The players interviewed all talked about being involved in their communities with clinics, camps, and appearances, many associated with youth soccer; however, local soccer politics played into the level of support and the ability to maintain continuity between the WUSA and the organizations throughout its 3-year cycle according to two of the general managers.

The three founding players, Churchill, Frazier, and Michaels mentioned the support they felt from various women's organizations, highlighted by the Women's Sports Foundation (WSF). The support of the WSF was a combination of working with like-minded organization as well as working with political elites, as the WSF plays an active role in the politics of supporting opportunities for women and girls to participate in athletics at all levels. Jenny Frazier, served as a Board Member of the WSF from 20002002 and continued to stay involved with the organization in a formal capacity until 2006, while continuing to work with them on a more informal basis. Her relationship with the organization certainly helped them play a role in the early support of the WUSA: “Women's Sports Foundation supported...I think Billie Jean King at the Women's Sports Foundation, and Donna Lopiano, Donna de Varona...was very helpful," said Frazier. Churchill elaborated "Billie Jean King was a huge, huge, huge help for us... whether it was you know, just like kind of giving us encouragement or giving us advice as to you know, how do you attack these kinds of problems...I think the Women's Sports 
Foundation was very, you know, "What can I do to help you [the WUSA -players and league]?"

Two of the teams led by female general managers also managed to create a positive relationship with various women's organizations in their communities-not exclusively those in the sports realm. In one of the Mid-Atlantic teams, the organization and its general manager were able to establish a positive relationship with the Women's Bar Association, and in one of the West Coast markets, the general manager worked tirelessly to network with a number of female political leaders and nonprofit organizations. The founding players also described a feeling of support from female political groups throughout the process; however, they were usually not front and center and vocal in their support. Michaels spoke extremely positively of the support she felt from women's organizations: "I just think a lot of women's organizations were definitely onboard, making sure, you know, politically, we are taken care of." The other founding players interviewed shared similar sentiments.

The group of like-minded organizations that fits into the category of political elites and that got the interviewees the most excited and passionate throughout the interview was the corporate sponsors. The sponsors that came on board with the WUSA at both the national and local level all appeared to feel connected to the WUSA and wanted to be associated with the image of the league, teams, and players. The players praised the support of the sponsors, as did the league personnel interviewed in this study. Three interviewees, one GM, one asst GM/coach, and one of the founding players, felt very strongly about the support of some of the sponsors. Baker said, 
We had fantastic sponsors and they were committed, and I think they were in this mission. Oriented as we were... it actually bugged me a little bit at the end when the league folded that all the blame fell to the sponsors because actually their responsibility isn't to be mission-driven.

She elaborated in her rave review of the sponsorships. MacMillan spoke of the sponsorships with the WUSA team she worked for, "corporate partnerships were very good, so the sponsorship was very good to begin with...there was a corporate interest." Frazier also agreed, "I think generally the sponsors and everyone were very supportive." While the overall feeling was positive in regards to the political elites (corporate sponsors), a problem was there were not enough and gaining more support from sponsors as the league began to flounder would not happen as there appeared to be too much competition for the money and the fans.

When the league announced it was closing its doors on September 15, 2003, on the eve of the Women's World Cup, players, staff, and fans were stunned and disappointed. It came out that the league was in significant debt and even to stay open through the World Cup would have cost too much. The league cited multiple reasons for its failure, though John Hendricks blamed the $\$ 90$ million dollar loss on the lack of a large corporate sponsorship. The league leadership held out hope in the months following the league closing its doors as interest seemed to come and go from potential sponsors; however, it was not enough (Michaelis, 2003; Whiteside, 2003a, 2003b).

Competition for organizational space and acquiring resources and support. One of the many difficulties in establishing a successful SMO is competing with other likeminded or similarly situated organizations and competing for resources and financial 
support. This included sponsorship dollars and, in the case of a sport team, viewership and attendance figures. The WUSA was no different as one reason the interviewees gave for the lack of cooperation with like-minded organizations was because many of the organizations felt they were in direct competition with the WUSA. Most notably mentioned by the majority of the interviewees was the perceived competition between the MLS and the WUSA: "You're fighting for your life basically... you want your league to do well," (Churchill in describing the relationship between the MLS and the WUSA). Barnstable described the MLS team in the market of the WUSA team she oversaw by saying they "were protective of their market...they were territorial." The protection of the MLS markets by the league and teams hindered the growth of those WUSA teams competing with the already more-established league and teams instead of aiding in the growth of professional soccer, an assumption made by the WUSA initially. Similarly the WUSA looked to gain the financial support of U.S. Soccer, similar to support it provided to the MLS. The final plea by the WUSA in August of 2003 was not accepted by U.S. Soccer as it chose to focus its resources on MLS and the Women's World Cup kicking off on U.S. soil the following month (Berkowitz, 2003).

Additionally, looking at the factor of acquiring resources and support intertwines considerably with competition for organizational space, most notably, the competition with other soccer organizations and other women's sports leagues for sponsorship dollars and viewership/attendance. Many of the leaders explained that frequently soccer organizations allocate a set dollar amount for tickets or games and that when the WUSA entered MLS marketplaces, both leagues got smaller amounts. Kramer spoke of the perceived thoughts of the MLS towards the addition of women's professional soccer: 
They [the MLS] totally saw that and knew that they're sharing dollars now with somebody else and they don't like that because they have less of an opportunity to make money. Even if the impact is small, it's still an impact on them.

Other administrators in the league also mentioned similar stories of having to divide an allotted amount of money between a variety of soccer experiences, primarily from local youth programs.

While most of the interviewees also spoke very favorably about the support of the WUSA sponsors, trouble came from not being able to acquire adequate sponsorships to help keep the league financially solvent. Because of the crowded sport landscape in the United States and the limited public support of women's sports in particular, sponsors were wary of getting on board with a league lacking significant attendance at games and more importantly ratings on television. Viewership, or "eyeballs" as described by Frazier, was never as high as most sponsors would require if they were to work with the WUSA. The WUSA leaders understood the necessity of filling seats, selling tickets, and gaining television ratings in order to gain additional sponsorships. However it was a reciprocal relationship as the WUSA needed the sponsorship money to bring in a greater audience in the way the organization began (from top up, as opposed to a more organic and grassroots bottom-up philosophy). Barnstable spoke heavily of the "top-up" mentality of the early WUSA decision makers, meaning that the league started and thought big, as opposed to starting smaller and using grass roots marketing to build up a fan base, which she thought would have made the league more sustainable in the long term. This thought was echoed by other interviewees when discussing the issues with the league leadership and administration. 
Administrative structure. Administrative structure was a constant source of concern throughout the cycle of the WUSA. In its infancy, the WUSA was based out of John Hendrick's Discovery Communications in Washington, DC; however, once the league formally launched, its base of operations was located to New York City in an attempt to formally announce its place in the sports market. The WUSA league offices were housed in Manhattan leading in to the first season of the league, before choosing to move to a more affordable market at the conclusion of the first season. The decision to base the league office out of New York City was viewed as detrimental to the longevity of the WUSA by Churchill, as it was not perceived as a financially savvy maneuver:

When you're spending money to be in New York City with your head office, I think that's just a bad move for a small league, you know you don't have to. You have to probably have had your feet wet... so that obviously was the downfall of all.

The league moved its base of operations for the 2002 and 2003 seasons to Atlanta, Georgia and was housed in the offices of the Cox Corporation, an investor in two of the league's teams, which provided a great amount of infrastructure to the fledgling league while simultaneously keeping operating costs down.

The decision to be headquartered in New York City made many question the financial responsibility of league personnel in its infancy. Michaels was particularly critical of it, "I think when you're not on budget that's a management issue," when explaining that the WUSA went through the majority of its allotted funds for a 5 -year period in its first year. Frazier elaborated "I think our business plan of course was incomplete as we were spending much more than we anticipated." The founding players 
were very attuned to what was going on at the league and team levels and grew more and more frustrated with the lack of fiscal responsibility by those they were entrusting with their dream of a professional women's soccer league.

Once the league moved to a new headquarters in Atlanta complete with a new CEO, formerly the GM of the Atlanta Beat, the administrative structure was questioned even more as many of the key league personnel were still located in the Northeast corridor, creating a less cohesive group of leaders at the highest level. Promoting an individual from one team to the highest post also created some dissent and initial distrust not only with the structure of the league, but with the league leadership. The founding players and general managers spoke candidly about the degrading relationship between the players and the league. "I think the bigger issue was more of the players with the league officers and just some, I think, soured" Frazier said. General managers, Barnstable and Baker, both also spoke of the growing distrust that existed between the league and the players, especially following the league office move to Atlanta and the change at the top to a new President and CEO, the former General Manager from the Atlanta Beat. In discussing the numerous changes the league went through in the 3 -year cycle Barnstable stated "Those kinds of things really kind of - they just destroy the relationship." The simple statement encompassed the thoughts expressed by many of the interviewees when discussing the diminished trust between the league and its players and teams.

Summary. Many of the factors associated with social movement theory and more specifically the success and failures of social movements and social movement organizations were discussed by the eight interviewees when asked about their thoughts 
and experiences with the WUSA and their teams. The thoughts of the interviewees clearly establish the WUSA as a social movement organization within the women's movement as many of the themes the interviewees broached can fall into the factors touched on previously that define a SMO.

Virtually all of the interviews spoke about the events that led up to the idea and eventual formation of the WUSA. The critical mobilizing event (CME) that all eight individuals mentioned was the 1999 Women's World Cup. They knew this event showcased the team (Team USA) and the sport and it was necessary for the league and its investors to believe in the ability of the league to succeed financially. Many of the interviewees also spoke of earlier events such as the passage of Title IX and the 1996 Olympic Games as laying the foundation for both the ultimate CME (the 1999 Women's World Cup) and the creation of the WUSA.

The leadership that was displayed in establishing the WUSA was also paramount to the league getting off the ground. The founding players were credited by all of the interviewees as being the major force in making the WUSA a reality, along with John Hendricks and his vision. This leadership was necessary for any organization to get up and running; however, in the case of the WUSA and other SMOs, it is the dynamic and charismatic leadership necessary to create the organization.

Cooperation with like-minded organizations and specific access to political elites who frequently work with prior established organizations were highlighted in the interviews. The two most frequently mentioned like-minded organizations throughout the eight interviews were U.S. Soccer and Major League Soccer. Unfortunately a lack of cooperation with these two, well-established organizations was the prevalent theme. 
While the relationship with many of the soccer entities seems strained at times, the WUSA did feel support from other women's organizations, especially the Women Sports Foundation, as well as lesser support from the WNBA and also local women's groups.

Competition for organizational space and acquiring resources and support tie in well with the prior factors and themes as one reason over half of the interviewees explained that they did not get better cooperation from U.S. Soccer and MLS. Both organizations seemed to feel as though they had to compete with the WUSA and if the WUSA was able to sustain itself it would be to the detriment to the MLS or U.S. Soccer as a whole. Additionally, due to the economic climate, resources such as sponsor dollars and television time were scarcer than even in 1999 and 2000 when the idea for the WUSA really took shape.

Administrative structure is also a common factor examined when establishing a SMO and many of the interviewees mentioned two areas of concern. The first concern related to the initial decision to be based out of Manhattan, the most expensive marketplace. The second was the move to Atlanta and basically into the offices of one of the current teams. This move meant many of those team leaders had to transition to becoming league leaders. This lack of stability in the administrative structure mirrored many SMOs in their infancies as well.

\section{RQ 1: How Was the WUSA Founded?}

All eight interviewees spoke of the 1999 Women's World Cup team and the roles of the team members in creating and establishing a league and most others also spoke of the role that founder John Hendricks played in ensuring the WUSA would come to fruition. While this theme relates back to the critical mobilizing event and leadership 
factors associated with social movement theory and was touched on previously in this chapter, both points are elaborated on in answering the first research question of "How was the WUSA founded?

The three founding players were the only three of the eight individuals interviewed here that could discuss with significant knowledge how the WUSA was founded. This was because the five other individuals interviewed were all hired and integrated into the league following the creation of the WUSA, while the three founding players interviewed were involved in its creation to varying degrees. One of the general managers was able to touch on this research question as she was hired early on in the creation of the WUSA and had close ties in with John Hendricks throughout the infancy of the league.

The founding players who were interviewed were particularly passionate about the role they played in bringing attention to women's soccer. Michaels spoke of the timing of establishing the league and the integral role she and her teammates played: "I think that's the biggest thing for us was trying to take advantage of what the National Team had created in terms of the fervor and the fanship and the fan base." She elaborated on her point explaining how the WUSA needed to

take those names and the players from that team and create something that was a little bit diluted in the sense that they were going to be on different teams, but at the same time, to try to carry that over so that the league can be very successful. Michaels was not the only one to share thoughts that the how key the specific members 1999 World Cup team were in establishing the WUSA, engendering tremendous fan support and marketing power. 
Churchill spoke in depth about the role the founding players played with John Hendricks in establishing the WUSA:

These two forces of this really great team like these founding players existed and the general public got to see them so they had this kind of spotlight...and then you had someone like John Hendricks who was really passionate about it.

As she wrapped up her thoughts about how the WUSA was founded, "Those two things kind of colliding at the same time with the same feelings and wanting to go in the same direction was helpful." Churchill nicely tied the relationship between John Hendricks and the founding players together in establishing the WUSA in 2000.

Jenny Frazier was one of the founding players most tied in to the establishment of the league. She, along with Carla Overbeck and a handful of others, played a pivotal role in the early stages of establishing the league. In her discussion of how the WUSA actually came to be, Frazier said,

We started talking with John about the creation of the league and we weren't making much progress in other areas in terms of like WMLS or something like that...John was willing to take a chance and sent out a proposal.

Additionally, Frazier was able to touch on the role the players continued to play after Hendricks proposal was accepted by numerous cable operators through his prior relationships in the field. These cable operators, such as Time Warner, Cox, and Comcast, along with Hendricks and the founding players moved forward in establishing the WUSA, "We had helped create it and the players had a voice and information and how it was structured..." Not only did the founding players create a product which cable operators saw as having potential in the 1999 Women's World Cup, they played a pivotal 
role throughout the process of getting the league up and running. They made sure they, the players, had a voice through their ownership stake in the league and were integral in getting the league up and running.

Kaley Baker discussed some of the logistics that went into how the WUSA made it to the inaugural game on April 28, 2001, as one of the first members of the front office staff to be hired. In the early days, prior even to the official announcement of the WUSA kick-off, Baker was able to work with Hendricks and COO Tony DiCicco as the WUSA applied to U.S. Soccer for "official sanctioning as a league." The application process was described by Baker as a " 200 page application to U.S. Soccer...It would be like 25 appendices of the business plan." The process of establishing the WUSA as the sanctioned professional women's soccer league by U.S. Soccer was a tedious one, with the ultimate goal to make sure the league was solvent and able to sustain itself for the future.

Barnstable and Baker were also able to break down the WUSA to the individual team level and explain how specific teams were able to become reality from the time they were hired and given their individual charge. Baker had a head start over Barnstable as she was in place before the league was even announced, while Barnstable was the last general manager hired. Getting one of the West Coast organizations up and running was a virtual game of catch up as it was also the only team created in a dual ownership, without having any sort of infrastructure readily available to Barnstable and her soon to be employees: "We were the only team in the league that had no built-in infrastructure through the investors." She went on to describe what she had to rally her troops to do in 
order to create her West Coast team for its first game "so now we had to build the entire business from scratch," and the challenges in doing so.

Answering the question of how the WUSA was founded was best answered by the founding players as they were the most involved in the process in conjunction with John Hendricks.As the vocal leader of the founding players and as a member of the Board of Governors, Jenny Frazier was most equipped to shed light on its creation. In conjunction with the other interviewees, she highlighted the 1999 Women's World Cup as the pivotal event (critical mobilizing event - CME) that led them to a relationship with John Hendricks, a visionary who wanted to see women's professional soccer league and had the connections and wherewithal to make it happen.

\section{RQ 2: Why Was the WUSA Founded?}

All eight of the individuals interviewed spoke about why the WUSA was founded. The "how" part of this question examines more specifically what transpired in establishing the WUSA, whereas this second research question, "why" was the WUSA founded, is able to examine it more broadly. In examining why the WUSA was founded though the answers from the interviewees provided a spectrum of answers and touched on themes larger than just simple answers, looking more broadly at social and cultural contexts, again falling into the factors of social movement theory.

Brittany Churchill was articulate in answering why the WUSA was able to come to fruition and the role the players played in establishing the league,

The players have the wonderful responsibility of being both players and ambassadors for the league as well as marketers and PR...I think the hats are, you know, you take one off, you put the other one on...there's still responsibility. 
Kramer elaborated on Churchill's thoughts by highlighting the power wielded by the founding players:

You had some of the core players from that team [1999 Women's World Cup Champions] that found the league and they were the best. They were the best voices for the league and the best representatives of the league...they had some popularity already going into it.

These founding players played a unique role in establishing the WUSA as the team had gained popularity and endeared themselves to the country en route to the Women's World Cup trophy. These women were seen as more than just soccer players and embraced the role and the opportunities that came their way, highlighted by getting their own, wholly professional, women's soccer league.

A number of the interviewees spoke about the idea of a premier women's professional soccer league being their dream and ultimate goal, especially in light of the MLS establishing itself in the sport marketplace shortly following the 1994 World Cup held throughout the United States. Frazier stated, "We had always wanted the league of course." Shanna described being at the 1999 Women's World Cup and seeing for the first time the potential to have a professional women's soccer league in the United States. Everyone who saw what was happening knew international players would be important and Shanna saw that as well, "We're going to have a chance to be involved...yeah, this is going to happen...I couldn't believe because this was a dream come true." The perceptions of the international players in the WUSA were different throughout the course of the league's existence, but one theme remained the same - the creation of the WUSA was a dream that became a reality. 
Interviewees spoke about the passion felt by numerous individuals who could help a fledgling league take off. Focusing that passion helped the WUSA leaders able to get the league up and running. "I think just the overall care that people, you know, how they cared about the players and the staff and the volunteers. I just really think that the people really, really cared about it" (Churchill). Frazier elaborated on Churchill's thoughts, " There are some tremendous people involved...I mean just really unique people that love women's soccer and wanted it to be successful and their intentions were great." The work ethic and determination of the players and front office staffs key to the league even being able to last three years.

The views of these two founding players were substantiated by members of the various front office staffs. Baker spoke glowingly of the role all team employees had on establishing the league, "I think the strengths were the players, the commitment of most of the staff." She, Barnstable, and Kramer spoke about the work that went into getting the league and various teams up and running, including the tireless effort of the players, both on and off the field, as well as the often overlooked front office staff in each of the teams they led. "The people working in it [the WUSA] were very passionate about soccer and particularly women's soccer and women's sports and so you were able to get a lot done with little," Kramer reiterated the passion that seemed almost commonplace in the front office staffs of the eight teams in the WUSA.

The question, why was the WUSA founded, tied in greatly with the how it was founded and simply elaborates more on the cultural and social context and how it actually came to fruition once the idea of the league had been created and established. The leadership and passion of the players and team staff was highlighted as why the WUSA 
was able to get off the ground and why it was able to exist for the three seasons. Most notably, in answering the question of why the WUSA was founded, the interviewees spoke of the time being right and numerous individuals ready to help make the WUSA a reality.

\section{RQ 3: Why Did the WUSA Fail?}

All eight interviewees had a variety of thoughts in reflecting on why the WUSA failed after only three seasons. Five primary themes arose throughout the interviews in regards to what led to the cessation of the WUSA. First and foremost was the discussion of the inadequate business plan or the business model. This is one of the most common reasons given for the failure of the league and while it is certainly a major reason the league failed, it cannot be seen as the sole cause for the league's demise. The second theme that arose and was discussed in regards to why the league failed was that of leadership. This focused primarily on a lack of trust between the league leadership and the individual teams, and more specifically the diminishing relationship between the league leadership and the players. Additionally, a lack of professional sport experience by many of the league and team front office staffs was mentioned by over half of the interviewees as detrimental to operation of the WUSA. A third theme discussed in regards to why the league failed was the lack of acceptance and support of women's athletics, particularly in regards to women's team sports. The fourth theme that appeared throughout the interviews was the idea of the WUSA as a philanthropic organization and its lack of a well-defined identity of its place in the sports marketplace. This lack of a well-defined identity and trying to fall somewhere in between a professional sport league and a nonprofit with a mission of increasing opportunities for women was mentioned in 
over half of the interviews as a potential downfall to the league. Finally, the fifth theme was an inevitable feeling that the league was going to fail from its first season. Virtually all eight interviewees spoke of changes and cuts made from year-to-year and the way those actions influenced the thoughts both inside and outside the organization that the WUSA would fail in the near future. These were the five most prevalent themes throughout the eight interviews when examining why the WUSA was forced to suspend its operations only three seasons after its inaugural kick-off. Each will be elaborated on below.

Business plan. First and foremost the business plan of the WUSA has been critiqued as what doomed the WUSA before it even played its first game (Chapin, 2000; Stossel, 2001). Virtually every individual interviewed spoke of the business plan or business model and its many flaws and how that contributed to the decline of the WUSA. Kaley Baker clearly articulated her perception of the business plan when she was brought onboard,

It was fundamentally flawed...the business plan assumed that the owners would basically house the teams and the team offices, so there was no start-up expenses at all in the business plan...It became clear halfway through the first year that there was absolutely no way we're going to meet that business plan because, again, you can't start something for nothing...that anyone who would be involved in the MLS would have thought that was a realistic business plan is unbelievable. Jenny Frazier was simplistic in her approach to the initial business plan, "We were naïve...our business plan was incomplete in terms of we were spending much more than we anticipated." Frazier went on to critique part of the plan and explained "we 
needed better business model in terms of control of what the GMs were doing and spending at different rates and doing things they didn't need to do and could have been done more efficiently." The lack of a complete business plan, one that took into account all the necessary information before establishing a well-conceived plan, was looked at as a primary reason the WUSA was unable to continue into a fourth season according to those WUSA leaders interviewed.

In numerous newspaper articles, league and team leaders discussed the business plan. Many of them stressed the league hit the targeted attendance goals; however a lack of national sponsors led to the league running through its initial $\$ 40$ million investment, an investment that was supposed to last at least 5 years. While the business plan was designed to not break even for the first 4 to 6 years, it did not account for all of the initial start-up costs and the league leadership was unable to make the necessary adjustments to stay on track (Straus, 2003; Weiner, 2001).

Leadership. The issues with leadership were varied and according to the majority of the interviewees, played a key role in the league's failure. While virtually all eight interviewees spoke glowingly of the leadership of John Hendricks and the founding players in making the WUSA a reality, the lack of professional sport experience of the front office staff at both the league and team level was mentioned as detrimental to the long-term success of the league (Albanese, 2010).

There were also criticisms from all of the interviewees who had multiple interactions with the leadership of key league-level personnel. Many of the interviewees spoke of a distrust that existed between the players and the league as well as from the individual teams to the league level. Furthermore, the interviewees spoke of an overall 
feeling of disrespect towards many WUSA leaders and the failure of these individuals to properly lead the WUSA to succeed:

I think that was a frustrating thing and there was some friction obviously with Lynne, the commissioner and her... what we felt was an unwillingness to make corresponding cuts at that level and have it out in the board meetings with her on the other owners about that, because we obviously wanted to get it right, I think that was unfortunate.

There was a continual distrust of league leaders by the players, highlighted by the pay-cuts the players kept taking, while many other league employees were not doing the same. The players felt as though they were under-appreciated which left negative feelings in their mind even years later.

\section{Lack of professional sport experience. The lack of professional sport} experience; by the majority of both the WUSA league and individual team staff; was mentioned as a hindrance to the WUSA by the majority of interviewees. Many of the individuals involved in ticket sales were newly trained and were not equipped to aid a new league in selling the product. MacMillan spoke about it, as she gained a greater perspective once she moved to the front office side from the sidelines, "We didn't put enough experienced ticket sales people in anywhere, like in our market we didn't actually have one, so the guy who directed ticket sales the first year or two was really a finance guy." She felt that this was just one instance of not having professionals in front offices and served as a major hindrance to the league being able to be successful.

Theresa Michaels spoke about the difficulty the lack of professional experience of virtually every employee in the league imposed on them all. 
With the infancy of it all...Where did these coaches and players and referees, where did they learn how to be a pro? Where did these general managers learn how to manage a pro sport environment, women's environment, with all of these challenges? Where did these coaches learn that they're at a higher level?

Churchill also saw a weakness of the league in the lack of leaders with specific soccer experience working in the front office, "Maybe not enough soccer people involved in the front office," when assessing what led to the failure of the WUSA. Kramer was concise when discussing the leadership of the WUSA: "It just wasn't the right people being put into the top spots." Additionally, many of the owners/investors in the WUSA had little experience on top of the front office employees having limited professional sport experience. Baker mentioned "none of these owners has been involved in sports before," and the lack experience at not only the office level, but at the ownership level as well, was a weakness of the league.

Lack of trust between parties. In regards to the growing tension between the players and the league, all of the founding players as well as the general managers interviewed expressed strong feelings about the way the relationship deteriorated throughout the 3-year cycle of the WUSA. Frazier spoke candidly about the deteriorating relationship and the frustration the players felt as they continued to sacrifice, but many times did not see other staff members do the same: "One of the low points was the players were asked to make cuts... You can't be paying a coach still $\$ 150,000$ and me getting now $\$ 60,000$. Are they coming to watch me or are they coming to watch the coach?" Churchill added, 
When you have to negotiate how much money you're going to give back to the league so the league can exist...you just knew that the end was coming and so no matter how much we gave up, it wasn't going to matter.

Churchill's thoughts seemed to sum up what many of the players in the WUSA felt as the end approached.

Baker attempted to account for the distrust that existed between the players and the WUSA:

There were just silly, silly things that ended up becoming disputes with the Players Association. I think they had been so conditioned to being taken advantage of by the Federation [U.S. Soccer] that they would come on too strong and I think sometimes the league would get overly protective of our revenue and our brands and not trusting the players...both sides came with a chip on their shoulders.

She felt the tumultuous relationship many of the founding players went through with U.S. Soccer may have contributed to the distrust they felt throughout the existence of the WUSA.

When looking at the relationship between the teams and the league office leadership, one senses a growing discontent and increased frustration each year."I thought that with the WUSA that the relationship, at least with our team, wasn't positive. There was a kind of disconnect," she continued, When you start questioning them, you lose faith in what they're doing and the minute you start losing faith, then anything they say to you, you stop listening...I 
think there was a lack of respect in a lot of ways from the league level to the team level and vice versa...

MacMillan had a slightly different experience, originally starting off with a southeastern WUSA team as a coach and then moving in to the front office and being thrust into a new role. She stated "I mean obviously the league leadership kept changing and that was difficult...I was frustrated at the league at the very end...it was difficult." This tumultuous relationship did not help the league survive and seems to have played a part in the failure of the WUSA at the end.

Lack of support for women's team sports. The third theme that arose throughout the interviews in regards to what led to the demise of the WUSA was the overall lack of support for women's team sports. While this theme has been written about in articles and books and covered in newspapers as well, the interviewees definitely viewed this as a contributing factor. While countless little girls play soccer and other team sports, their play does not translate into tickets sold in the stands and television ratings. Over half of the interviewees mentioned the lack of support for female athletes and women's sport teams as a reason the WUSA could not make it to a fourth season. "That's resistance of accepting women as being powerful athletes...you're trying to take away the credibility of a female athlete even to just say women's sports are not like men's sports," said Michaels when speaking about the resistance she felt during the 1999 Women's World Cup media frenzy and even to this day.

Probing into the resistance the interviewees felt society placed on women in team sports led to why the WUSA specifically chose to create a league separate and independent from the MLS. The founders felt it was important the league could control 
its destiny and never have to take the backseat to a primary entity or backer like many of the founding players felt the WNBA players had to do. "They didn't want to be like the second class citizens in an organization and that is why they wanted an independent league" Kaley Baker said in regards to not trying to piggy-back with the MLS and have to be a second class citizen, a sentiment that many of the interviewees felt the WNBA had to deal with in its relationship with the NBA.

While media coverage was scarce for soccer in general in the WUSA markets, getting fans in seats proved difficult as well. Churchill spoke passionately about the attendance issue: “

We have too many people playing soccer in this country, and then not come to the game...that's a flaw. When you have 250,000 girls playing soccer in Northern California and you have 6,500 people come to the game and you know only half of those are kids, you have to figure out why.

This seemed to be a question the WUSA continually struggled with throughout itsthree year existence as it was unable to tap into the youth soccer players market and have them fill seats in the stadiums.

Many journalists discussed the lack of popularity of women's team sports and the role that would play in the league's success. Articles continually discussed the low attendance figures as well as the dismal television ratings, yet many others talked about the power the founding players had during the summer of 1999 and the possibility that power would translate over to the WUSA (Brennan, 2001; Glier, 2002; Michaelis, 2003). Just as the 1999 Cup signaled an awakening to women's sports in this country, the WUSA's demise raises tough questions about whether women's sports can, in the 
wake of Title IX, attract not just a growing number of participants but a broadening base of spectators. (Michaelis, 2003, p. 1C)

The failure of the WUSA to gain a foothold into the sport landscape illustrates both how women's team sports are not able to gain a significant fan base and female athletes and soccer players are not translating into women's soccer fans.

League identification and message. A fourth theme leading to the failure of the WUSA that came to light in the interviews was the lack of an identification in how the WUSA branded itself throughout the cycle of the league. It seemed to many of the WUSA leaders interviewed indicated the league could not decide if it was a professional sport organization or if it was a goodwill or philanthropic organization promoting women's team sports. Both players and team leaders spoke of moving between both identities as they sold sponsorships, reached out to various fan bases, and made pleas to local and national media outlets for increased promotion and recognition.

"I mean we just didn't behave in some ways like a start-up and...we sold ourselves too much as a social cause and not with a lot of requisite good business practices," said MacMillan. Kramer spoke of trying to tap into the philanthropic desires of sponsors and investors:

The way we approach it is you have to find somebody in the organization that grew up, has a woman playing sports and gets it...you find that person who feels sorry for you or has some sort of compassion really and thinks of it as more of a goodwill gesture.

Frazier expanded on the idea of relying too much on the WUSA as a social cause or part of a larger social movement: 
I think the other thing was to a social movement point, I think we relied on that too much, why wouldn't you want to spend $\$ 500,000$ as a sponsor, look at these great role models...I think that was a very important part of it, but ultimately, at the end of the season, a sponsor had to say 'Okay, well how many eyeballs am I getting?

Comments like this reiterated the idea of a mixed identity for the league as it moved between social cause and professional sport organization.

Not only was there the external struggle 'about the mixed messages and identity the WUSA was striving when approaching sponsors and drawing fans, but there was also an internal struggle about the message the league was sending within the organization at times about its purpose. Many of the team and league personnel, including the players, did not seem to know what the purpose of the league was: to serve as role models and inspiration for young girls or to provide the best women's soccer in the world while also having the event atmosphere frequently associated with professional sport. This inner conflict created a struggle. Without a clear, cohesive internal message being sent internally, the league could in turn not send a clear message externally.

While the league was first and foremost the only wholly professional women's soccer league in the world with the best players from around the globe, the media seemed to be continually confused about how to write about the WUSA. Numerous articles spoke about the great on-field product and the new rivalries of former national team players as they suited up for different teams; however, many of these articles also spoke of the league in terms of the role models the WUSA were providing, something not 
typically mentioned in articles about men's professional sport leagues or games (Glier, 2002; Michaelis, 2003; Weiner, 2001; Whiteside, 2003c).

The idea of mixed messages about the league was prevalent as the WUSA continued to search for an identity throughout its existence. Each of the eight teams, as well as the league office had different messages as they sought sponsorships and partnerships at the national and local levels. Over half of the interviewees saw this as detrimental to the success of the WUSA. Some felt as though it made the organization seem less professional, while others simply thought it was confusing for all parties involved.

Inevitable failure. The final theme mentioned by over half of the interviewees in regards to why the WUSA failed after only 3 years was the evolution of the league and the continued sense that the WUSA was about to fail. The league started with a grand, 5year plan with all the bells and whistles and every year, even midway through the first season, there were greater cutbacks and rumblings that the league was imminently going to fail. Both players and front office staff felt the instability, which led to anxiety and unease throughout the league.

Michaels was perhaps the most passionate about her feelings about the continued rumblings among the WUSA team and league leaders virtually from the onset:

One of the major low points for me was...throughout, even the first year, the rumblings that we may not even be operating beyond Year 1...that was from somewhat early in the first season, that is - and that was very troubling for me as a player, because all of a sudden, here I was, you know, thinking that I could have 
a different environment away from the National Team to be able to develop and play for and be under, and then all of a sudden that might be taken away as well. Michaels was a player that was finally able to forge her own identity as a leader and make a mark outside of her national team duties.

Frazier also spoke about sitting in on league meetings and conference calls and "staring at the numbers every time you had a board meeting...because you see this team is losing $\mathrm{X}$ amount of dollars." She listened to these conversations while she was a player up until that final conference call when it was decided the WUSA would suspend operations as she sat in her hotel room during a break from training with the National Team for the 2003 Women's World Cup. Recalling that moment she said, "I just remember sitting on the floor in my room with my head down thinking, oh my God, how am I going to tell the team about this?" Frazier's role as a WUSA Board Member gave her a different perspective than any other player in the league as well as any other league or team official. Her role through the final days of the league illustrated the way the WUSA began and maintained its player driven philosophy from its inception. Though the burden placed on Frazier in the midst of preparing for the World Cup seems unfair, she did say she would not have done it any other way.

The general managers also spoke about the league cycle and the discussions with investors about how long it would be able to survive as well amid the continued media speculation that the league was continually on the brink of folding. One team manager explained the constant media scrutiny about inevitable failure, "Oh, they changed their ticket pricing. What does this mean?" And they just want you to fail. They already have your obit ready which is disheartening. It's hard," she described.Virtually every article 
written in USA Today about the WUSA in the time leading up to the first game of the league on April 14, 2001 mentioned the league failing or not having success in some way. Even in the first articles announcing the creation of the WUSA, journalists talked about other failed professional sport leagues and the chances the league would be able to survive (Brewington, 2000a, 2000b, 2000c; Hiestand 2001; Weiner, 2001).

One general manager was extremely forthcoming with her staff about the dire situation, especially as it neared; however other front office staffs in the league were dumb-founded at the announcement of the suspension of operations. Some of the teams had continued to spend freely and two teams had made an important trade, only days earlier. The Boston Breakers and San Diego Spirit announced the biggest trade in the history of the WUSA on September 4, 2003, when two National Team players, Aly Wagner and Angela Hucles, were traded across the country (Capozza, 2003) clearly illustrating the communication issues that permeated the WUSA.

Summary. Five themes arose in the interviews. All five of these themes were mentioned and discussed in detail by at least half of the interviewees. The business plan or business model was the first theme that arose in the interviews. None of the individuals interviewed felt the initial plan was realistic in its assumptions about tickets sales, sponsorship dollars, and other sources of income. Additionally, most of them mentioned inaccurate presumptions about the day-to-day office operating costs and the basic expectations the league had from the investors.

The second theme throughout the interviews dealt with leadership issues. While the initial key leaders including the founding players and John Hendricks were positive and powerful in enabling the WUSA to come to fruition, once the league was established 
there were many issues with the league leadership that those interviewed felt contributed to the league failure. Within the leadership theme two subthemes emerged: (a) the lack of professional sport experience with those placed in leadership positions and (b) the lack of trust between those in leadership positions and the players. Significant trust issues between the league and the players, as well as with the various front office staffs, and a lack of communication were addressed in many of the interviews.

The third theme discussed by the interviewees was the overall lack of support for women's sports as well as soccer overall. The general population as well as many mainstream media markets got behind the 1999 World Cup Team, but couldn't do the same on a more frequent basis for the WUSA. Both women's team sports and soccer in general have yet to gain a stronghold in the U.S. sports market.

A lack of a specific league identification and consistent message was the fourth theme to emerge in the interview process. Interviews indicated mixed messages were sent from the league, the teams, and the players at times. Sometimes these individuals focused purely on the professional sport experience when interacting with the media and sponsors while at other times focused on a message of "do the right thing" and "support the WUSA/women's sports." The lack of a clearly defined message, and more specifically the contradicting messages, was seen as a cause of concern to the WUSA leaders interviewed.

The final theme to emerge in answering the third research question of "Why did the WUSA fail?" was a sense of both inevitable failure and an indefinite future from before the first kick-off in 2001 . Virtually every interviewee mentioned points in each season throughout the 3-year cycle where they did not know if they would have a job in 
the near future. This feeling was described as coming from within the league as well as the individual teams. Additionally, the interviewees mentioned the constant scrutiny of the media and other societal avenues seeming to savor the idea of the league being unsuccessful.

These are the five major contributing factors to the WUSA being one of many unsuccessful SMOs in the women's movement and the women's sports movement. These factors are similar to others that led to the failure of various other social movements and SMOs (O'Connor, 1980; Vose, 1972). The WUSA is just one more SMO that was unable to be successful in the long term; however, a lot can be learned in moving forward and ideally lend information to future SMOs so they can have greater, long-term success.

\section{Summary}

This study examined the rise and fall of the WUSA as a social movement organization. The background information collected about the eight WUSA leaders helps illustrate the varied backgrounds, roles, and personalities that shaped the WUSA and provides tremendous insight into the creation of the WUSA. Each of the eight interviewees helped in establishing the WUSA as a SMO by firmly linking their perceptions about the rise and fall of the league to the factors commonly associated with social movement organizations and in social movement theory research.

Additionally, these interviews help in answering the three research questions about how and why the WUSA was founded and why it failed. The themes surrounding the WUSA rising to existence included (a) critical mobilizing events, (b) strong and charismatic leadership, (c) working with like-minded organizations, and (d) the cultural 
and social contexts that existed as the time. Similarly many of the factors enabling the WUSA to rise ended up playing a part in its failure as the themes mentioned by the interviewees feel primarily into five categories: (a) an ill-conceived business model with poor administrative structure, (b) issues within the leadership, (c) the role of women's sports teams in society, (d) the lack of a strong league identification and message, and (d) the sense of inevitable failure. 


\section{CHAPTER V}

\section{SUMMARY OF FINDINGS, DISCUSSION, AND IMPLICATIONS}

This study provided suggestions for social movement scholars, sport

professionals, and students interested in the creation of professional women's sports leagues in the United States. This study examined the Women's United Soccer Association (WUSA) by conducting in-depth interviews with leaders within the organization. Additionally, the interviews integrated primary materials pertinent to the establishment of the WUSA as well as secondary materials chronicling the existence of the WUSA.

This chapter is designed for the reader to understand the WUSA as a SMO within the women's movement as well as to explain how it rose to fruition and failed in only a 4year time span. This chapter is divided into three sections: (a) summary of findings, (b) discussion, and (c) implications. Each of these sections is divided into additional subsections to best summarize the findings from this study and how they add to social movement literature.

\section{Summary of Findings}

Three research questions were established to examine the rise and fall of the WUSA: (a) How was the WUSA founded?; (b) Why was the WUSA founded?; and (c) Why did the WUSA fail? These questions were answered through the in-depth interviews with eight WUSA leaders, including founding players, general managers, and other team personnel. Table 4 highlights the major themes and categories established for each of the 
research questions. Each of these themes and categories will be explained in greater detail following the table.

Table 4

Themes for Each Research Question

Research question Themes

How was the WUSA founded?

Why was the WUSA founded?

Why did the WUSA fail?
Theme 1: The 1999 Women's World Cup Team

Theme 2: John Hendricks

Theme 3: The "collision" of the members of the 1999 Women's World Cup Team with John Hendricks.

Theme 1: Players provided great role models

Theme 2: The desire for a premier women's soccer league

Theme 3: The passion surrounding the team and the players (cultural and social contexts).

Theme 1: Failed business plan/model

Theme 2: Lack of support for women's sports

Theme 3: Lack of trust in leadership

Category 1: Between the league administrators and the teams administrators

Category 2: Between the league administrators and the players

Theme 4: League Identification and Message

Category 1: WUSA as a philanthropic organization?

Category 2: WUSA as a professional sport organization?

Theme 5: Inevitable feeling of failure 


\section{Research Question 1: How Was the WUSA Founded?}

This question was best answered by the founding players interviewed as they, as well as John Hendricks, were the most directly involved in the process. As the vocal leader of the founding players and as a member of the Board of Governors, Jenny Frazier was best equipped to shed light on the league's creation. In conjunction with the other interviewees, she highlighted the 1999 Women's World Cup as the pivotal event (critical mobilizing event-CME) that led to a relationship with John Hendricks, a visionary who wanted to see a women's professional soccer league and had the connections and wherewithal to make it happen. The success of the 1999 U.S. Women's World Cup Team and its members, in conjunction with John Hendricks, were credited by all of the interviewees in establishing the WUSA. Many interviewees elaborated about the "collision" of the two entities finding one another and how this "collision" led to the founding of the WUSA.

The founding of the WUSA is very similar to other social movement organizations in that dynamic leaders were needed to orchestrate its establishment (Berry, 1977; McCarthy \& Zald, 1987; McGlen \& O'Connor, 1983). Additionally, the CME, as discussed by all eight interviewees, supports the claim by scholars such as Oberschall (1973) and McGlen and O'Connor (1983) that a critical mobilizing event is imperative to establishing a SMO.

\section{Research Question 2: Why Was the WUSA Founded?}

The answer to the second research question, why was the WUSA founded, can be tied directly to how the league was founded. The data collected in this study elaborate on 
the cultural and social context and how the WUSA actually came to fruition once the idea of the league had been created and established. The founding members and additional players provided great role models for young women while also offering an opportunity for women to play professional soccer and make a living out of it. These female soccer players served as tremendous role models and the importance of this role in establishing the league reiterated the findings of Funk, Mahony, and Ridinger (2002) who found attendance at the 1999 Nike Cup was mainly explained by the women providing great role models to fans as opposed to even the product on the field. Additionally, the leadership of the players and team staff was highlighted as a reason the WUSA was able to get off the ground and exist for the three seasons. Most notably, in answering the question of why the WUSA was founded, the interviewees spoke of the time being right and numerous individuals ready to help make the WUSA a reality.

The events leading up to the founding of the WUSA were touched on above and indicated in the first research question. The social and cultural environment was ripe for establishing the WUSA. Two of the primary schools of thought, new social movement theory and political opportunity structure theory, stress the importance of the environment being conducive to the a new organization or overall movement (Anherirer, Neidhardt, \& Vorthart, 1998). More specifically, some scholars examined the necessary environment for women's soccer to attain success. The founding of the WUSA aligns with the findings by Pfister (2003) and also Markovits and Hellerman (2003b) that support from a National Governing Body, government support (i.e., Title IX), and various events lay the foundation necessary for an environment to be able to establish a new SMO. 


\section{Research Question 3: Why Did the WUSA Fail?}

The five major factors contributing to the WUSA becoming one of many unsuccessful SMOs in the women's movement and the women's sports movement were (a) an inadequate initial business model, (b) a social and cultural context that was unwilling to embrace and support women's professional sport teams, (c) ineffective upper-level leadership resulting in a lack of trust of the players and team-level leaders, (d) lack of a clear identity and branding message, and (e) a sense of inevitable failure from before the first kick-off. These same five factors are present in many failed SMOs including the Women's Equity Action League (WEAL), a spin-off from the National Organization for Women (O'Connor, 1980), and the WISH List, the Republican counterpart of EMILY's List. The WUSA is just one more SMO that was unable to sustain long-term success; however, much can be learned in moving forward and ideally lending information to future SMOs so they can have greater, long-term success.

While an inadequate business model does not fall into the social movement scholarship, a poor organizational model touches on many factors associated with the various social movement schools of thought, most specifically those falling under resource mobilization theory (Davis et al., 2005). In 1966, Zald and Ash discussed "organizational maintenance" and its importance in the longevity of SMOs. This theory encompasses the inadequate business model WUSA insiders and outsiders thought existed and brings the prevalence of Zald's earliest work to future scholarship in social movement theory.

The leaders of the WUSA felt the timing was right for a new addition to the women's sport landscape; however, the league could not generate a sufficient number of 
fans or amount of sponsor dollars. Even though support from the 1999 Women's World Cup seemed unstoppable (Markovits \& Hellerman, 2003b), the environment at the time would not support the WUSA. The social and cultural context for women's sport had not caught up, and sexism still permeated the coverage of women's sport (Bernstein, 2002; Carty, 2005; Higgs et al., 2003). The lack of acceptance and support of the WUSA enhances the scholarship on the necessity for society being willing and able to support a SMO.

The dynamic leadership necessary for a successful SMO (Berry, 1977; McCarthy \& Zald, 1987; McGlen \& O'Connor, 1983) also has a flipside that can contribute to the failure of a SMO. A lack of professional leadership experience can contribute to a failed SMO (Staggenborg, 1988; Vose, 1955), and the findings from this study reiterate this as over half of the interviewees discussed how many of the leaders lacked professional sport work experience. Elaborating on the lack of professional sport experience was the lack of leaders with deep enough pockets to carry the league through the economic difficulties that face many new businesses, unlike other professional sport leagues such as the MLS. Additionally, the relationships among the various leaders, teams, and league were sources of contention. Internal turmoil between leadership often causes SMOs to fail, such as was the case of WEAL (O'Connor, 1980).

The final two factors the WUSA leaders in this study felt contributed to the fall of the WUSA were the lack of a clear message or branding identity as well as a sense of inevitable failure. The first factor ties directly into previous research on social movement theory, while the latter does not. Based on literature discussing the internal struggle within women's organizations that lead them to fail, the theme of how lacking an identity 
contributed to the fall of the WUSA came as no surprise (O'Connor, 1980), in addition to discussing the inability to find one's niche in the social space (Stern, 1999; Taylor, 1989). Similarly, the ability to find organizations to work with while enhancing each other's causes (i.e., working with like-minded organization) was no surprise (Costain, 1980, 1981; Phillips, 1991). Internal struggles in the WUSA such as determining the message the league wanted to establish for its identity while occasionally sending mixed messages to fans and sponsors, as well as working effectively with like-minded organizations, were continual struggles for the WUSA.

\section{Summary}

The interviewees touched on a variety of factors that explained the rise and fall of the WUSA. The factors leading to the creation of the WUSA such as the dynamic leadership of the founding players and John Hendricks as well as the 1999 Women's World Cup are the same as other social movement organizations. Similarly, the factors that contributed to the fall of the WUSA, an inadequate business plan, the lack of support for women's sports, a lack of trust of the league leadership, a muddled branding message, and an inevitable sense of failure, are frequently associated with failed SMO's as well.

\section{Discussion}

This section includes a discussion of the WUSA as a social movement organization within the women's movement and how the rise and fall of the WUSA fits into and adds to the social movement literature. This section is divided into three sections: (a) the WUSA as a social movement organization, (b) specific findings from the WUSA, and (c) generalizability of the findings to other women's professional sport organizations as well as for other social movement organizations. 


\section{The WUSA as a social movement organization.}

In this study, the WUSA is examined as a SMO as defined in the social movement literature (Knoke, 1986; McCarthy \& Zald, 1987; Ruch \& Neidhardt, 2002) by conducting participant interviews. The interviewees answered questions relating to their thoughts and experiences with the WUSA as a whole, their individual teams, and many of the factors associated with social movement theory. More specifically, the interview questions addressed the success and failure of social movements and social movement organizations. The thoughts of the interviewees clearly establish the WUSA as a social movement organization within the women's movement as many of the themes they broached fall into the factors touched on previously that define a SMO. These factors are illustrated in Table 5.

All of the interviewees spoke about the events leading up to the idea and eventual formation of the WUSA. The critical mobilizing event (CME) that all eight individuals mentioned was the 1999 Women's World Cup. They felt this event showcased the team (Team USA) and the sport and was necessary for the league and its investors to believe in the ability of the league to succeed financially. Many interviewees also spoke of earlier events such as the passage of Title IX and the 1996 Olympic Games as laying the foundation for both the ultimate CME (the 1999 Women's World Cup) and the creation of the WUSA.

Social movement scholars frequently discuss the importance of a critical mobilizing event or events in the construction of a social movement or social movement organization (Freeman, 1975; McGlen \& O'Connor, 1983; Oberschall, 1973). These works reflect the thoughts of the interviewees in the present study as well since all eight 
of them pointed to the 1999 Women's World Cup as the catalyst for the creation of the WUSA.

Table 5

Themes Establishing the WUSA as a Social Movement Organization (SMO)

\begin{tabular}{|c|c|}
\hline Theme/factor & Category \\
\hline $\begin{array}{l}\text { Critical mobilizing event } \\
\text { (CME)/Social cultural } \\
\text { contexts }\end{array}$ & $\begin{array}{l}\text { Category 1: The } 1999 \text { Women's World Cup Team and } \\
\text { success. } \\
\text { Category 2: Title IX: increasing opportunities for } \\
\text { women to participate in athletics. } \\
\text { Category 3: The } 1996 \text { Olympic Games: Highlighting } \\
\text { the success of female athletes in the United States. }\end{array}$ \\
\hline Leadership & $\begin{array}{l}\text { Category 1: Founding players } \\
\text { Category } 2: \text { John Hendricks "Saint John" } \\
\text { Category 3: League and team leadership }\end{array}$ \\
\hline $\begin{array}{l}\text { Like-minded organizations } \\
\text { and access to political elites }\end{array}$ & $\begin{array}{l}\text { Category 1: Major League Soccer (MLS) and U.S. } \\
\text { Soccer } \\
\text { Category 2: Youth soccer } \\
\text { Category 3: Women's National Basketball Association } \\
\text { (WNBA) } \\
\text { Category 4: Women's Sports Foundation } \\
\text { Category 5: Various women's organizations }\end{array}$ \\
\hline $\begin{array}{l}\text { Competition for organizational } \\
\text { space and acquiring resources } \\
\text { and support }\end{array}$ & $\begin{array}{l}\text { Category 1: Soccer (youth and the MLS) } \\
\text { Category 2: Women's Sports (WNBA) } \\
\text { Category : Sponsorship }\end{array}$ \\
\hline Administrative structure & $\begin{array}{l}\text { Category 1: Locations (initially New York City then } \\
\text { Atlanta, Ga.) } \\
\text { Category 2: Personnel } \\
\text { Category 3: Players vs. the League }\end{array}$ \\
\hline
\end{tabular}

Additionally, many of the interviewees discussed the role the passage of Title IX played in allowing an event like the 1999 Women's World Cup to occur. This reinforces the belief of scholars that Title IX is one of the most important events in the women's 
movement and more specifically the women's sport movement (Markovits \& Hellerman, 2003b; Taylor, 2005).

The leadership that was displayed in establishing the WUSA was also paramount to the league getting off the ground. All the interviewees credited the founding players as being the major force in making the WUSA a reality, along with John Hendricks and his vision. Strong leadership is necessary for any organization to get up and running. In the case of the WUSA and other SMOs, this dynamic and charismatic leadership was necessary to create the organization.

Cooperation with like-minded organizations and specific access to political elites who frequently work with prior established organizations were highlighted in the interviews. The two most frequently mentioned like-minded organizations throughout the eight interviews were U.S. Soccer and Major League Soccer. Unfortunately the lack of cooperation with these two, well-established organizations was the prevalent theme. Many of the interviewees expressed the desire to want to be a separate entity from the MLS, unlike the WNBA, and this decision may have led to the lack of cooperation that permeated the WUSA from the onset. Additionally, the decision of the founding players to publicly state they would only play for a separate entity may have created a greater division with US Soccer as well making any beneficial relationship virtually impossible. By being a separate league, the WUSA leaders were making a statement as a women's organization that they wanted to do it on their own, however it did not allow them to have an established base that has provided support to the WNBA (NBA) and other entities such as the NCAA (as it phased out the AIAW). While the relationship with many soccer entities seemed strained at times, the WUSA did feel support from other women's 
organizations, especially the Women Sports Foundation, as well as lesser support from the WNBA and also local women's groups.

Competition for organizational space and acquiring resources and support all tie in well with the prior factors and themes as reasons over half of the interviewees felt they did not get more cooperation from U.S. Soccer and the MLS. Study participants stated that both leaders in US Soccer and the MLS felt as though they had to compete with the WUSA and if the WUSA was able to sustain itself it would be detrimental to the MLS or U.S. Soccer as a whole. Additionally, due to the economic climate, resources such as sponsor dollars and television time were scarcer than ever in 1999 and 2000 when the idea for the WUSA mainly took shape.

Administrative structure is also a common factor examined when establishing a SMO and many of the interviewees mentioned two areas of concern about administrative structure. The first concern related to the initial decision to be based out of Manhattan, the most expensive marketplace in the United States. The second was moving the league office to Atlanta and, basically, into the offices of one of the existing teams. This move meant many of those team leaders had to transition to becoming league leaders. This lack of stability in the administrative structure mirrored many SMOs in their infancies as well, such as NOW and WEAL (O'Connor, 1980). This strain on the administrative headquarters, coupled with the changes to the administrators at this level and the lack of professional sport experience many of them had going into the creation of the WUSA, is an additional concern to the overall administrative structure of the WUSA while also crossing-over with some of the concerns expressed about the leadership. 


\section{Specific findings for the WUSA}

The majority of the findings in this study are specific to the WUSA as is typical with historical case studies. In regard to social movement theory, however, this study added to the social movement literature as many studies focus on one organization. In examining the WUSA, virtually all the interviewees discussed two factors to some degree throughout their interviews: (a) the events leading to the creation of the WUSA and (b) the synergy of the 1999 Women's World Cup Team with John Hendricks as being paramount to the creation of the league. Additional findings specific to the WUSA included a few of the factors that led to its failure: (a) an inadequate business plan, (b) lack of a clearly defined league message and branding identity, and (c) the inevitable sense that the league was doomed before the first kick-off.

Factors specific to the creation of the WUSA. Two traditional factors of SMOs discussed in this study are most specific to the WUSA (McCarthy \& Zald, 1987). The first is the events the interviewees (as well as many media outlets) agreed led to the desire and belief that a women's professional soccer organization could be successful. The second was the timing of the meshing of two parties: the women of the 1999 World Cup Team with the visionary John Hendricks, nicknamed "St. John" by the founding players.

Events leading to the founding of the WUSA. The first event every interviewee spoke about as being paramount to the creation of the WUSA was the success of the U.S. Women's National Team during the 1999 Women's World Cup. The members of the team were embraced by all forms of national media outlets from ESPN to David Letterman to "Good Morning America" (Bernstein, 2002; Longman, 2001; Markovits \& Hellerman, 2003a). The members of the team became household names and were treated 
like rock stars as the tournament progressed. By the time the final whistle sounded and Brandi Chastain made her penalty kick, this team gave hope that there would be another place to see these women play soccer in the United States (Bernstein, 2002; Longman, 2001). This event created a unique phenomenon (Markovits \& Hellerman, 2003b) that has been similar to other large scale sporting events, such as the Olympic Games, but nothing had come close to this in the United States for female athletes.

Additionally, the majority of the interviewees felt that the success of the Women's United States National team and women's sports in general during the 1996 Olympic Games in Atlanta would consequently lead to success for the 1999 Women's World Cup in the U.S and of the team in general. The interviewees also believed Title IX was the ultimate catapult in creating athletic opportunities for women in high school and college and thus success was now becoming evident by the performance of U.S. teams on the international stage.

Title IX has benefited female athletes tremendously and has given them the opportunity to have success in their chosen sport from youth through college. Though Title IX does not guarantee equal opportunities at the professional level, it has created a few generations of female athletes who feel as though they deserve the opportunity to play at that level. All women's organizations, sport and otherwise, can acknowledge the role Title IX has played in the moving current and future generations of women forward. Additionally, the success of the 1996 Olympic Games served as the catapult for two professional women's basketball leagues, the American Basketball League (ABL) and the Women's National Basketball Association (WNBA) as well as discussions for other professional leagues for women in sports such as softball. This is similar to other 
ideas for potential professional sport leagues that stem from Olympic success such as the two women's professional basketball leagues as well as the National Pro Fastpitch League (softball). Currently though, only the WNBA continues to exist at a prominent national level, reiterating the need for another successful league in the United States to even give hope to future women's professional sport leagues.

The Founding Players and John Hendricks. All the interviewees spoke of the importance of the founding players to the creation of the WUSA. Additionally, the majority of the interviewees spoke of the role of John Hendricks in making the WUSA a reality and the "collision" of Hendricks with the founding players. This dynamic leadership group had the vision and entrepreneurial spirit to make the WUSA a reality through their connections to media outlets, passion for the game, and belief that the time was right for the first wholly professional women's soccer league.

Factors specific to the failure of the WUSA. Three factors brought up by the interviewees seem specific to the failure of the WUSA to last beyond three seasons, even though the initial business plan called for a 5 -year guarantee. These three factors included (a) an inadequate business plan, (b) a lack of a clearly defined league message and branding identity, and (c) the inevitable sense that the league was doomed before the first kick-off.

Inadequate business plan. While many start-up organizations may have inadequate business plans that lead them to lack viability, the business plan the WUSA began with was unique to them and displayed problems from the onset according to a few of the interviewees, although no one was willing to challenge it initially. A closer examination of the initial business plan of the WUSA would allow the leaders of the 
WUSA to see where they misjudged. An examination of the business plan could also help other new women's sport organizations.

Basically, one insider faulted two major problems with the business plan. First, as drafted by an MLS manager on loan to the new league, the plan had unrealistic expectations for start-up costs such as facility modifications, signage, and office space. Second, faulty assumptions about investing in the league and how it would translate into ticket sales and sponsorship dollars also led to the league's collapse in the third year of what was supposed to be a 5-year plan. It is also important to decipher why, when some individuals saw the plan as flawed from the onset, no one spoke up to challenge it.

Lack of a clearly defined message/branding idlentity. A unique characteristic of the WUSA was that its leadership seemed to lack a clearly defined message to send to fans and sponsors. When appealing to fans and potential sponsors, the league leadership felt strongly that it was providing the best women's soccer in the world as well as the only wholly professional women's soccer playing opportunity. That message was occasionally muddled, however, as many times the leadership also stressed that fans should come and watch because it was important to support female athletes.

Additionally, league leaders would try to solicit sponsorships based on "doing the right thing" and helping the cause of women's sports. Similar to the internal issues of WEAL in formalizing its purpose (O'Connor, 1980), the interviewees felt the leadership of the WUSA sent conflicting messages, hindering the ability of the league to achieve success as it never seemed to fully know its mission and purpose and continued to struggle with both the internal branding message as well as the external one. 
Inevitable sense of failure. Unique to the WUSA was the sense of inevitable failure that seemed to pervade the entire duration of the WUSA's existence. Virtually all of the leaders mentioned feeling a sense of doom even before the inaugural game which negated many of the league's successes throughout its 3-year cycle. The team and league managers constantly felt pressure to make the league sustainable and to overcome the feeling of imminent doom that many of the interviewees said they felt from the time they began working for the WUSA. This immediate feeling of defeat is a finding most specifically geared for the WUSA from interviewing the WUSA leaders about the WUSA and the role it played in its demise.

\section{Summary}

Examining the WUSA as a SMO within the women's movement adds to the overall field of social movement literature, as sport is an often-overlooked area of scholarship. The role of women's athletics in the women's movement is frequently left out of movement. Placing the WUSA within the movement will give an added area of study when examining women's athletics. Additionally, the findings from this failed SMO will help provide guidance to future SMOs in avoiding similar pitfalls of the WUSA.

\section{Implications}

The implications derived from this study can be divided into three sections, including implications for (a) social movement theorists, (b) sport managers, and (c) future researchers.

\section{Implications for social movement theorists}


Generalizability in case studies provides "little basis for scientific generalizations" (Yin, 2009, p. 15) as the research is based on one specific case. This does not mean, however, that information and themes cannot be taken out of the findings from this case study of the WUSA. The factors that contributed to the initial excitement and ability to establish the WUSA are commonplace among other social movement organizations, as are the factors that led to its inability to find its niche or foothold in the sport landscape in the United States. The findings from this study are an important addition to the social movement literature as well as a guide for future women's sport leagues.

New start-up women's organizations, for example, need to be particularly attentive to the mundane (i.e., space, start-up costs, and dependence on external donors as well as issues of niche and message). In an era of myriad women's groups competing for enthusiastic supporters, chances of success are not guaranteed. Early questions about success, moreover, should tell a cautionary tale to leaders seeking to capitalize on CMEs. A cohesive, understandable message and supportive donors, or financiers even a critical mobilizing event may not (or should not) mean a new SMO is needed.

The lessons learned through the interview process and subsequent analysis reiterate many of the themes established in social movement literature in regards to why SMOs come to fruition and then typically fail in a short life cycle. Additionally, the thick descriptions provided by the interviewees about the WUSA as an organization allow other scholars to decipher the parts from this study that will carry over to the organizations they chose to examine. Examining the WUSA as a SMO allows this study 
to add to the literature on social movement theory and provides a template for other women's soccer organizations, as well as other women's sports entities.

The addition of this study to social movement literature is two-fold as this study is one of a limited number examining sport in social movement theory and also explains the WUSA as a SMO by using the three primary schools of thought in social movement theory instead of just one. This hybrid of the three primary schools of thought within social movement literature provides a new template for examining social movement organizations. All three models of social movement theory provide factors useful in examining SMOs and allow social movement scholars to more fully understand where SMOs succeed and fail. The hybrid used in this study provides a good starting point for future examination of social movement organizations as well as for social movement scholars looking for a more complete understanding of social movements and social movement organizations.

Implications for sport managers. This study provides information to individuals interested in helping women's professional sport organizations succeed. Interestingly, lessons important for social movement theorists are also important to sport managers. Leaders of one of the most publicized women's professional sport leagues opened up about how the league came to fruition and failed. Practitioners are able to see the importance of critical mobilizing events and dynamic leadership in making dreams a reality in the short term. They can also assess the climate to make individuals believe in a league that has no concrete marketplace. Additionally, the data derived from this study can help fledgling leagues learn from the mistakes of the WUSA, most notably having an 
extensive and well thought out business plan, a clear message and purpose, and transparent and trustworthy leadership.

The factors highlighted in this study will enable practitioners to be able to better gauge if society has a space and a need for the sport organization the practitioners would like to establish, which may also be a SMO. Additionally, they can gain insight in identifying the factors that would contribute to a failed sport organization in an effort to preempt any premature failures.

Practitioners and policy makers are able to gain greater insight into the factors they need to focus on when establishing a women's professional sport league. A quality on-field product is not the sole basis for a successful league and policy makers must understand the importance of a strong foundation of fans, sponsors and experienced leadership for a women's league, or any SMO, to have success.

Sport managers looking to create a new professional women's soccer league can learn a number of lessons from the limited successes the WUSA had as well as from its numerous failures. The outreach by the teams and many of the players to their communities and the efforts by the teams to provide access to the players were seen by all interviewees as strengths of the league. Additionally, there was a consensus that the onfield product was the best in the world, which was deemed another strength. The factors contributing to the failure of the WUSA can also serve as a good outline for future women's soccer leagues. Currently, the new Women's Professional Soccer (WPS) is a work in progress and has taken some early hits with four of the original seven teams ceasing to exist, while simultaneously adding three teams. The WPS, as well as other women's soccer leagues (such as the W-League, a semi-professional women's soccer 
league), and future women's soccer leagues can extrapolate from the WUSA and through the thick description provided can pull out information that would prove useful in moving forward.

Additionally, women's sport organizations and leagues can use the limited successes and failures of the WUSA as a template for establishing other women's sport leagues. Future women's professional sport leagues can use the template from the WUSA in deciphering when society is ready to embrace a continued women's professional sport team presence beyond the WNBA. Sport managers in other women's sport leagues are able to learn more about the challenges of creating a league separate from an established men's league while also working within similar markets and even sharing facilities. Again, the thick description provided in Chapter 4 allows sport managers in other leagues the opportunities to utilize those aspects pertinent for their benefit, such as findings about the role of a passionate, financially well situated leader such as John Hendricks, as well as the importance of timing and trust.

Finally, the researcher would provide the following suggestions for a future women's professional soccer league based on the findings of this study: (a) hire individuals to lead at the league and team levels with professional sport experience to ensure they are not blinded purely by passion when making decisions as well as understand how to communicate in a way to secure trust, (b) secure individuals with a passion as well as significant financial resources to help enhance the ability of the league to make it through the inevitable tough years, (c) have a cohesive and consistent branding message when approaching potential sponsors as well as when reaching fans. In addition to these three suggestions, it is imperative for a league to make sure it has the financial 
resources necessary for not only initial start-up costs, but also reserve funds in the case of an economic downturn which would negatively affect sponsorship and ticket sales, something that has seemed to take its toll on the current WPS.

\section{Directions for Future Research}

Examining the WUSA and other women's sport organizations through the lens of social movement theory gives a fresh and more encompassing way of seeing how the WUSA rose and fell in such a short time period. Many sport professionals and critics of the WUSA point simply to a poor business model as why the league was unable to sustain itself for more than three seasons. An insufficient business plan in and of itself, however, does not fully explain the multitude of factors that contributed to the league's downfall when examining the WUSA as a SMO. Examining the WUSA as a SMO provides numerous areas that would benefit from future study, including the following: (a) the importance of a solid business plan, (b) comparing the WUSA to other women's professional sport leagues, (c) the social and cultural contexts of women's professional sport in the U.S, (d) media coverage of female athletes, and (e) the use of new social media.

The importance of a solid business plan. The inadequate business plan is commonly cited as the reason the WUSA failed. While many of the failures of the WUSA can be tied to the ineffective business model as explained by the interviewees, it is not the sole reason. As one of the most commonly mentioned factors contributing to the failure of the WUSA it is imperative for the ineffective business plan to be examined in greater detail to see exactly where it went wrong and how none of the WUSA leadership was able to see where the plan was flawed. Greater discussions with the 
individuals who spearheaded the establishment of the WUSA, such as John Hendricks and some of the founding players, as well as other individuals from U.S. Soccer and the MLS, would be able to shed light on the initial business model. Additionally, the three CEOs of the WUSA would be able to explain changes that were made throughout the three seasons as well as leading up to the first kick-off in 2001 and how those changes were able to sustain the league into a third season, though the business plan was for five years. Qualitative research designs would provide the best options for gathering this type of data.

Still, the study of business plans opens up the relevance of this study to a far wider and different audience. Intangibles such as long-term interest of supporters and the relevance of "the product" through sound messaging make these findings of interest to a range of business professionals.

Comparing the WUSA to other women's professional sport leagues. The WUSA started four years after the WNBA and five years after the failed ABL. Comparing the WUSA to both leagues should be considered as a future research area. While the ABL did not have the backing of the NBA like the WNBA, comparing both highly publicized basketball leagues to the WUSA would be beneficial to all parties. Specific comparisons between the ABL and WUSA should be examined as both leagues specifically chose not to pair with the established men's league and also competed in the same season as the men's league.

Additional research comparing the WUSA with the recently established and continually shifting Women's Professional Soccer League (WPS) is also an area to be examined. WPS executives claimed to have learned from many of the mistakes of the 
WUSA, and its promoters felt confident it would find its niche in the U.S. sports landscape (Canales, 2009; Gregory, 2009). However, the first two years of the new league has seen four teams fold, including both WPS champions only months after winning the league trophy. The league has also added another three teams, and already changed leadership at the top.

Many of the WUSA leaders transitioned into leadership roles within the WPS, including five of the interviewees for this study. Two of the three interviewees not associated with the WPS felt as though they were excluded from the creation of the new league and were shocked at how little they were used. The one additional interviewee not associated with the WPS felt she was only used as a resource because of previous working relationships she had with new leaders in the WPS. This served as a point of frustration to most of the interviewees and is definitely an area that could be explored more in examining the success and failure of women's professional soccer in the United States.

Additional comparisons could be drawn between the WUSA and a host of other professional women's sport leagues as well as organizations. Examining the WUSA in relation to other leagues such as the Women's Professional Softball League (WPSF) and its evolution to National Pro Fastpitch (NPF), as well as the Ladies Professional Golf Association (LPGA), and even the coed World Team Tennis (which was created by Billie Jean King) would be interesting. Tying the WUSA into other women's sport organizations such as the national Women's Sport Foundation could also provide an area of scholarly inquiry. Why ultimately, for example, did the Women's Sports Foundation, also created by Billie Jean King, fail to assist the league in any significant way? Was that 
another example of competition for scarce resources? Answering these questions would be of interest to social movement theorists and practitioners.

A final area of league comparisons could be drawn with other niche sports that have started as small, regional professional leagues and grew as sponsorship and the fan base allowed. Examples of such leagues would be the National Lacrosse League (NLL) and Major League Lacrosse (MLL). While these two leagues are men's leagues, both have seen franchise movement, expansion, as well as teams folding while maintaining a somewhat promising foothold in the United States professional sport landscape. These niche sports would be an interesting comparison with the WUSA.

Additionally, a comparison of the WUSA to other more established professional sport leagues could be of benefit to the future of women's professional sport leagues. Most of the current professional sport leagues, such as the NFL and MLB. These leagues had to suffer through tens of years before breaking even and turning a profit and tried numerous avenues in order to make the leagues subsist throughout the challenging economic swings. Seeing the differences, could allow future women's leagues to situate themselves in a better place and surround themselves with a more complete investor base.

Social and cultural context of women's professional sport. Similarly, the social fit of women's professional sport needs to be examined more. There have been studies on women's sport spectatorship and women as a fan base (Fink, Trail, \& Anderson, 2002; Funk et al., 2002), the lack of success and support of various women's sport entities (Lough \& Irwin, 2001), and specific questions about the potential for women's soccer (Collins, 2006; Martinez, 2008; Southall, Nagel, \& LeGrande, 2005). However, many of these studies are narrowly focused. Additional studies need to examine not only why 
fans support women's sports, but why they do not. More qualitative and quantitative studies examining this phenomenon are necessary to better understand the professional sport landscape.

Social and cultural contexts of women and sport also raise issues about sex role stereotyping and the decline in girls' interest in competing in sport when they reach a certain age. It is 40 years since passage of Title IX and women and girls still do not compete in sport at the same rates as men. Clearly, social and cultural constraints still exist but need to be better identified.

Media coverage. Research on media coverage of women's sports and female athletes need to continue. Even during events such as the Olympic Games, women routinely receive less media coverage than men. In many broadcasts, sexism still permeates the airways (Bernstein, 2002; Carty, 2005; Tuggle \& Owen, 1999). The new WPS teams were rarely covered in their local media outlets, much less nationally (Gregory, 2009). While the WUSA was covered occasionally, the Women's World Cup holdovers such as Mia Hamm, Brandi Chastain, and Julie Foudy, who were considered "America's Sweethearts," received the lion's share of the media's attention.

Use of new social media. The new women's soccer league, the WPS, has focused on using new social media as a way to get its message to the broader community. Research on the effectiveness of this medium can benefit all sport organizations (Hambrick, Simmons, Greenhalgh, \& Greenwell, 2010). Many of the interviewees involved with the new WPS spoke of the use of social media and other free media sources as being pivotal in promoting the new league. Social media outlets such as Twitter, Facebook, and blogs provide inexpensive ways to get information out and 
connect with fans, but questions about their longevity and ability to motivate the sport consumer would truly benefit fledgling leagues so they could focus their dollars most effectively. Access to well-developed fan lists versus the costs and benefits of creating new lists could also be examined.

\section{Conclusion}

Social movement theory can be used to examine many facets of professional and collegiate sport and could provide rich findings for the successes and failures of specific organizations. This study adds to the limited literature on sport in social movement theory while also providing greater insight to the rise and fall of the WUSA as women's soccer continues to attempt to gain a foothold in the United States' sport landscape. This study also provided a rare opportunity to interview and gain perspective from individuals pivotal in establishing the WUSA. The interviewees were able to share their thoughts on the creation of the league, the role of women's soccer and soccer in general in the United States, and the future of other women's professional soccer and professional sport leagues in the United States. They were also given an opportunity to reflect on the strengths and weaknesses of the league and give insight to future leaders and policy makers in women's professional sport. 


\section{REFERENCES}

Abel, T. (1937). The pattern of a successful social movement. American Sociological Review, 2, 347-352.

Adams, T., \&Tuggle, C. A. (2004). ESPN's SportsCenter and coverage of women's athletics: "It's a boys club." Mass Communication and Society, 7, 237-248.

Adrian, M. (1993). Don't Just do something - stand there: Problematizing community action for women in sport. Women in Sport \& Activity Journal, 2(2), 63-67.

Anheirer, H. K., Neidhardt, F., \&Vortkamp, W. (1998). Movement cycles and the Nazi Party.The American Behavioral Scientist, 41, 1262-1281.

Banaszak, L. A. (1996). Why movements succeed or fail: Opportunity, culture, and the struggle for woman suffrage. Princeton, NJ: Princeton University Press.

Barasko, M. A. (2006). Sustaining grassroots activism in NOW, 1966-2000. Women \& Politics, 28, 189-211.

Becker, D. (1996, August 5). Triumphs could pace the way for new programs for girls. USA Today, 12C.

Benford, R. D., \& Snow, D. A. (2000). Framing processes and social movements: An overview and assessment. Anmual Review of Sociology, 26, 611-639.

Bernstein, A. (2002). Is it time for a victory lap? International Review for the Sociology of Sport, 37, 415-428.

Berry, J. (1977). Lobbying for the people. Princeton, NJ: Princeton University Press.

Bishop, R. (2003). Missing in action: Feature coverage of women's sports in Sports Ilhustrated. Journal of Sport \& Social Issues, 27, 184-194.

Blee, K. M., \& Taylor, V. (2002). Semi-structured interviewing in social movement research. In B. Klandermans\& S. Staggenborg, (Eds), Methods of social movement research (pp. 92-117), Minneapolis: University of Minnesota Press.

Borland, J., \& MacDonald, R. (2003). Demand for sport. Oxford Review of Economic Policy, 19, 478-491. 
Boueije, H. (2002). A purposeful approach to the constant comparative method in the analysis of qualitative interviews. Quality \& Quantity, 36, 391-409.

Bray, C. (1988). Sport and social change: Socialist feminist theory. Joumal of Physical Education, Recreation, \& Dance, 59(6), 50-53.

Brewington, P. (2000a, February 16). "Women attack crowded field Games to begin 2001 for 8-10 teams." USA Today, 14C.

Brewington, P. (2000b, March 31). MLS sets forth rival plan to start women's pro league. USA Today, 22C.

Brewington, P. (2000c, April 11). Women's pro league group lands cable deal. USA Today, 16C.

Brewington, P. (2000d, May 24). WUSA, MLS settle their differences Women's, men's pro leagues ready to cooperate. USA Today, 13C.

Brewington, P. (2000e, December 13). Longtime leader Overbeck to step down from U.S. national team. USA Today, 2C.

Brewington, P. (2001, June 28). DC area reaps benefits of doubleheaders. USA Today, $8 \mathrm{C}$.

Brown, S. (2007). Fleet feet: The USSF and the peculiarities of soccer fandom in America. Soccer \& Society, 8, 366-380.

Campbell, J. L. (2006). Where do we stand? In G. F. Davis, D. McAdam, W. R. Scott, \& M. N. Zald (Eds.) Social movements and organizational theory (pp. 4168). New York: Cambridge University Press.

Caniglia, B. S., \&Carmin, J. (1995). Scholarship on social movement organizations: Classic views and emerging trends. Mobilization: An International Journal, $10,201-211$.

Capozza, K. (2003, September 5). "Timing of Wagner trade scrutinized." USA Today, $15 \mathrm{C}$.

Carmin, J., \&Balser D. B. (2002). Selecting repertoires of action in environmental movement organizations. Organization \& Environment, 15, 365-388.

Carty, V. (2005). Textual portrayals of female athletes: Liberation or nuanced forms of patriarchy. Frontiers, 26, 132-155. 
Chaves, M., \& Cavendish, J. (1997). Recent changes in women's ordination conflicts: The effect of a social movement on intraorganizational controversy. Journal for the Scientific Study of Religion, 36, 574-584.

Christopherson, N., Janning, M., \& McConnell, E. D. (2002). Two kicks forward, one kick back: A content analysis of media discourses on the 1999 Women's World Cup soccer championship. Sociology of Sport Joumal, 19, 170-188.

Clemens, E. S., \& Hughes, M. D. (2002). Recovering past protest: Historical research on social movments. In B. Klandermans, \& S. Staggenborg, (Eds), Methods of social movement research (pp. 201-230), Minneapolis: University of Minnesota Press.

Cole, C. L. (2000). The year that girls ruled. Journal of Sport and Social Issues, 24(1), 37.

Collins, S. (2006). National sports and other myths: The failure of US Soccer. Soccer \& Society, 7, 353-363.

Cooper, P. L. (1992). The "visible hand" on the footrace: Fred Lebow and the marketing of the marathon. Journal of Sport History, 19, 244-256.

Corbett, D. (1999). Ethics and moral behavior in sport: A human rights issue. Ethics in sport newsletter. The First International Conference on Sports and Human Rights: Conference Proceedings (pp. 165-175). Sydney, Australia : University of Technology.

Costain, A. N. (1980). The struggle for a national women's lobby: Organizing a diffuse interest. The Western Political Quarterly, 33, 476-491.

Costain, A. N. (1981). Representing women: The transition from social movement to interest group. The Western Political Quarterly, 34, 100-113.

Costain, A. N., \&Majstorovic, S. (1994). Congress, social movements and public opinion: Multiple origins of women's rights legislation. Political Research Quarterly, 47, 111-135.

Crossley, N. (2002). Making sense of social movements. Open University Press: Buckingham, England.

Davis, G. F., McAdam, D., Scott, W. R., \&Zald, M. N. (Eds.). (2005). Social movements and organizations theory. New York, NY: Cambridge University Press.

Davis-Delano, L. R., \&Crosset, T. (2008). Using social movement theory to study outcomes in sport-related social movements. International Review for the Sociology of Sport, 43(2), 115-134. 
Della Porta, D., \&Diani, M. (2006). Social Movements: An introduction (2nd ed.). Malden, MA: Blackwell.

Disney, J. L., \& Gelb, J. (2002). Feminist organizational "success": The state of U.S. women's movement organizations in the 1990's. Women \& Politics, 21(4), 39-76.

Dugas, J. C. (2001). The origin, impact, and demise of the 1989-1990 Colombian student movement: Insights from the social movement theory. Journal of Latin American Studies, 33, 807-837.

Edwards, B., \& McCarthy, J. D. (2004). Strategy matters: The contingent value of social capital in the survival of local social movement organizations. Social Forces, 83 , 621-651.

Fasting, K., \&Pfister, G. (2000). Female and male coaches in the eyes of female elite soccer players. European Physical Education Review, 6(1), 91-110.

Feree, M. M., \& Martin, P. Y. (Eds.). (1995). Feminist organizations: Harvest of the new women's movement. Philadelphia, PA: Temple University Press.

Feree, M. M., \& Martin, P. Y. (1995). Doing the work of the feminist movement. In M. M. Feree\& P. Y. Martin (Eds.), Feminist organizations: Harvest of the new women's movement (pp. 3-27). Philadelphia, PA: Temple University Press.

Fink, J. S., Trail, G. T., \& Anderson, D. F. (2002). Environmental factors associated with spectator attendance and sport consumption behavior: Gender and team differences. Sport Marketing Quarterly, 1I(1), 8-19.

Freeman, J. (1975). The politics of women's liberation. New York, NY: McKay.

Freeman, J. (1995). From seed to harvest: Transformation of feminist organizations in scholarship. In M. M. Feree\& P. Y. Martin (Eds.), Feminist organizations: Harvest of the new women's movement (pp. 3-27). Philadelphia, PA: Temple University Press.

Frey, J. H., \&Eitzen, S. (1991). Sport and society.Ammual Review of Sociology, 17, 503-522.

Funk, D. C., Mahony, D. F., \&Ridinger, L. L. (2002). Characterizing consumer motivation as individual difference factors: Augmenting the Sport Interest Inventory (SII) to explain level of spectator support. Sport Marketing Quarterly, II(1), 33-43.

Gamson, W. A., \& Modigliani, A. (1989). Media discourse and public opinion on nuclear power: A constructionist approach. American Journal of Sociology, $95,1-37$. 
Gamson, W. (1990). The strategy of social protest (2nd ed.). Elmont, CA: Wadsworth.

Gamson, W. A., \& Stuart, D. (1992). Media discourse as a symbolic contest: the bomb inpoliticalcartoons. Sociological Forum, 7, 55-86.

Giler, R. (2002, August 22). WUSA takes wait-and-see approach to attendance drop. USA Today, 8C.

Gladden, J. M., Mahony, D. F., \&Apostolopoulou, A. (2005). Toward a better understanding of college athletic donors: What are the primary motives? Sport Marketing Quarterly, 14(1), 18-30.

Glesne, C. (2006). Becoming qualitative researchers: An introduction (3rd ed.).Boston, MA: Pearson.

Goldstone, J. A. (2003). Comparative historical analysis and knowledge accumulation in the study of revolution. In J. Mahoney \& D. Rueschemeyer (Eds.), Comparative historical analysis in the social sciences (pp. 41-90). Cambridge: Cambridge University Press.

Greer, H. S. (1982). The future of Olympism as a social movement.Arena Review, 6(2), 22-25.

Grise-Owens, E., Vessels, J., \& Owens, L. W. (2004). Organizing for change: One city's journey toward justice. Journal of Gay \& Lesbian Social Services, 16(3/4), 1-15.

Gutterman, D. S. (2005).Prophetic politics: Christian social movements and American democracy. Ithaca, NY: Cornell University Press.

Hambrick, M. E., Simmons, J. M., Greenhalgh, G. P., \& Greenwell, T. C. (2010). Twitter in sport: A content analysis of professional athlete tweets. International Journal of Sport Communication, 3, 454-471.

Harris, J. (2005). The image problem in women's football.Journal of Sport \& Social Issues, 29, 184-197.

Harvey, J., \&Houle, F. (1994). Sport, world economy, global culture, and new social movements. Sociology of Sport Journal, 11, 337-355.

Heino, R. (2000). New sports: What is so punk about snowboarding? Journal of Sport \& Social Issues, 24, 176-191.

Henry, J. M. (1999) Gender egalitarianism in coed sport: A case study of American soccer. International Review for the Sociology of Sport, 34, 277-290. 
Hiestand, M. (2001, April 13). "WUSA goals not lofty Big question: Will female fans watch?" USA Today, 3C.

Higgs, C. T., Weiller, K. H., \& Martin, S. B. (2003). Gender bias in the 1996 Olympic Games. Journal of Sport \& Social Issues, 27, 52-64.

Howard, D. R., \& Crompton, J. L. (2003). An empirical review of the stadium novelty effect.Sport Marketing Quarterly, 12(2), 111-116.

Ingram, A. G. (1981). Educational documents generated from 1971 to 1981: An explosion of information on the topic of women's athletics. Retrieved from http://www.eric.ed.gov/ERICWebPortal/search/detailmini.jsp?_nfpb=true\&_\&ER ICExtSearch_SearchValue_0=ED262029\&ERICExtSearch_SearchType_0=no\&a ccno $=$ ED262029

Jackman, J. (2002). Anatomy of a feminist victory: Winning the transfer of RU 486 patent rights to the United States, 1988-1994. Women \& Politics, 24(3), 81-99.

James, J. D., Kolbe, R. H., \& Trail, G. T. (2002). Psychological connection to a new sport team: Building or maintaining the consumer base. Sport Marketing Quarterly, 11, 215-225.

Jenkins, J. C. (1983). Resource mobilization theory and the study of social movements.Ammal Review of Sociology, 9, 527-553.

Jeydel, A. S. (2004). Political women: The women's movement, political institutions, the battle for women's suffrage and the ERA. New York, NY: Routledge.

Johnson, H., \&Klandermans, B. (Eds.) (1995). Social movements and culture: Social movements, protest, \& contention, volume 4. Minneapolis: University of Minnesota Press.

Katzenstein, M. F., \& Mueller, C. M. (Eds.). (1987). The women's movements of the United States and Western Europe. Philadelphia, PA: Temple University Press.

Katzenstein, M. F. (1995). Discursive politics and feminism activity in the Catholic Church. In M. M. Feree\& P. Y. Martin (Eds.), Feminist organizations: Harvest of the new women's movement (pp. 35-69). Philadelphia, PA: Temple University Press.

Klandermans, B., \&Staggenborg, S. (Eds.) (2002). Methods of social movement research. Minneapolis: University of Minnesota Press.

Knoke, D. (1986). Associations and interest groups.Annual Review of Sociology, 12, 121. 
Knoppers, A., \&Anthonissen, A. (2003). Women's soccer in the United States and the Netherlands: Differences and similarities in regimes of inequalities. Sociology of Sport Journal, 20, 351-370.

Koch, J. V., \& Leonard, W. M. (1978). The NCAA: A socio-economic analysis: The development of the college sports cartel from social movement to formal organization. The American .Journal of Economics and Sociology, 37, 225239.

Koopmans, R. (1992). The missing link between structure and agency: Outline of an evolutionary approach to social movements'. Mobilization: An International Journal, $10,19-35$.

Kriesi, H., Koopmans, R., Duyvendak, J. W., \&Giuni, M.G. (1992). New social movements and political opportunities in Western Europe. European Journal of Political Research, 22, 219-244.

Lawlor, C. (2001, February 16). Women attack crowded field Games to begin 2001 for 810 teams. USA Today, 14C.

Leddy, E. F. (1985), The National Rifle Association: The evolution of a social movement. Ph.D dissertation, Fordham University, United States, New York. Retrieved January 24, 2006 from Proquest Digital Dissertations Database. (Publication No. AAT 8612860 )

Liston, K. (2006). Women's soccer in the Republic of Ireland: Some preliminary sociological comments. Soccer \& Society, 7, 364-384.

Lofland, J. (1996). Social movement organizations: Guide to research on insurgent realities. Hawthorne, NY: Aldine de Gruyter.

Lough, N. L., \& Irwin, R. L. (2001).A comparative analysis of sponsorship objectives for U.S. women's sport and traditional sport sponsorship.Sport Marketing Quarterly, $10,202-210$.

Lucas, S. (2000). Nike's commercial solution: Girls, sneakers, and salvation. International Review for the Sociology of Sport, 35(2), 149-164.

Luders, J. (2006). The economics of movement success: Business responses to Civil Rights mobilization. The American Journal of Sociology, 111, 963-999.

Maddison, S. (2004).Young women in the Australian women's movement.International Feminist Journal of Politics, 6, 234-256. 
Mahony, D. F., Nakazawa, M., Funk, D. C., James, J. D., \& Gladden, J. M. (2002). Motivational factors influencing the behaviour of J. League spectators.Sport Management Review, 5, 1-24.

Mansbridge, J. (1995). What is the feminist movement? In M. M. Feree\& P. Y. Martin (Eds.), Feminist organizations: Harvest of the new women's movement (pp. 2734). Philadelphia, PA: Temple University Press.

Markoff, J. (1996). Waves of democracy: Social movements and political change. Thousand Oaks, CA: Pine Grove Press.

Markovits, A. S., \&Hellerman, S. L. (2003a). The "Olympization" of soccer in the United States. American Behavioral Scientist, 46, 1533-1549.

Markovits, A. S., \&Hellerman, S. L. (2003b). Women's soccer in the United States: Yet another American "exceptionalism." Soccer \& Society, 4(2/3), 14-29.

Martin, P. Y. (1990). Rethinking feminist organizations. Gender and Society, 4, 182206.

Martinez, D. P. (2008). Soccer in the USA: 'holding out for a hero'? Soccer \& Society, 9 , 231-243.

McAdam, D. (1995). Conceptual origins, current problems, future direction.In D. McAdam, J. D. McCarthy, \& M. N. Zald (Eds.), Comparative perspectives on social movements: Political opportnmities, mobilizing stmctures, and cultural framing. New York, NY: Cambridge University Press.

McAdam, D., McCarthy, J. D., \&Zald, M. N. (Eds.) (1996). Comparative perspectives on social movements: Political opportunities, mobilizing structures, and cultural framing. New York, NY: Cambridge University Press.

McAdam, D., Tarrow, S., \&Tilly, C. (1997).Towards an integrated perspective on social movements and revolution. In M. I. Lichbach\& A. Zuckerman (Eds.), Ideals, interests, and institutions: Advancing theory in comparative politic. Cambridge, England: Cambridge University Press

McCallister, S. G., Blinde, E. M., \& Phillips, J. M. (2003) Prospects for change in a new millennium: Gender beliefs of young girls in sport and physical activity. Women in Sport \& Physical Activity Journal 12(2), 83-98.

McCammon, H. J., Campbell, K. E., Granberg, E. M., \& Mowery, C. (2001). How movements win: Gendered opportunity structures and U.S. women's suffrage movements, 1866-1919. American Sociological Review, 66, 49-71. 
McCarthy, J. D., \&Wolfson, M. (1996). Resource mobilization by local social movement organizations: Agency, strategy, and organization in the movement against drinking and driving. American Sociological Review, 61, 1070-1088.

McCarthy, J. D., \&Zald, M. N. (1987). Social movements in an organizational society: Collected essays. New Brunswick, NJ: Transaction.

McGinnis, L., McQuillan, J., \& Chapple, C. L. (2005). I just want to play: Women, sexism, and persistence in golf. Journal of Sport \& Social Issues, 29, 313-337.

McGlen, N. E. \& O'Connor, K. (1983).Women's Rights: The stmggle for equality in the nineteenth and twentieth centuries. New York City, NY: Praeger.

McGlen, N. E.\& O'Connor, K. (1998).Women, politics, and American society (2nd ed.). Upper Saddle River, NJ: Prentice-Hall.

Merton, R. K. (1936). The unanticipated consequences of purposive social action. American Sociological Review, 1, 894-904.

Merton, R. K. (1938). Social structure and anomie. American Sociological Review, 3 , 672-682.

Merton, R. K. (1945). Sociological theory. The American Journal of Sociology, 50, 462-473.

Merton, R. K. (1957). Social theory and social structure (revised and enlarged ed.). New York, NY: The Free Press.

Michaelis, V. (2003, September 16). "Women's soccer league folds." USA Today, 3C.

Miles, M. B. \&Huberman, A. M. (1994). Qualitative Data Analysis (2nd ed.). Thousand Oaks, CA: Sage Publications.

Miller, M. (1999). All-American girls. New York City, NY: Archway.

Minkoff, D. C. (1993). The organization of survival: Women's and racial-ethnic voluntarist and activist organizations, 1955-1985. Social Forces, 71, 887-908.

Minkoff, D. C. (1994). From service provision to institutional advocacy: The shifting legitimacy of organizational forms. Social Forces, 72, 943-969.

Minkoff, D. C. (1997). The sequencing of social movements. American Sociological Review, 62, 779-800.

Mishler, E. G. (1986). Research interviewing: Context and narrative. Cambridge, MA:Harvard University Press. 
Morris, A. (2000). Charting futures for sociology: Social organization. Contemporary Sociology, 29, 445-454.

Oberschall, A. (1973) Social conflicts and social movements. Englewood Cliffs, NJ: Princeton University Press.

O'Connor, K. (1980). Women's organizations' use of the courts. Lexington, MA: Lexington Books.

Otis, M. D. (2004). One community's path to greater social justice: Building on earlier successes. Journal of Gay \& Lesbian Social Services, 16(3/4),17-34.

Nowak, S. (1977).Methodology of sociological research: General problems. Dordrecht, Holland: Reidel.

Parsons, T (1938). The role of ideas in sociological action. American Sociological Review, 3, 652-664.

Parsons, T. (1942). Age and sex in the social structure of the United States. American Sociological Review, 7, 604-616.

Pelak, C. F. (2002). Women's collective identity formation in sports: A case study from women's ice hockey. Gender and Society, 16, 93-114.

Pelak, C. F. (2005). Negotiating gender/race/class constraints in the new South Africa: A case study of women's soccer. Imternational Review for the Sociology of Sport, $40,53-70$.

Pfister, G. (2003). The challenges of women's football in East and West Germany: A comparative study. Soccer \& Society, 4(2/3), 128-148.

Phillips, S. D. (1991). Meaning and structure in social movements: Mapping the network of national Canadian women's organizations. Canadian Journal of Political Science, 24, 755-782.

Poster, W. R. (1995). The challenges and promises of class and racial diversity in the women's movement: A study of two women's organizations. Gender and Society, $9,659-679$.

Rhode, D. L. (1995). Media images, feminist issues. Signs, 20, 685-710.

Robnett, B. (1996). African-American women in the Civil Rights Movement, 1954-1965: Gender, leadership, and micromobilization. American Journal of Sociology, 101, $1661-1693$. 
Rohlinger, D. A. (2002). Framing the abortion debate: Organizational resources, media strategies, and movement-countermovement dynamics. Sociological Quarlerly, 43, 479-507.

Rossman, G. B. \& Rallis, S. F. (2003).Learning in the field: An introduction to qualitative research. Thousand Oaks, CA: Sage Publications.

Roth, A., \&Basow, S. A. (2004). Femininity, sports, and feminism. Journal of Sport \& Social Issues, 28, 245-265.

Rucht, D., \&Neidhardt, F. (2002). Towards a 'movement society'? On the possibilities of institutionalizing social movements. Social Movement Studies, 1, 7-30.

Schlozman, K. L., \&Tierney, J. (1983). More of the same: Washington pressure group acts in a decade of change. Journal of Politics, 45, 351-377.

Schreiber, R. (2002). Injecting a woman's voice: Conservative women's organizations, gender consciousness, and the expression of women's policy preferences. Sex Roles, 47, 330-342.

Scott, K. W., \& Howell, D. (2008). Clarifying analysis and interpretation in grounded theory: Using a conditional relationship guide and reflective coding matrix. International Journal of Qualitative Methods, 7(2), 1-15.

Scraton, S., Fasting, K, Pfister, G., \& Bunuel, A. (1999). It's still a man's game? The experiences of top-level European women footballers. International Review for the Sociology of Sport, 34(2), 99-111.

Searles, P., \& Berger, R. J. (1987). The feminist self-defense movement: A case study. Gender and Society, 1, 61-84.

Shaulis, D. (1999). Pedestriennes: Newsworthy but controversial women in sporting entertainment. Journal of Sport History, 26(1), 29-50.

Sigelman, L. \& Wilcox, C. (2001). Public support for gender equity in athletics programs. Woman \& Politics, 22(1), 85-96.

Small, A. W. (1897). The meaning of the social movement. The American Journal of Sociology, 3, 340-354.

Snow, D. A., \&Trom, D. (2002). The case study and the study of a social movement. In B. Klandermans,S. \& Staggenborg, (Eds), Methods of social movement research (pp. 146-172), Minneapolis: University of Minnesota Press. 
Southall, S. G., Nagel, M. S., \& Legrande, D. J. (2005). Build it and they will come? The Women's United Soccer Association: a collision of exchange theory and philanthropy. Sport Marketing Quarterly, 14(3), 158-167.

Spencer, N. E. (2000). Reading between the lines: A discursive analysis of the Billie Jean King vs. Bobby Riggs "Battle of the Sexes." Sociology of Sport Joumal, 17, 386402.

Spencer, N. E., \& McClung, L. R. (2001). Women in sport in the 1990s: Reflections on "embracing stars, ignoring players." Journal of Sport Management, 15, 318-349.

Staggenborg, S. (1988). The consequences of professionalization and formalization in the pro-choice movement. American Sociological Review, 53, 585-606.

Staggenborg, S. (1995). Can feminist organizations be affective? In M. M. Feree \& P. Y. Martin (Eds.), Feminist organizations: Harvest of the new women's movement (pp. 3-27). Philadelphia: Temple University Press.

Staggenborg, S. (2001). Beyond culture versus politics: A case study of a local women's movement. Gender and Society, 15, 507-530.

Stevenson, W. B., \& Greenberg, D. (2000). Agency and social networks: Strategies of action in a social structure of position, opposition, and opportunity. Administrative Science Quarterly, 45, 651-678.

Sugden, J., \& Tomlinson, A. (1996). What's left when the circus leaves town? An Evaluation of World Cup USA 1994. Sociology of Sport Journal, 13, 238-258.

Talley, W. K., \&Keedy, J. L. (2006). Assessing school council contribution to the enabling conditions for instructional capacity building: An urban district in Kentucky. Education and Urban Society, 38, 419-454.

Tarrow, S. G. (1994).Power in movement: Social movement, collective action, and politics. Cambridge, England: Cambridge University Press.

Taylor, J. (2005). Who manages feminist-inspired reform? An in-depth look at Title IX coordinators in the United States.Gender \& Society, 19, 358-375.

Taylor, V. (1989). Social movement continuity: The women's movement in abeyance. American Sociological Review, 54, 761-775.

Thirer, J., \& Wright, S. D. (1985). Sport and social status for adolescent males and females. Sociology of Sport Journal, 2, 164-171.

Thomas, J. E. (1999). "Everything about US is feminist": The significance of ideology in organizational change. Gender and Society, 13, 101-119. 
Thomas, R. M. (2003). Blending qualitative and quantitative research methods in theses and dissertations. Thousand Oaks, CA : Corwin Press.

Tilly, C. (2004). Social movements: 1768-2004. Boulder, CO: Paradigm.

Tomlinson, A., Markovits, A. S., \& Young, C. (2003). Mapping sports space. American Behavioral Scientist, 46, 1463-1475.

Touraine, A. (2002). The importance of social movements. Social Movement Studies, $1,89-95$.

Tetreault, M. A., \&Teske, R. L. (Eds.). (2003). Partial tmiths and the politics of community, Volume 2. Columbia: University of South Carolina Press.

Truman, D. B. (1952).The governmental process. New York City, NY: Knopf.

Tuggle, C. A., \& Owen, A. (1999). A descriptive analysis of NBC's coverage of the Centennial Olympics. Journal of Sport \& Social Issues, 23, 171-182.

Vose, C. (1972). Constitutional change: Amendment politics and Sipreme Court litigation since 1900. Lexington, MA: Lexington Books.

Wearden, S. T., \& Creedon, P. J. (2002). 'We got next': Images of women in television commercials during the inaugural WNBA season. Sport and Society, 5, 189-210.

Weeks, M. J. (2003, April 2).WUSA a run-up to World Cup.USA Today, 3C.

Weiner, R. (2001, April 13). "WUSA" Creating a legacy U.S. women at fore of premier soccer league ready to kick off." USA Today, 1C.

Wheeler, R. F. (1978). Organized sport and organized labour: The workers'sports movement. Journal of Contemporary History, 13, 191-210.

Whiteside, K. (2001a, July 6). Milbrett tops in goals, accolades Most exciting league player, say coaches. USA Today, 11C.

Whiteside, K. (2001b, August 23). Stage set for WUSA title game, Chastain. USA Today, $9 \mathrm{C}$.

Whiteside, K. (2001c, August 27). CyberRays, founders savor joy of first title. USA Today, 7C.

Wilson, B., \& White, P. (2002). Revive the pride: Social process, political economy, and a fan-based grassroots movement. Sociology of Sport Journal, 19, 119-148. 
Women's Sports Foundation. (n.d.). About us. Retrieved from http://www .womenssportsfoundation.org/cgi-bin/iowa/about/more.html

Y in, R. K. (2009). Case study research: Design and methods ( $4^{\text {th }}$ ed.). Thousand Oaks, CA: Sage Publications.

Zald, M. N., \& Ash, R. (1977). Social movement organizations: Growth, decay and change. Social Forces, 327-341. 


\title{
APPENDIX A
}

\author{
Interview Protocol
}

Introduction: Thank you for agreeing to be interviewed. As I mentioned previously when scheduling this interview, I am currently working on my dissertation on the rise and fall of the WUSA and am speaking to you, as you were an instrumental leader in the creation of the league. Please feel free to ask any questions you may have about this interview, now or in the future.

Basic demographic information collection: Background information, initial sport experience, initial soccer experiences, additional soccer experiences (college, national team, professional, etc.)

\section{Additional Background Information}

1) Can you tell me a bit about when and how you began to get involved in women's soccer and/or sport, and more specifically the WUSA?

2) What positions did you hold within the league? Soccer? What concretely were the main duties of those jobs?

3) At what point did you become concerned and interested in creating a professional soccer league for women? How? How did you end up becoming a founding member of the WUSA?

4) When did you leave the WUSA? Other jobs/positions since that time?

5) To what degree did your position in the WUSA allow you to influence the development of the league? Can you give me concrete examples? (Probe multiple times)

6) To what degree did your position in the WUSA allow you to influence or dictate how the league functioned? (Probe for concrete examples). 
The Women's United Soccer Association (WUSA) as a Social Movement Organization (SMO)

7) What event(s) do you think led to the creation of the WUSA? Your thoughts on the timing of the creation of the league.

8) What was the initial response to the creation of the WUSA from various groups (soccer, women's sports, professional sports communities, etc.)?

9) Stories about how women in sport and/or soccer influenced the founding of the WUSA. Can you tell me about this? Even after the WUSA's founding, were there other ways leaders in the sport, marketing, or other professional arenas able to influence the development or tactics of the WUSA?

10) What was the relationship within the WUSA leadership to other leaders of like minded organizations, leagues (MLS, WNBA, youth soccer organizations, etc.)? Did these differences ever cause divisions between the organizations?

11) What were the high and low points of the WUSA? (probe)

12) What were the major strengths of the league? The weaknesses?

13) The cycle of the WUSA: From 2000 when the league was announced until 2003 when the league suspended operations what transpired? Were there changes each season/year?

The Future of the WUSA

14) What do you think the future holds for the WUSA or a similar professional soccer league? What do you think will be necessary for it to succeed?

15) Thoughts on the plans for the 2008 WUSA.

Additional Information

16) I'm interested in talking to other WUSA leaders - are there any that you would suggest?

17) Are there other questions that you think I should have asked or other events that you think might be important to my work that haven't yet been covered?

THANK YOU!!! 


\section{APPENDIX B:}

Interview Protocol

(With citations)

Introduction: Thank you for agreeing to be interviewed. As I mentioned previously when scheduling this interview, I am currently working on my dissertation on the rise and fall of the WUSA and am speaking to you, as you were an instrumental leader in the creation of the league. Please feel free to ask any questions you may have about this interview, now or in the future.

Basic demographic information collection: Background information, initial sport experience, initial soccer experiences, additional soccer experiences (college, national team, professional, etc.)

The research question(s) are listed before the question is written below: (RQ1) How was the WUSA founded?; (RQ2) Why was the WUSA founded?; (RQ3) Why did the WUSA fail?

Additional Background Information (not tied with research questions, but clarifying the role of each leader being interviewed-the research did not deem it necessary to ground the first four questions in the literature because they are not theoretical in nature).

1) Can you tell me a bit about when and how you began to get involved in women's soccer and/or sport, and more specifically the WUSA?

2) What positions did you hold within the league? Soccer? What concretely were the main duties of those jobs?

3) At what point did you become concerned and interested in creating a professional soccer league for women? How? How did you end up becoming a founding member of the WUSA? 
4) When did you leave the WUSA? Other jobs/positions since that time?

5) To what degree did your position in the WUSA allow you to influence the development of the league? Can you give me concrete examples? (Probe multiple times) (Berry 1977; Jeydel 2004; McCarthy \&Zald, 1977; McGlen\& O'Connor 1983; Pelak 2002)

6) To what degree did your position in the WUSA allow you to influence or dictate how the league functioned? (Probe for concrete examples). (Berry 1977; Jeydel 2004; McCarthy \&Zald, 1977; McGlen\& O'Connor 1983; Pelak 2002)

The WUSA as an SMO

7) (RQ1, RQ2) What event(s) do you think led to the creation of the WUSA? Your thoughts on the timing of the creation of the league. (Jeydel, 2004; Luders, 2006; McGlen\& O'Connor, 1983; Pfister, 2003)

8) (RQ2, RQ3) What was the initial response to the creation of the WUSA from various groups (soccer, women's sports, professional sports communities, etc.)? (Harris, 2005; Jackman 2002; Jeydel 2004; Markovits\&Hellerman, 2003b; McMammon, et al, 2001; Minkoff, 1993; Stern 1989)

9) (RQ1, RQ2, RQ3) Stories about how women in sport and/or soccer influenced the founding of the WUSA. Can you tell me about this? Even after the WUSA's founding, were there other ways leaders in the sport, marketing, or other professional arenas able to influence the development or tactics of the WUSA? (Cooper, 1992; McCarthy \&Zald, 1971; McGlen\& O'Connor, 1983; Minkoff, 1993; Staggenborg, 1988; Taylor 1989)

10) (RQ1, RQ3) What was the relationship within the WUSA leadership to other leaders of like minded organizations, leagues (MLS, WNBA, youth soccer organizations, etc.)? Did these differences ever cause divisions between the organizations? (Jackman, 2002; McCarthy \&Zald, 1971; McGlen\& O'Connor, 1983; Minkoff, 1993)

11)(RQ3) What were the high and low points of the WUSA? (probe) (Cooper, 1992; Markovits\&Hellerman, 2003b)

12) (RQ3) What were the major strengths of the league? The weaknesses? (Cooper, 1992; Markovits\&Hellerman, 2003a; Markovits\&Hellerman, 2003b; Taylor 1989; Wearden\&Creedon, 2002)

13) (RQ3) The cycle of the WUSA: From 2000 when the league was announced until 2003 when the league suspended operations what transpired? Were there changes each season/year? (Disney \& Gelb, 2002; Markovits\&Hellerman; 2003b, Minkoff, 1993)

The Future of the WUSA 
14) (RQ3) What do you think the future holds for the WUSA or a similar professional soccer league? What do you think will be necessary for it to succeed? (Disney \& Gelb, 2002, Markovits\&Hellerman, 2003b; Phillips 1991; Taylor 1989)

15) (RQ1, RQ2, RQ3) Thoughts on the plans for the 2009 WUSA.

Additional Information

16) I am interested in talking to other WUSA leaders - are there any that you would suggest?

17) Are there other questions that you think I should have asked or other events that you think might be important to my work that we did not discuss in this interview?

THANK YOU!!! 
APPENDIX C: Coding Map

\begin{tabular}{|c|c|c|c|}
\hline \multicolumn{2}{|c|}{ WUSA as a SMO } & \multirow{2}{*}{$\begin{array}{l}\text { WS } \\
\text { WS-CME }\end{array}$} & \multirow{2}{*}{$\begin{array}{l}\text { RESEARCH } \\
\text { QUESTION } \\
\text { RQ1, RQ2 } \\
\end{array}$} \\
\hline WS & Critical Mobilizing Event(s) & & \\
\hline WS & Cultural/Social Context & WS-CSC & RQ1, RQ2, RQ3 \\
\hline WS & $\begin{array}{l}\text { Leadership } \\
\text { Leadership-John Hendricks } \\
\text { Leadership-Players } \\
\text { Leadership-League } \\
\text { Leadership-Others } \\
\end{array}$ & $\begin{array}{l}\text { WS-L. } \\
W S-L-J H \\
W S-L-P \\
W S-L-L \\
W S-L-O \\
\end{array}$ & $\begin{array}{l}\text { RQ1, RQ2, RQ3 } \\
\text { RQ1, RQ2 } \\
\text { RQ1, RQ2 } \\
\text { RQ1, RQ2, RQ3 } \\
\text { RQ1, RQ3 }\end{array}$ \\
\hline WS & $\begin{array}{l}\text { Like-Minded Organizations \& Political } \\
\text { Elites } \\
\text { LMO/PE-Soccer } \\
\text { LMO/PE-Sports } \\
\text { LMO/PE-Women's Organizations } \\
\text { LMO/PE-Corporate Sponsors }\end{array}$ & $\begin{array}{l}\text { WS-LMO/PE } \\
\text { WS-LMO/PE-So } \\
W S-L M O / P E-S p \\
W S-L M O / P E-W \\
W S-L M O / P E-C S\end{array}$ & $\begin{array}{l}\text { RQ1, RQ2, RQ3 } \\
\text { RQ1, RQ2, RQ3 } \\
\text { RQ1 } \\
\text { RQ1 } \\
\text { RQ1, RQ2, RQ3 }\end{array}$ \\
\hline WS & Communication Networks & WS-CN & RQ3 \\
\hline WS & Organizational Base & WS-OB & RQ3 \\
\hline WS & Administration Structure & WS-AS & RQ3 \\
\hline WS & Collective ID & WS-CI & RQ1, RQ2, RQ3 \\
\hline WS & Personal Beliefs & WS-PB & RQ1, RQ2, RQ3 \\
\hline \multicolumn{4}{|l|}{ WS } \\
\hline \multicolumn{2}{|c|}{ LEAGUE FORMATION } & LF & \\
\hline LF & $\begin{array}{l}\text { Contributing Events } \\
\text { (Historical, role) }\end{array}$ & $\begin{array}{l}\mathrm{LF}-\mathrm{CE} \\
L F-C E / H / R\end{array}$ & RQ1, RQ2 \\
\hline LF & Image (of players, of soccer, of stars) & $\begin{array}{l}\mathrm{LF}-\mathrm{IP} \\
(L F-(E / P / \mathrm{S} / \mathrm{S} t)\end{array}$ & $\mathrm{RQ1}, \mathrm{RQ2}$ \\
\hline $\mathrm{LI}$ & Role of Media & LF-RM & $\mathrm{RQ1}$ \\
\hline LF & Timing & LF-T & $\mathrm{RQ1}, \mathrm{RQ2}$ \\
\hline \multicolumn{2}{|c|}{ WUSA CYCLE } & WC & \\
\hline WC & High Points (actual events) & WC-HP & RQ2 \\
\hline $\mathrm{WC}$ & Low Points (actual events) & WC-LP & RQ3 \\
\hline WC & Teams & WC-T & RQ1, RQ3 \\
\hline WC & Strengths (organization, league, etc.) & WC-S & RQ1, RQ2 \\
\hline WC & Weaknesses (organization, league, etc.) & WC-W & $\mathrm{RQ3}$ \\
\hline WC & League Structure & WC-LS & RQ1, RQ3 \\
\hline WC & Leadership & WC-L & RQ1, RQ3 \\
\hline WC & Image & WC-I & $\mathrm{RQ1}, \mathrm{RQ3}$ \\
\hline \multicolumn{2}{|c|}{ FUTURE FOR WOMEN'S SOCCER } & FWC & \\
\hline FWC & America Readiness & FWC-AR & RQ1, RQ2 \\
\hline FWC & Women's World Cup & FWC-WWC & \\
\hline FWC & Festivals & FWC-F & \\
\hline FWC & $\begin{array}{l}\text { Needs } \\
\text { (stars, acceptance, business plan) }\end{array}$ & $\begin{array}{l}\text { FWC-N } \\
(F W C-N / S / A / B P)\end{array}$ & RQ1, RQ2 \\
\hline FWC & Women's Soccer Initiative, Inc (WSII) & FWC-WSII & RQ3 \\
\hline FWC & WUSA 2009 & FWC-9 & RQ3 \\
\hline
\end{tabular}

The research question(s) are listed before the question is written below: (RQ1) How was the WUSA founded?; (RQ2) Why was the WUSA founded?; (RQ3) Why did the WUSA fail? 


\section{CURRICULUM VITAE}

\section{Meghan O'Connor McDonogh}

Department of Athletics

The Catholic University of America

620 Michigan Ave. NE

Washington, DC 20064

202-319-4745(o)

404-931-7010(c)

mcdonogh@cua.edu

EDUCATION:

M.Ed The University of Georgia, 2002

Sports Management

B.A. American University, cum laude, 2001

Women and Gender Studies

Syracuse University, 1997-1998

COACHING EXPERIENCE:

9/06- present

5/08-present

5/10-present

$12 / 04-8 / 06$

9/04-6

$1 / 04-5 / 04$

$9 / 02-5 / 03$

$9 / 01-6 / 01$
Head Coach, Women's Lacrosse, The Catholic University of America

Assistant Athletic Director (Compliance Coordinator)

Senior Woman Administrator

Head Coach, Club-Varsity Team, University of Louisville

Assistant Tournament Director

C-CUSA Tennis Tournament, NCAA Field Hockey

Championships

Assistant Coach, Limestone College

Assistant Coach, The University of California, Berkeley

Player-Coach, The University of Georgia 
OTHER WORK EXPERIENCE:

$3 / 03-10 / 03$

San Jose CyberRays (WUSA), Operations Asst/Merchandise Coordinator/Equipment Manager

$5 / 02-09 / 02$

San Jose CyberRays (WUSA), Intern, May-August 2002

04/01-08/01

Washington Freedom (WUSA), Intern

SERVICE:

Intercollegiate Women's Lacrosse Coaches Association (IWLCA), Board of Directors, 2009-present

Project IRM

Mentor, 2008-present

US Lacrosse,

Board of Directors, 2007-2009

US Lacrosse, Women's Division

Board of Governors, 2005-2007

US Lacrosse, Women's Division National Tournament, Co-Director, 2005-2008

US Lacrosse, Women's Division of Intercollegiate Associates

Secretary, 2004-2006

Tournament Field Director, 2005, 2006

Southeastern Women's Lacrosse League

President, 2004-2006

Past-President, 2007

HONORS \& AWARDS:

University Fellow, University of Louisville, 2004-2006

American University, BA

cum laude, 2001

Golden Key Honor Society (top 15\% of junior class), 2000

Syracuse University

Big East Academic All Star Team (Soccer), 1994

Dean's Scholarship, 1994-95

PUBLICATIONS: $\quad$ Women in Professional Sports," in M.A. Hums, G.G. Brower, \& H. Grappendorf, eds. Women as leaders in sport; Impact and Influence.Reston, VA: NAGWS (2007).

"Billy Jean King," in K. O'Connor, ed. Gender and Leadership, vol. 2. Thousand Oaks, CA: Sage Publications(2010). 
"Women in Professional Sport," in K. O'Connor, ed. Gender and

Leadership, vol. 2. Thousand Oaks, CA: Sage Publications(2010).

“THE CASE OF THE WOMEN'S UNITED SOCCER

ASSOCIATION: Explaining the Rise and Fall of a Social

Movement Organization" Unpublished dissertation. University of Louisville. Louisville, KY. 